University of Tennessee Health Science Center

UTHSC Digital Commons

\title{
Acetaldehyde and Epithelial Junctions: Role of Pp2A and Occludin Phosphorylation
}

\author{
Mitzi Dunagan \\ University of Tennessee Health Science Center
}

Follow this and additional works at: https://dc.uthsc.edu/dissertations

Part of the Chemicals and Drugs Commons, Diseases Commons, and the Substance Abuse and Addiction Commons

\section{Recommended Citation}

Dunagan, Mitzi , "Acetaldehyde and Epithelial Junctions: Role of Pp2A and Occludin Phosphorylation" (2012). Theses and Dissertations (ETD). Paper 61. http://dx.doi.org/10.21007/etd.cghs.2012.0075. 


\title{
Acetaldehyde and Epithelial Junctions: Role of Pp2A and Occludin Phosphorylation
}

\begin{abstract}
Chronic alcohol consumption causes health problems including cancers, liver damage, and

cirrhosis. These problems are exacerbated by endotoxins from the bacterial population of the colon, which can enter the bloodstream when gastrointestinal tight junctions, protein complexes that prevent paracellular passage of molecules, are compromised. The mechanisms of this barrier disruption are the subject of current study.

Acetaldehyde, produced as a result of ethanol breakdown by intestinal microflora as well as intestinal epithelia, is a known carcinogen. It compromises the barrier function of intestinal epithelial cells by causing irregularities in the phosphorylation of tight junction proteins. It also reacts with proteins, lipids, and DNA to cause cellular malfunction.
\end{abstract}

This project explored the roles of PP2A (a protein phosphatase) in acetaldehyde-mediated tight junction disruption, wound healing, and morphological differentiation. Intestinal epithelial cell culture in monolayers on permeable membranes were used to test the effects of acetaldehyde in the presence or absence of specific inhibitors on barrier function via transepithelial resistance and the paracellular passage of fluorescent molecules. Immunocytochemistry and confocal microscopy were used to track the localization of occludin in the cell lines tested, in cells cultured in monolayers or in a threedimensional model in Matrigel. Results for acute administration of acetaldehyde were confirmed in mouse ileum.

Acute administration of acetaldehyde was demonstrated to have deleterious effects on the barrier function and wound healing of Caco-2 cells and mouse ileum, with varying degrees of attenuation of the effects of acetaldehyde via PP2A inhibition. Transepithelial resistance declined and inulin flux increased in the presence of acetaldehyde, as occludin was dephosphorylated and internalized by the cell in the presence of increased PP2A association and activity. PP2A inhibition by fostriecin, siRNA, or a specific peptide inhibitor not only rescued the cells from the disruption indicated by inulin flux, but also decreased the association of PP2A with occludin, resulting in preservation of threonine phosphorylation and localization of occludin at the tight junction. These results were confirmed by experiments with fostriecin in mouse ileum ex vivo. At all concentrations tested, acute exposure to acetaldehyde inhibited wound healing in an established in vitro model. Migration was not restored by PP2A inhibition, indicating that acetaldehyde's effects on wound healing were PP2A independent.

Chronic exposure to acetaldehyde disrupted differentiation in cells grown in Matrigel, as shown by changes in morphology, in a manner attenuated by fostriecin pretreatment. These results indicated that the known effects of acetaldehyde on cell differentiation may be PP2Adependent, and that intact tight junctions with appropriately-phosphorylated proteins may be important for maintaining the polarity of differentiated Caco-2 cells.

In conclusion, acetaldehyde disrupted tight junction barrier via occludin dephosphorylation by PP2A to cause leaky epithelia and deficient differentiation of cells. It slowed wound healing in a PP2A-independent manner. All of these findings contribute to an understanding of the mechanisms by which acetaldehyde causes health problems in alcoholics

\section{Document Type}

Dissertation 


\section{Degree Name}

Doctor of Philosophy (PhD)

\section{Program}

Biomedical Sciences

\section{Research Advisor}

Radhakrishna Rao, Ph.D.

\section{Keywords}

acetaldehyde, occludin, PP2A

\section{Subject Categories}

Chemicals and Drugs | Diseases | Medicine and Health Sciences | Mental and Social Health | Substance Abuse and Addiction 


\title{
ACETALDEHYDE AND EPITHELIAL JUNCTIONS: ROLE OF PP2A AND
} OCCLUDIN PHOSPHORYLATION

\author{
A Dissertation \\ Presented for \\ The Graduate Studies Council \\ The University of Tennessee \\ Health Science Center
}

\author{
In Partial Fulfillment \\ Of the Requirements for the Degree \\ Doctor of Philosophy \\ From The University of Tennessee
}

By

Mitzi Dunagan

May 2012 
Copyright (C) 2012 by Mitzi Dunagan.

All rights reserved. 


\section{DEDICATION}

This work is dedicated to my grandfathers. Orville Montgomery Reams should have been a physician or veterinarian, but could not attend college due to the Great

Depression. Paul Alexander Fann was an alcoholic who died of cancer at the age of 56. Half of his brothers were alcoholics, and they died of cancer as well. Between the two, these men and their families have inspired me to pursue and persevere in this project. PawPaw, this is for you. 


\section{ACKNOWLEDGEMENTS}

I would like to acknowledge the people who made this project possible. First Radhakrishna Rao, my principal investigator, who enabled me to earn an NIH predoctoral fellowship, and to speak in conferences in San Diego, California, New Orleans, Louisiana, and Bilbao, Spain. Takuya Suzuki, Bertha Elias, Ankur Seth, Suneet Jain, Sudhir Aggarwal, Noel de los Santos, Lynn Crosby, Geetha Samak, Kamaljit Chaudhry, Ruchika Gangwar, and Hina Mir helped me with various aspects of the project. Chris Waters allowed me to use his microscope, even on weekends. Anjaparavanda Naren provided use of equipment and advice. Susan Senogles and Gabor Tigyi offered valuable advice and criticism as my committee members. Larry Tague and Clark Blatteis offered valuable career guidance, lunch debate, and experimental assistance. The Physiology department of the University of Tennessee Health Science Center has offered a supportive working environment, and I appreciate the assistance and training from all.

I have been supported by NIH grants, AA12307 and DK55532 to Dr. Rao, and a Ruth Kirchstein F31 NRSA award AA018243 to me. I was also supported by scholarships from Mort and Myra Friedman, the Belz family, the J. Paul Quigley award, and the Gerwin fellowship. All of these grants, fellowships, and scholarships have enabled me to continue my studies at this institution. 


\begin{abstract}
Chronic alcohol consumption causes health problems including cancers, liver damage, and cirrhosis. These problems are exacerbated by endotoxins from the bacterial population of the colon, which can enter the bloodstream when gastrointestinal tight junctions, protein complexes that prevent paracellular passage of molecules, are compromised. The mechanisms of this barrier disruption are the subject of current study.

Acetaldehyde, produced as a result of ethanol breakdown by intestinal microflora as well as intestinal epithelia, is a known carcinogen. It compromises the barrier function of intestinal epithelial cells by causing irregularities in the phosphorylation of tight junction proteins. It also reacts with proteins, lipids, and DNA to cause cellular malfunction.
\end{abstract}

This project explored the roles of PP2A (a protein phosphatase) in acetaldehydemediated tight junction disruption, wound healing, and morphological differentiation. Intestinal epithelial cell culture in monolayers on permeable membranes were used to test the effects of acetaldehyde in the presence or absence of specific inhibitors on barrier function via transepithelial resistance and the paracellular passage of fluorescent molecules. Immunocytochemistry and confocal microscopy were used to track the localization of occludin in the cell lines tested, in cells cultured in monolayers or in a three-dimensional model in Matrigel. Results for acute administration of acetaldehyde were confirmed in mouse ileum.

Acute administration of acetaldehyde was demonstrated to have deleterious effects on the barrier function and wound healing of Caco-2 cells and mouse ileum, with varying degrees of attenuation of the effects of acetaldehyde via PP2A inhibition. Transepithelial resistance declined and inulin flux increased in the presence of acetaldehyde, as occludin was dephosphorylated and internalized by the cell in the presence of increased PP2A association and activity. PP2A inhibition by fostriecin, siRNA, or a specific peptide inhibitor not only rescued the cells from the disruption indicated by inulin flux, but also decreased the association of PP2A with occludin, resulting in preservation of threonine phosphorylation and localization of occludin at the tight junction. These results were confirmed by experiments with fostriecin in mouse ileum ex vivo. At all concentrations tested, acute exposure to acetaldehyde inhibited wound healing in an established in vitro model. Migration was not restored by PP2A inhibition, indicating that acetaldehyde's effects on wound healing were PP2A independent.

Chronic exposure to acetaldehyde disrupted differentiation in cells grown in Matrigel, as shown by changes in morphology, in a manner attenuated by fostriecin pretreatment. These results indicated that the known effects of acetaldehyde on cell differentiation may be PP2A-dependent, and that intact tight junctions with appropriately-phosphorylated proteins may be important for maintaining the polarity of differentiated Caco-2 cells. 
In conclusion, acetaldehyde disrupted tight junction barrier via occludin dephosphorylation by PP2A to cause leaky epithelia and deficient differentiation of cells. It slowed wound healing in a PP2A-independent manner. All of these findings contribute to an understanding of the mechanisms by which acetaldehyde causes health problems in alcoholics. 


\section{TABLE OF CONTENTS}

CHAPTER 1. INTRODUCTION .......................................................................................1

Ethanol Breakdown, Enzymes, and Products .........................................................

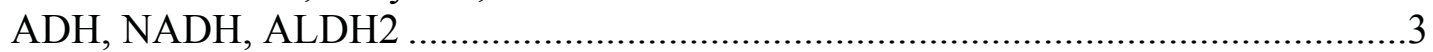

CYP450 2E1 (Mitochondrial Ethanol Oxidizing System)......................................5

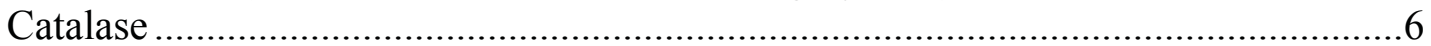

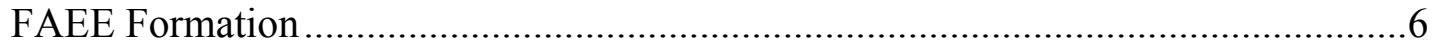

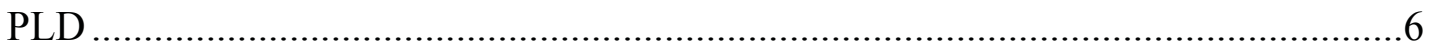

Acetaldehyde Pharmacology ................................................................................

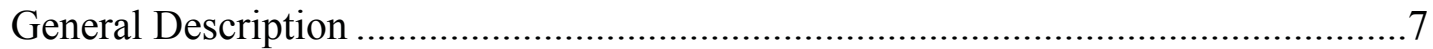

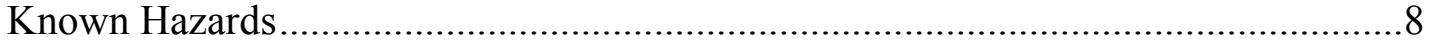

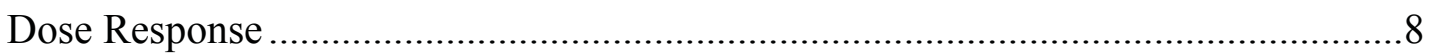

Acetaldehyde Adduct Formation: Proteins and Enzymes .........................................

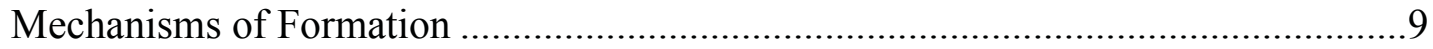

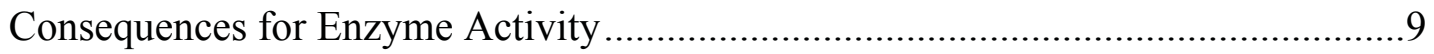

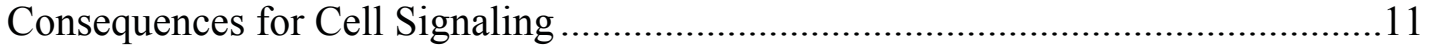

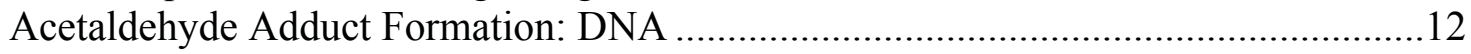

Mechanisms of Formation .............................................................................. 12

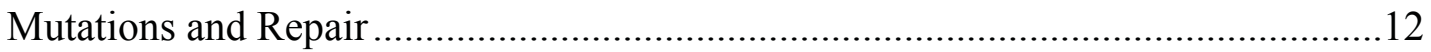

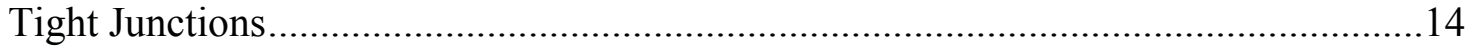

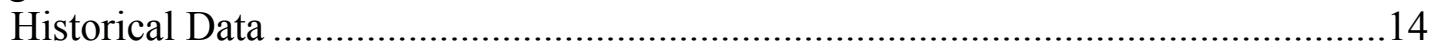

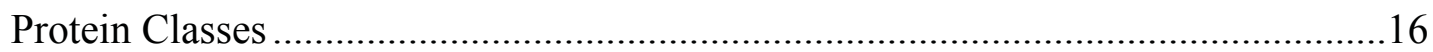

Phosphorylation and Function of Occludin and Claudins ....................................19

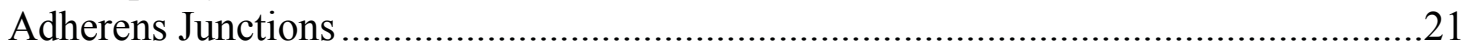

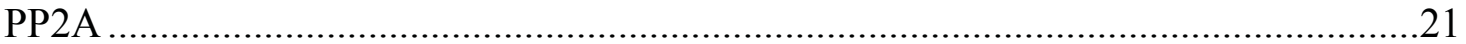

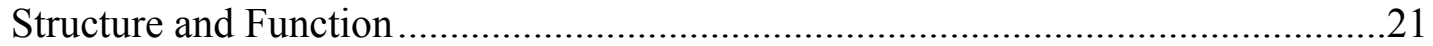

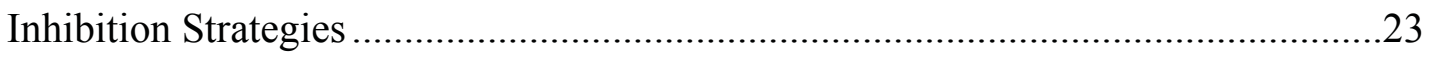

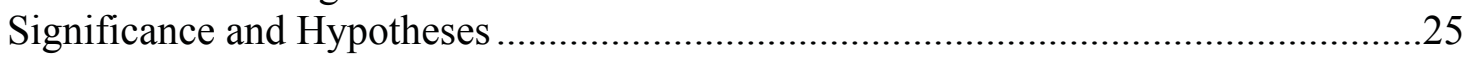

CHAPTER 2. METHODS AND MATERIALS................................................26

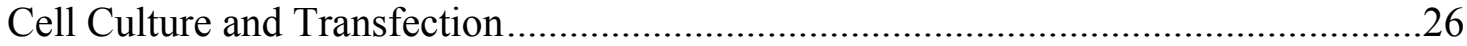

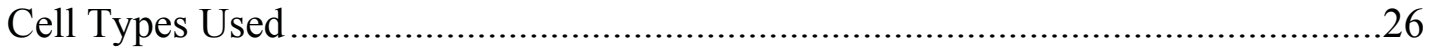

Cells Grown in Transwells................................................................................26

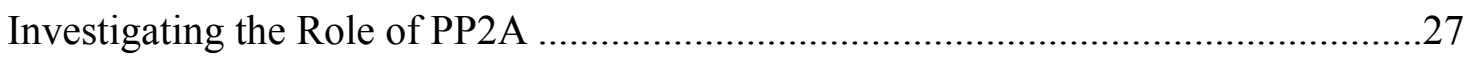

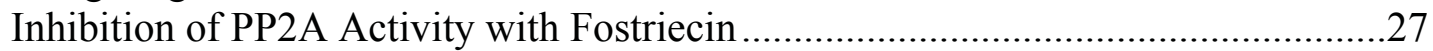

Knockdown of PP2A-C $\alpha$ by SiRNA Transfection ..............................................28

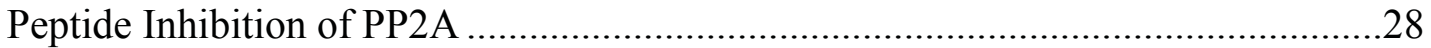

Acetaldehyde Treatment .......................................................................................... 30

Measurement of Barrier Function............................................................................... 30

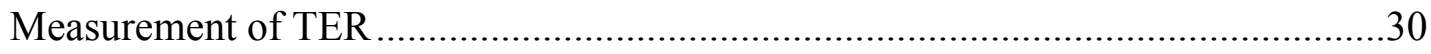

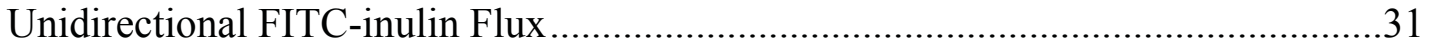

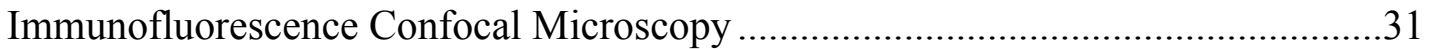

Cell Viability Assay: Lactate Dehydrogenase Release............................................32

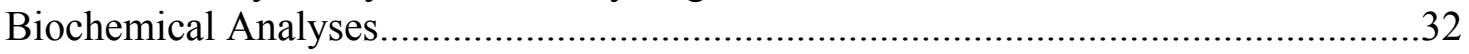




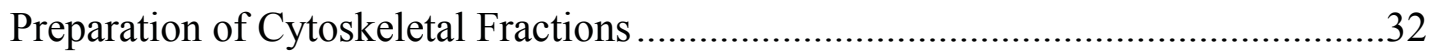

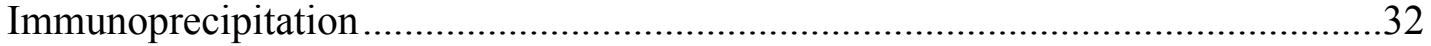

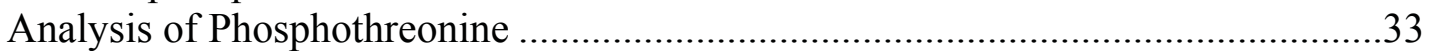

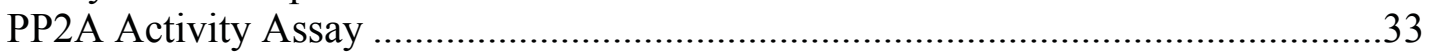

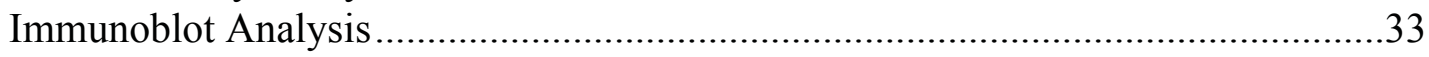

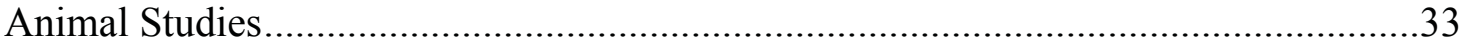

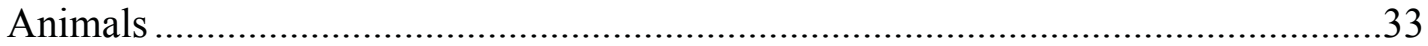

Acetaldehyde Treatment of Mouse Ileum...................................................................34

Preparation of Detergent-insoluble Fractions from Mouse Ileum ...............................34

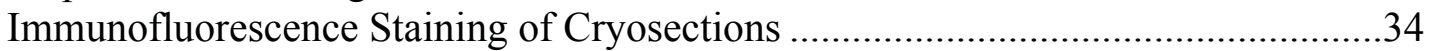

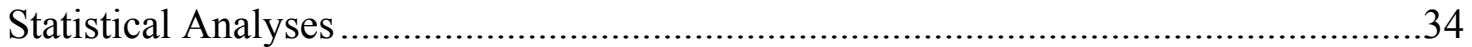

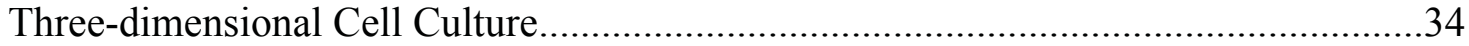

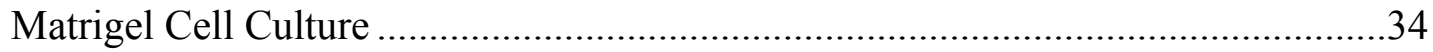

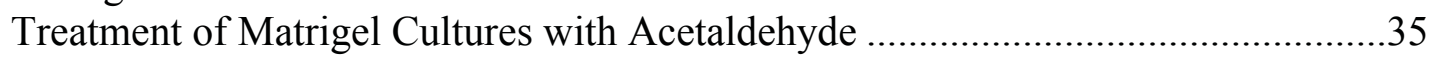

Fixation of Matrigel Cultures..................................................................................35

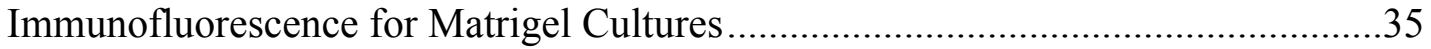

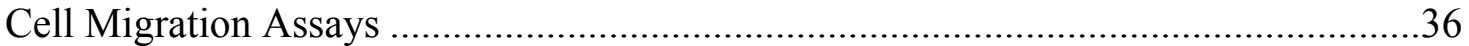

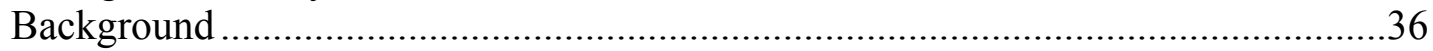

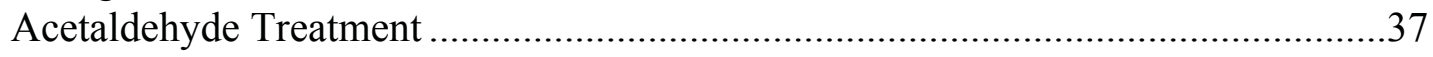

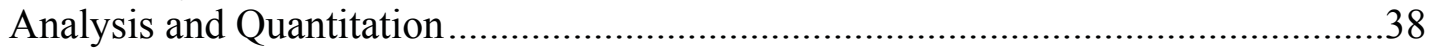

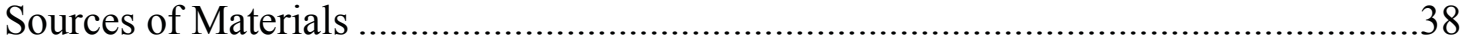

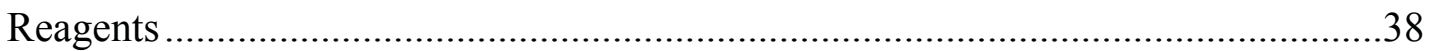

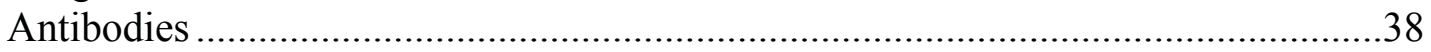

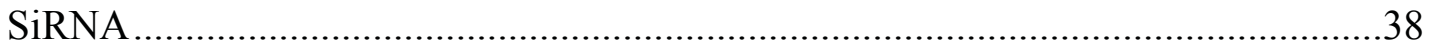

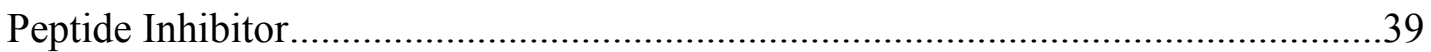

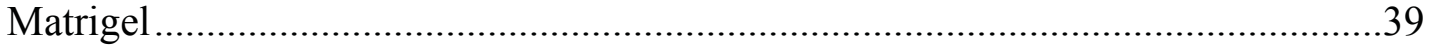

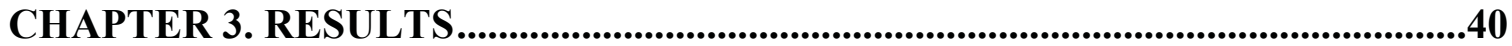

Specific Aim 1: To Determine the Role of PP2A and Thr-dephosphorylation of Occludin in Acetaldehyde-induced Disruption of Tight Junctions and Adherens Junctions

Acetaldehyde Disrupts Tight Junctions and Adherens by a PP2A-dependent Mechanism

Acetaldehyde Disrupts Barrier Function in Caco-2 Cell Monolayers by a Mechanism That Involves PP2A

Acetaldehyde Disrupts Tight Junctions in Caco-2 Cell Monolayers by a

Mechanism That Involves PP2A

Acetaldehyde Disrupts Adherens Junctions in Caco-2 Cell Monolayers by a PP2A-dependent Mechanism

Acetaldehyde Disrupts Tight Junctions and Adherens Junctions in Mouse Ileum by a PP2A-dependent Mechanism .........................................................................46

Knock Down of PP2A Attenuates Acetaldehyde-induced Barrier Dysfunction and Tight Junction Disruption .

Acetaldehyde-induces PP2A Translocation by a Tyrosine Kinase-dependent Mechanism

Acetaldehyde Increases Association of PP2A with Occludin 
PP2A Translocation Inhibitor Attenuates Acetaldehyde-induced Barrier

Dysfunction and Tight Junction Disruption.......................................................50

Tyrosine Kinase Activity Mediates Acetaldehyde-induced PP2A Translocation .....50

Acetaldehyde Dephosphorylates Occludin on Threonine Residues by a PP2A-

dependent Mechanism ........................................................................................54

PP2A Translocation Inhibitor Blocks Acetaldehyde-induced Threonine

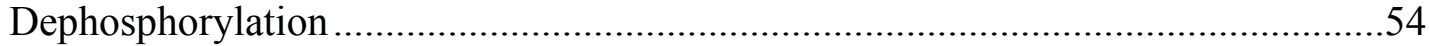

Tyrosine Kinase Activity Mediates Acetaldehyde-induced Occludin

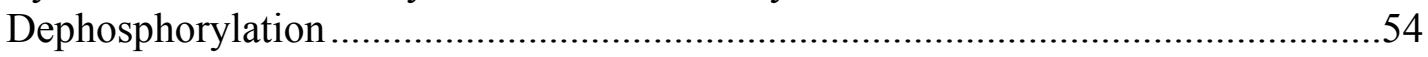

Acetaldehyde-induced Activity of PP2A Does Not Depend on Changes in PP2A

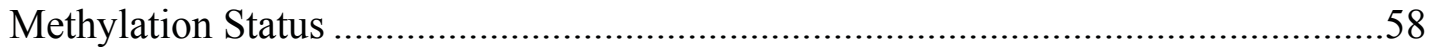

Specific Aim 2: To Determine That Acetaldehyde Alters Migration and

Differentiation by a PP2A-dependent Mechanism ...................................................58

Acetaldehyde Promotes Cell Migration by a Mechanism That Involves PP2A

and Thr-dephosphorylation of Occludin ........................................................58

Acetaldehyde Inhibits Cell Migration in Caco-2 Cells at Low Concentrations ........60

Inhibition of Migration by Acetaldehyde Exposure is Not PP2A-dependent............60

Acetaldehyde Affects Growth and Differentiation of Caco-2 Cells by a PP2A-

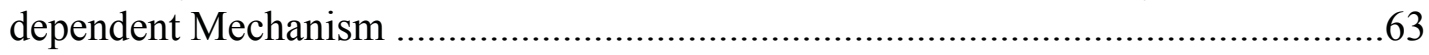

Acetaldehyde-induced Differentiation Problems Are PP2A-dependent...................63

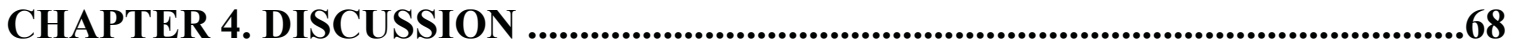

Acetaldehyde Disrupts Apical Junctional Complexes and Barrier Function in Intestinal Epithelium by a PP2A-dependent Mechanism ....

Acetaldehyde Dephosphorylates Occludin on Thr Residues by a PP2A-dependent

Mechanism

Acetaldehyde Inhibits Cell Migration by a Mechanism That Does Not Involve

PP2A

Acetaldehyde Alters Morphology of Cells Grown in Matrigel in a Dose-dependent

Manner .

Summary

LIST OF REFERENCES. 


\section{LIST OF TABLES}

Table 1-1. Important ADH and ALDH Polymorphisms............................................4

Table 2-1. $\mathrm{IC}_{50}$ for Fostriecin and Okadaic Acid ......................................................27 


\section{LIST OF FIGURES}

Figure 1-1. Reactions Forming Acetaldehyde in Humans ..............................................2

Figure 1-2. Fatty Acid Ethyl Ester Formation and Breakdown ....................................3

Figure 1-3. Effects of Ethanol on PLD Signaling....................................................

Figure 1-4. Formation of Protein Adducts with Acetaldehyde...................................10

Figure 1-5. DNA Adduct Formation in the Presence of Acetaldehyde ..........................13

Figure 1-6. Electron Micrograph of the Tight Junction .............................................15

Figure 1-7. Tight Junction Basic Structure .......................................................17

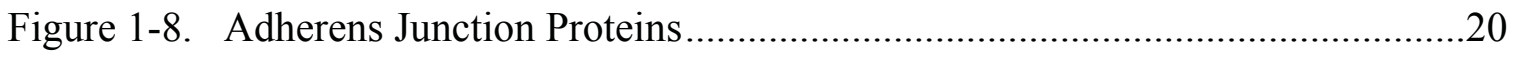

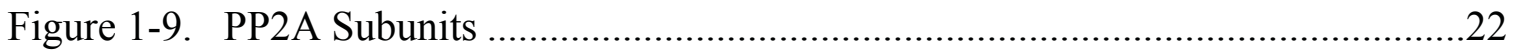

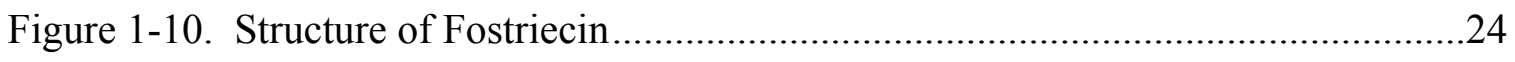

Figure 2-1. TPDYFL Transfection and Chariot Peptide.............................................29

Figure 3-1. TER and FITC-inulin Flux in Acetaldehyde-treated Cells ........................41

Figure 3-2. Effects of Fostriecin on Acetaldehyde-induced Tight Junction

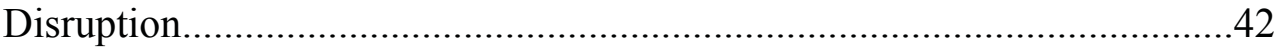

Figure 3-3. Effects of Fostriecin on Acetaldehyde-induced Tight Junction Disruption.

Figure 3-4. Confocal Images of Tight Junction Effects of Acetaldehyde and Fostriecin

Figure 3-5. Effects of Acetaldehyde and Fostriecin on Adherens Junctions ..................46

Figure 3-6. Effects of Acetaldehyde and Fostriecin on Mouse Ileum ..........................47

Figure 3-7. SiRNA Knockdown of PP2A Attenuates Effects of Acetaldehyde .............49

Figure 3-8. Effects of Acetaldehyde on PP2A Activity and Association with Occludin

Figure 3-9. Effects of Peptide Inhibition on Acetaldehyde-induced Tight Junction

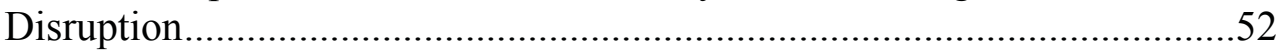

Figure 3-10. Genistein Effect on PP2A Association with Occludin. 53 
Figure 3-11. Effects of Acetaldehyde and Fostriecin on Threonine Phosphorylation

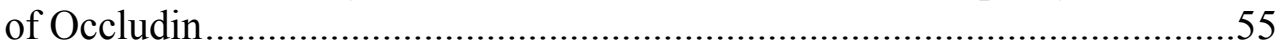

Figure 3-12. PP2A Inhibition with TPDYFL Restores Threonine Phosphorylation of

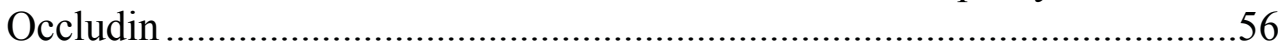

Figure 3-13. Effects of Tyrosine Kinase Inhibition with Genistein on Acetaldehyde induced Threonine Dephosphorylation of Occludin

Figure 3-14. Methylation Status of PP2A in the Presence of Acetaldehyde

Figure 3-15. Cell Migration Dose Response in the Presence of Acetaldehyde .61

Figure 3-16. Effects of Fostriecin at Range of Concentrations of Acetaldehyde ...... .62

Figure 3-17. Effects of Acetaldehyde at High Concentration on Growth in Matrigel .....64

Figure 3-18. Cells Exposed to Reduced Acetaldehyde Concentrations in the Presence or Absence of Fostriecin .66 


\section{LIST OF ABBREVIATIONS}

$\begin{array}{ll}\text { ADH } & \begin{array}{l}\text { alcohol dehydrogenase } \\ \text { aldehyde dehydrogenase } \\ \text { ALDH }\end{array} \\ \text { CYP2E1 } & \begin{array}{l}\text { cytochrome } \text { diacylglycerol } 2 \mathrm{E} 1 \\ \text { endoplasmic reticulum }\end{array} \\ \text { DAG } & \begin{array}{l}\text { lactate dehydrogenase } \\ \text { ER }\end{array} \\ \text { LDH } & \text { photinamide adenine dinucleotide } \\ \text { NAD } & \text { phosphatidic acid } \\ \text { PA } & \text { phosphatidylcholine } \\ \text { PC } & \text { phospholipase D } \\ \text { PEt } & \text { protein phosphatase 2A } \\ \text { PLD } & \text { protein tyrosine phosphatase 1B } \\ \text { PP2A } & \text { zonula occludens one, two, three }\end{array}$




\section{CHAPTER 1. INTRODUCTION}

\section{Ethanol Breakdown, Enzymes, and Products}

Ethanol consumption has been linked to a variety of health problems ranging from neurodegeneration to liver disease to aerodigestive and other cancers. It is estimated to be linked to approximately $4 \%$ of deaths and $5 \%$ of years lost to disability worldwide (IARC 2010). Studies in Mumbai, India have found increased risk of death from liver disease, digestive disease, tuberculosis, oral cancer, and cardiovascular disease among drinkers consuming more than 33 g ethanol per day (Pednekar, Sansone, and Gupta 2011). Studies in Italian alcoholics have found a several-fold increased risk of death from liver cirrhosis, respiratory diseases, mental illness, diabetes, cardiovascular disease, cancer, and infectious disease (Saieva et al. 2012). Many of these health problems can be linked directly to the enzymatic breakdown of ethanol to form acetaldehyde, then acetate. Acetate is innocuous, but acetaldehyde can bind to a variety of proteins, lipids, and DNA in the cell, forming adducts. These adducts can interfere with normal cellular enzymatic reactions, slowing reaction rates and forming abnormal by-products. Acetaldehyde disrupts intracellular junctions in different epithelia to allow foreign substances into the body, causing further havoc. Ethanol breakdown in general and acetaldehyde processing in particular cause destructive consequences in the cells of persons engaging in acute or chronic high levels of alcohol consumption.

Ethanol breakdown occurs in one major pathway and several minor ones, which can be classified as oxidative and non-oxidative. The major pathway is conversion by alcohol dehydrogenase (ADH) to form acetaldehyde, with further breakdown by aldehyde dehydrogenase (ALDH) to form acetate. Each dehydrogenation causes reduction of NAD to NADH, which can cause changes in the redox status of cells with continued ethanol exposure (Lieber 2005) (Figure 1-1).

Other oxidative processes also exist. Cytochrome P4502E1 (CYP2E1) and catalase are activated by high levels of ethanol, resulting in added production of acetaldehyde. CYP2E1 produces hydroxyethyl radicals as well as acetaldehyde, adding to the oxidative stress of the cell (Comporti et al. 2010). These species add to the cellular stress by their production of acetaldehyde and other molecules.

Non-oxidative ethanol processing occurs through fatty-acid-processing enzymes and phospholipase D (PLD) . Ethanol competes with phosphatidylcholine, the normal substrate of PLD. Instead of phosphatidic acid, an important second messenger in proliferative pathways, PLD produces phosphatidylethanol by the process of transphosphatidylation (Rydzewska, Jurkowska, and Gabryelewicz 1996).Fatty acid processing enzymes such as fatty acid ethyl ester synthase form compounds such as ethyl stearate and ethyl palmitate (Pragst et al. 2001; Best and Laposata 2003), which stimulate toxic calcium release in sensitive cells (Petersen et al. 2009). These non-oxidative forms of ethanol processing can be lethal to cells in the pancreas and toxic in other tissues (Figure 1-2). 


\begin{tabular}{|l|l|}
\hline ALCOHOL DEHYDROGENASE \\
$\mathrm{CH}_{3}-\mathrm{CH}_{2} \mathrm{OH}+\mathrm{NAD} \longrightarrow \mathrm{CH}_{3}-\mathrm{CHO}+\mathrm{NADH}+\mathrm{H}^{+}$ \\
\end{tabular}

Figure 1-1. Reactions Forming Acetaldehyde in Humans

These reactions oxidize ethanol to form acetaldehyde. $\mathrm{CH}_{3}-\mathrm{CH}_{2} \mathrm{OH}$ is ethanol. $\mathrm{CH}_{3} \mathrm{CHO}$ is acetaldehyde. NADH is nicotinamide adenine dinucleotide (reduced from NAD). $\mathrm{NADPH}$ is nicotinamide adenine dinucleotide phosphate (reduced from NADP ${ }^{+}$). Source: Reprinted with permission. Comporti M, C Signorini, S Leoncini, C Gardi, L Ciccoli, A Giardini, D Vecchio, and B Arezzini. 2010. "Ethanol-induced Oxidative Stress: Basic Knowledge.” Genes \& Nutrition 5 (2) (June): 101-109. 


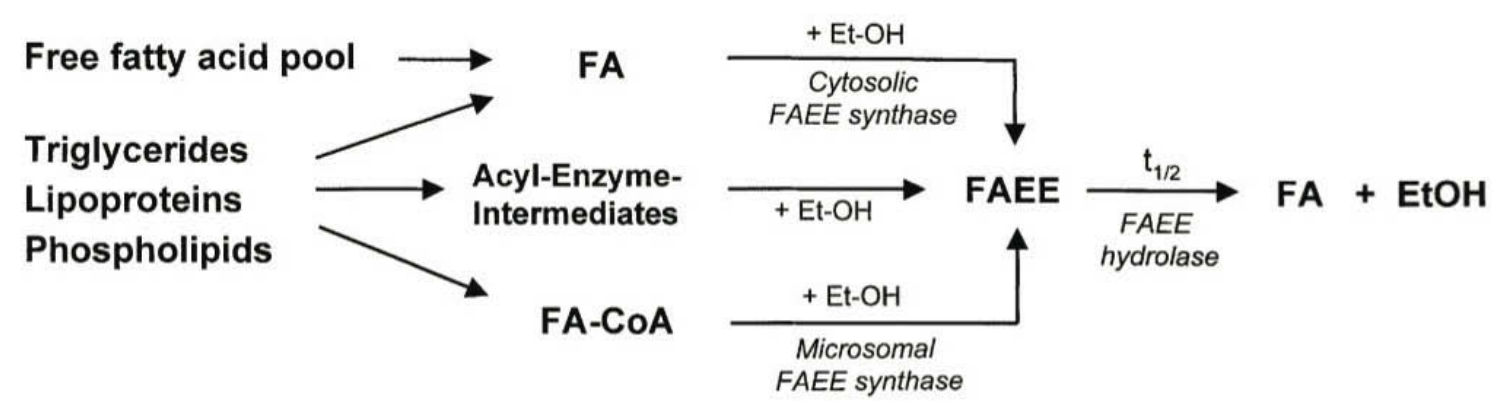

Figure 1-2. Fatty Acid Ethyl Ester Formation and Breakdown

A summary of reactions forming and breaking down fatty acid ethyl esters indicates a variety of lipid pools contributing to FAEE formation.

Source: Reprinted with permission. Pragst F, V Auwaerter, F Sporkert, and K Spiegel. 2001. "Analysis of Fatty Acid Ethyl Esters in Hair as Possible Markers of Chronically Elevated Alcohol Consumption by Headspace Solid-phase Microextraction (HS-SPME) and Gas Chromatography-mass Spectrometry (GC-MS)." Forensic Science International 121 (1-2) (September 15): 76-88.

\section{ADH, NADH, ALDH2}

When humans consume ethanol, acetaldehyde is produced by ADH in epithelial tissues lining the digestive tract and by bacteria and yeast occupying various parts of the digestive tract. The acetaldehyde is further broken down to acetate by ALDH, an enzyme with low activity in intestinal bacteria, but higher activity in human epithelial cells (Salaspuro 1996).

Mutations in the genes for these enzymes cause alterations in function, resulting in faster or slower processing of acetaldehyde by intestinal epithelial cells (Seitz and Becker 2007). For example, the His47Arg mutation in ADH1B results in higher risk of colorectal cancer (Gao et al. 2008). This mutation attenuates the activity of ADH1B, an isoform of $\mathrm{ADH}$ found in the liver ( $\mathrm{CH}$ Cho and Purohit 2006). The resulting increased blood alcohol levels may increase the risk of colorectal cancer by unknown mechanisms, or may provide more alcohol for the action of bacterial ADH in the gastrointestinal tract, resulting in colonic acetaldehyde accumulation (Matsuo et al. 2006).

There are three different allelic variants of the ADH1B gene responsible for most ethanol processing in the liver (Edenberg 2007). ADH1B*1, the reference allele common in Caucasians, has an Arg at positions 48 and 370 (Table 1-1). ADH1B*2 has a histidine at position 48 . ADH1B*3 has a cysteine at position 370 . Both of these mutations increase the turnover rate of the enzyme 70 to 80 fold because nicotinamide adenine dinucleotide (NADH) is released more quickly at the end of the reaction than usual (Edenberg 2007). Fast ADH processing can result in buildup of acetaldehyde in the system, resulting in 
Table 1-1. Important ADH and ALDH Polymorphisms

\begin{tabular}{cll}
\hline \multicolumn{2}{l}{ Class and Gene } & Tissue Distribution \\
\hline ADH & & \\
& & \\
I. & ADH1A & liver, lungs, kidneys \\
& ADH1B*1 & liver, lungs, kidneys \\
& ADH1B*2 & liver, lungs, kidneys \\
& ADH1B*3 & liver \\
II. & ADH2 & all tissues \\
III. & ADH3 & stomach, esophagus, liver, skin, cornea \\
IV. & ADH4 & stomach \\
V. & ADH5 & all tissues \\
& & \\
ALDH & & \\
& & ALDH1 \\
I. & ALDH2 1 & liver, stomach, brain (cytosol) \\
II. & ALDH2*2 & liver (mitochondrion) \\
& & liver, stomach (mitochondrion) \\
\hline
\end{tabular}

Source: Reprinted with permission. Jelski W, and M Szmitkowski. 2008. "Alcohol

Dehydrogenase (ADH) and Aldehyde Dehydrogenase (ALDH) in the Cancer Diseases." Clinica Chimica Acta; International Journal of Clinical Chemistry 395 (1-2)

(September): 1-5. Copyright 2008 Elsevier. 
increased risk of acetaldehyde-specific, alcohol-related health problems (Jelski and Szmitkowski 2008).

ALDH mutations can also cause problems. The ALDH2 Glu487Lys mutation causes inactivation of ALDH, resulting in build-up of acetaldehyde in the system, facial flushing, and other symptoms (Y in et al. 2007). These symptoms usually protect a person from excessive alcohol consumption, but heterozygotes may tolerate the symptoms, continue to drink heavily, and increase their risk of cancer (A. Yokoyama et al. 2008). The ALDH2 Glu487Lys mutation is common in Asian populations (Eng, Luczak, and Wall 2007).

These ADH and ALDH mutations contribute to malfunctions in the colon. Studies from Japan and Taiwan have implicated the inactive ALDH2 and over-active ADH genes common in Asians in an increased risk of colorectal cancer among Asian alcoholics ( $\mathrm{T}$. Yokoyama et al. 2005; Chiang et al. 2012). In both cases, a build-up of acetaldehyde in the colon is part of the mechanism of increased risk.

\section{CYP450 2E1 (Mitochondrial Ethanol Oxidizing System)}

CYP2E1 is induced by high levels of ethanol in cells, via chronic alcohol consumption. CYP2E1 processes alcohol to acetaldehyde, but produces superoxide radicals as unwanted byproducts, resulting in cellular damage (Lieber 2005)

(Figure 1-1). When CYP2E1 is activated, it also processes exogenous chemicals in the body, such as carbon tetrachloride and bromobenzene, to toxic metabolites (Lieber 2005). This accounts for excessive liver toxicity of acetaminophen in alcoholics, as the alcohol and the acetaminophen act synergistically to activate CYP2E1 and harm the liver. Shortly after ceasing excessive alcohol consumption, alcoholics are particularly vulnerable to the toxic effects of CYP2E1 as the alcohol stops competing for the enzyme, and toxic metabolites of other environmental chemicals reach their peak (Gonzalez 2005).

CYP2E1 activation has been shown to occur in the colonic mucosa of rats and humans exposed to alcohol (Seitz, Maurer, and Stickel 2005), and may contribute to the higher risk of colon cancer in alcoholics by several mechanisms. CYP2E1 generates acetaldehyde, which is both mutagenic and carcinogenic (Salaspuro 2009). CYP2E1 induction by ethanol consumption is known to increase the effects of dietary nitrosamines by generating DNA adducts (Gonzalez 2005). CYP2E1 may also play a role in colonic hyper-regeneration in rats exposed to chronic alcohol consumption, as exposure to alpha tocopherol, a radical scavenger, alleviates alcohol-induced colonic hyper-regeneration (Vincon et al. 2003). Since colonic hyper-regeneration increases the risk of colon cancer in humans, the activation of CYP2E1 in the presence of heavy alcohol consumption may be part of the pathogenesis of alcohol-related colorectal cancer. 


\section{Catalase}

Catalase is an enzyme found in peroxisomes that is capable of oxidizing alcohol to acetaldehyde in the presence of hydrogen peroxide (Keilin and Hartree 1945). It uses hydrogen peroxide to oxidize alcohol to acetaldehyde, but "leaks" free radical species in the process (Figure 1-1). Hydrogen peroxide generating enzymes such as xanthine oxidase and NADPH oxidase are necessary for its function. It seems to be an important source of ethanol oxidation in the kidney, heart, and brain (Orellana et al. 1998; Pastor, Sanchis-Segura, and Aragon 2002; Zimatkin and Buben 2007), but relatively insignificant in the liver (Lieber 2005).

\section{FAEE Formation}

Fatty acid ethyl esters (FAEEs) form as a minor product during the non-oxidative elimination of ethanol (Figure 1-2). They accumulate in the pancreas, liver, and heart during acute ethanol administration (Laposata and Lange, 1986), organs damaged in many alcoholics. It has been shown in the pancreas that FAEEs cause lethal release of calcium from the endoplasmic reticulum, resulting in calcium-dependent necrosis (Petersen et al. 2009). The binding of FAEEs to mitochondrial membranes may contribute to malfunction of oxidative phosphorylation and generation of toxic fatty acids (Lange and Sobel 1983).

\section{PLD}

Phospholipase D is a membrane-associated enzyme that normally cleaves phosphatidylcholine to release phosphatidic acid (Figure 1-3). It also produces the important signaling molecules diacylglycerol and lysophosphatidic acid. These molecules participate in signaling pathways such as regulation of kinases and matrix metalloproteinases (Liscovitch et al. 2000). PLD is also essential for acetylcholine formation in cholinergic neurons.

PLD can use short-chain alcohols as substrates to produce phosphatidylethanol (Liscovitch et al. 2000). Phosphatidylethanol accumulation has been shown to increase colonic cell proliferation and intestinal hyperplasia in rats (Pannequin et al. 2007). PLD has also been shown to be inhibited by ethanol in the rat pancreas (Rydzewska, Jurkowska, and Gabryelewicz 1996). Inhibition of PLD and competition as a substrate by ethanol disrupt the signaling pathways (such as stimulation of PKCs and MAPKs) normally modulated by the products of PLD. 

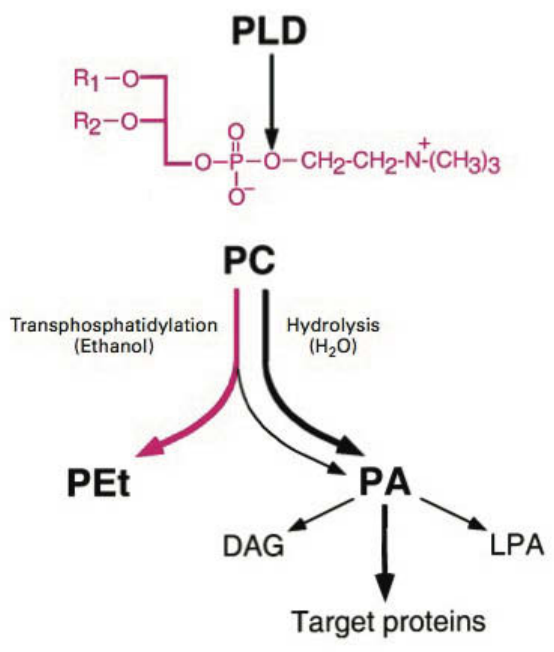

Figure 1-3. Effects of Ethanol on PLD Signaling

Ethanol competes with phosphatidylcholine for the activity of phospholipase D, resulting in formation of non-functional phosphatidylethanol instead of phosphatidic acid (PA). Source: Reprinted with permission. Liscovitch, M, M Czarny, G Fiucci, and X Tang. 2000. "Phospholipase D: Molecular and Cell Biology of a Novel Gene Family." Biochemical Journal 345: 401-415.

\section{Acetaldehyde Pharmacology}

\section{General Description}

Acetaldehyde, also known as ethanal or $\mathrm{CH}_{3} \mathrm{CHO}$, is one of the "aromatics", volatile compounds found in low concentration in alcoholic beverages which give them a characteristic bouquet (Regodon Mateos, Perez-Nevado, and Ramirez Fernandez 2006). At low concentrations it contributes to a fruity aroma in alcoholic beverages, but in high concentrations it is pungent and unpleasant. It is produced by the yeast during fermentation from pyruvate, by the enzyme pyruvate decarboxylase (Lees and Jago 1978). The different yeast strains used to ferment alcoholic beverages produce different amounts of acetaldehyde (Querol et al. 2003) under different growth conditions (Roustan and Sablayrolles 2002; Regodon Mateos, Perez-Nevado, and Ramirez Fernandez 2006). Home-brewed and distilled alcoholic beverages tend to have higher acetaldehyde levels than those produced in large-scale facilities (Boffetta et al. 2011), as temperature and brewing conditions change microflora and the resulting acetaldehyde content.

Human ingestion of ethanol results in acetaldehyde production, as ethanol is broken down to acetaldehyde by gastrointestinal microflora and epithelial cells. About $2-10 \%$ of ethanol taken orally can be eliminated through the kidneys or lungs (Lieber 2005). The rest is metabolized by the body, mostly in the liver, resulting in low blood 
acetaldehyde levels under normal conditions (Lieber 2005) Acetaldehyde production can be measured in saliva following ethanol ingestion, both from acetaldehyde in the beverage and endogenous production by oral microflora, with heavy smokers and drinkers having higher levels of acetaldehyde production (Homann et al. 2000). Roughly $40-75 \%$ of alcohol consumed in an evening of drinking is absorbed in the stomach, with some processed there to produce high levels of acetaldehyde in gastric juice (Lieber 2005; Salaspuro 2009). Microflora in the large intestine process residual alcohol and alcohol diffused from the bloodstream to form acetaldehyde, but lack ALDH to oxidize it to acetate. High levels of acetaldehyde in the saliva, gastric juice, and colonic contents can be traced to the action of microbes and epithelial cells, increasing the risk of digestive cancer (Salaspuro 2003).

\section{Known Hazards}

The presence of acetaldehyde in the beverage, especially when consumed at chronically high doses, may contribute to the risk of human cancer in a variety of ways. It may encourage the growth of bacteria in the gastrointestinal tract which are tolerant of high acetaldehyde levels (Hooper, Wilson, and Crean 2009) and in turn produce more acetaldehyde themselves (Salaspuro 2003). It may contribute to cancer directly by generation of DNA adducts and DNA-protein crosslinks (Lorenti Garcia et al. 2009). Acetaldehyde also decreases cell differentiation with chronic exposure, decreasing cell adhesion to common extracellular matrix collagens and increasing proliferation (Koivisto and Salaspuro 1998).

\section{Dose Response}

Dose-response information about acetaldehyde is limited by its chemical and physical properties. It is volatile, evaporating at $20^{\circ} \mathrm{C}$. It contains an electrophilic carbonyl carbon (Lorenti Garcia et al. 2009), making it highly reactive with biological macromolecules including DNA, proteins, and phospholipids. It is constantly formed and broken down in the presence of ethanol intake. Most ethanol processing takes place in the liver, with significant processing along the alimentary canal as well. Though concentrations of acetaldehyde in the blood are usually low, concentrations in the digestive tract are increased by the presence of bacteria with efficient ADH, but insufficient ALDH to break down the acetaldehyde generated (Salaspuro 1996). Variability in the types and processing efficiencies of the bacteria in the digestive tracts of individuals, as well as genetic differences in the human alcohol consumers, make establishing a dose of acetaldehyde per dose of alcohol in humans very difficult. The chemical and physical properties of acetaldehyde, as well as variations in the ability to process ethanol limit the dose-response information it is possible to obtain about acetaldehyde from alcohol consumption in free-living humans.

Some dose response information has been acquired despite the daunting methodological challenges. Blood concentrations of $30 \mu \mathrm{M}$ have been noted in 
alcoholics, with higher concentrations of 750 and $2410 \mu \mathrm{M}$ in alcoholics actively drinking (Brecher, Hellman, and Basista 1997). Acetaldehyde concentrations of 100-200 $\mu \mathrm{M}$ have been seen in the mouths of humans consuming beverages with high ethanol content (Homann et al. 2000). Mice with ALDH2 knockout subjected to ethanol gavage had blood acetaldehyde levels up to $247 \mu \mathrm{M}$, with wild type mice experiencing levels of $14 \mu \mathrm{M}$ at the same ethanol dose (Isse et al. 2005). Measurable doses of acetaldehyde tend to vary among subjects and species, depending on the ethanol dose, genetic background of the subject, enzymes induced, and presence or absence of chronic alcohol consumption.

\section{Acetaldehyde Adduct Formation: Proteins and Enzymes}

\section{Mechanisms of Formation}

Acetaldehyde is a reactive molecule, which can form protein adducts directly or indirectly. It may interact with lysine residues or terminal amines to produce an unstable Schiff base, which may be reversed or may be reduced to form a more stable adduct (Grazi et al. 1963; Mauch et al. 1986). More recent studies have found that alcoholinduced aberrant lipid peroxidation in the liver produces malondialdehyde, which can react with acetaldehyde and protein to produce protein adducts that may induce inflammation and fibrosis (Tuma et al. 2001). Hydrogen peroxide and acetaldehyde react with an amino group on a protein to form an unstable adduct. Malondialdehyde reacts with another amino group to form a Schiff base. The Schiff base may be further reduced, allwoing more complex combinations of reactions to occur among proteins. Such modified proteins stimulate antibody production against the carrier proteins, causing fan immune response to already-stressed liver cells. The resulting proteins may form a stable product capable of stimulating cytokine release, inflammation, and fibrosis in the livers of alcohol-fed rats (Figure1-4) (Tuma et al. 2001).

\section{Consequences for Enzyme Activity}

Several enzymes have been shown to be affected by interaction with acetaldehyde. For example, carbonic anhydrase II has 24 lysine residues, and has been shown to form Schiff-base adducts with 9-19 acetaldehyde molecules per molecule CAII. This interaction slows the reaction rate of the enzyme (Bootorabi et al. 2008), which could potentially lead to reduced gastric acid formation, reduced alkalization of pancreatic secretions, and other secretory difficulties involving acid-base balance. Acetaldehyde also affects lipoprotein lipase and hepatic lipase, altering lipid processing in favor of atherosclerosis by increasing triglyceride levels and serum cholesterol (Frohlich 1996). 
<smiles>CC=O</smiles>

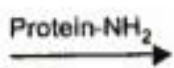<smiles>O=CCC=O</smiles>

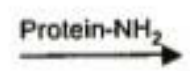<smiles>CC(NP)c1ccoc1</smiles>

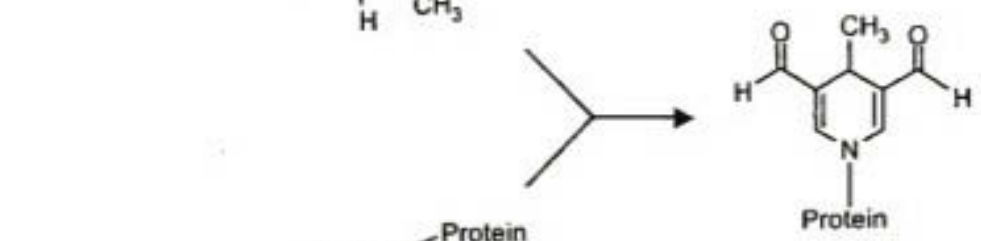

Figure 1-4. Formation of Protein Adducts with Acetaldehyde

Proteins react with acetaldehyde and malondialdehyde to form inflammatory adducts as shown above. $\mathrm{CH}_{3} \mathrm{CHO}$ is acetaldehyde. $\mathrm{CHOCH}_{2} \mathrm{CHO}$ is malondialdehyde. Schiff bases (bottom of figure) can combine with other adducts to form complex protein products that elicit inflammatory responses in the liver.

Source: Reprinted with permission. Tuma DJ, ML Kearley, GM Thiele, S Worrall, A Haver, LW Klassen, and MF Sorrell. "Elucidation of Reaction Scheme Describing Malondialdehyde-acetaldehyde-protein Adduct Formation." Chemical Research in Toxicology 14 (7) (July): 822-832. Copyright 2001 American Chemical Society. 


\section{Consequences for Cell Signaling}

Chronic alcohol consumption triggers upregulation of CYP2E1, a cytochrome P450 found in the endoplasmic reticulum (ER) (Gonzalez 2005). CYP2E1 releases free oxygen radicals, resulting in oxidative stress to cells. Oxidative stress leads to an accumulation of protein in the endoplasmic reticulum of liver cells, myocardium, and cells of the cerebral cortex in mice (Ji 2012), resulting in the unfolded protein response and ER stress. The stress response reduces protein synthesis and increases the capacity to fold and unload proteins, restoring homeostasis to the cell if the stress is acute. If stress is prolonged or chronic, as in the alcoholic, signaling changes predispose cells to apoptosis by activating caspases and promoting mitochondrial leakage.

Acetaldehyde plays a critical role in this response to chronic alcohol consumption. Acetaldehyde-protein adducts can be found in every organ tested of rats fed a chronic diet of 15\% ethanol (Biewald, Nilius, and Langner 1998). In biopsies from patients with alcoholic liver disease, acetaldehyde-protein adducts were found in the rough ER and microsomes of hepatocytes (Paradis et al. 1996). ADH overexpression, increasing acetaldehyde exposure in mice fed ethanol, resulted in increased cardiac hypertrophy and ER stress (Li and Ren 2008). ALDH2 over-expression, which decreases acetaldehyde exposure, decreased ER stress and cardiac hypertrophy (Li et al. 2009). Acetaldehyde exposure increases ER stress and predisposes cells to apoptosis in many vital organs of the body.

Acetaldehyde has been shown to bind to tubulin and actin in vitro (Tuma, Jennett, and Sorrell 1987; Xu et al. 1989). This binding causes inhibition of tubulin assembly at concentrations as low as $200 \mu \mathrm{M}$ with prolonged exposure (Tuma, Jennett, and Sorrell 1987). This binding may contribute to cytoskeletal changes observed in cells exposed to acetaldehyde (Xu et al. 1989).

Acetaldehyde also affects beta-catenin and E-cadherin at the adherens junction in a time-dependent manner. The adherens junction, found just below the tight junction, functions as a point of cell-cell contact and communication. Acetaldehyde causes dissociation of protein tyrosine phosphatase (PTP-1B) from the adherens junction, resulting in phosphorylation of beta-catenin and disruption of the adherens junction (Atkinson and Rao 2001; Sheth et al. 2007). Tyrosine phosphorylation has been previously shown to cause relocalization of beta catenin to the nucleus of the cell and to promote its binding to TATA- binding protein (a basal transcription factor) (Piedra et al. 2001). This binding activates the Wnt signaling pathway for proliferation (Klaus and Birchmeier 2008). Accumulation of beta-catenin outside the adherens junction has been shown to be a negative prognostic indicator in many cancers (Kren et al. 2003; Polette et al. 2007; Caldwell et al. 2008). Thus the acetaldehyde-induced disruption of adherens junctions may play an important role in cancer promotion. 


\section{Acetaldehyde Adduct Formation: DNA}

\section{Mechanisms of Formation}

Acetaldehyde interacts directly with DNA to produce DNA-acetaldehyde adducts with the potential to stop both DNA and RNA polymerases during transcription, resulting in mutations from the actions of DNA repair enzymes (Stein et al. 2006). These G-to-A, $\mathrm{T}$, or $\mathrm{C}$ mutations can result in protein malfunction. In ALDH2 knockout mice, alcohol consumption with acetaldehyde accumulation results in increased formation of DNAadducts and mutation of immune cells (Matsuda et al. 2007; Kunugita et al. 2008). In human alcoholics with slow-metabolizing ALDH2, DNA-acetaldehyde adducts are found at much higher levels than in subjects with normal ALDH2 (Matsuda et al. 2006). An example of the formation of a relatively innocuous adduct which may be repaired properly is shown (Seitz and Stickel 2007) (Figure 1-5A). Multiple acetaldehyde molecules can also interact with DNA to form malondialdehyde and crotonaldehyde adducts, which are more complex and may result in more likely DNA damage (Figure 1-5B).

The acetaldehyde- DNA adduct $\mathrm{N}^{2}$-propano-deoxiguanosine has been shown to be able to form inter-strand crosslinks between complementary DNA molecules (Lorenti Garcia et al. 2009) (Figure 1-5B, C). Chromatid exchanges and DNA-protein crosslinks occur in cell culture in a dose-dependent manner as well (Lorenti Garcia et al. 2009). These results confirm increased levels of DNA damage in ALDH2-deficient alcoholics, whose increased levels of acetaldehyde exposure predispose them to higher risk of aerodigestive cancers (Matsuda et al. 2006).

\section{Mutations and Repair}

Mutations due to adducts are not the only problem associated with DNA and acetaldehyde. Acetaldehyde is known to interact with xanthine oxidase, increasing production of superoxide, which cleaves folate (S Shaw et al. 1989). There is conflicting epidemiological data, but some studies suggest that alcoholics tend to be folate deficient due to their diets, and excessive alcohol consumption depletes blood folate supplies (Ulrich 2007; Lightfoot et al. 2008) even further. This deficiency and depletion impedes DNA synthesis and repair mechanisms, increasing the risk of mutation in colorectal cells. Folate deficiency has been associated with improper methylation of tumor suppressor genes in studies of colorectal adenomas (van den Donk et al. 2007). Other studies suggest that defects in methylenetetrahydrofolate reductase (decreasing the amount of folate available) and $\mathrm{ADH}$ (increasing the concentration of acetaldehyde) can combine to create increased cancer risk (Hirose et al. 2005).

Acetaldehyde has been shown to promote dysfunction and cancer in a variety of organ systems. In the respiratory system, it promotes bronchospasm and wheezing in 


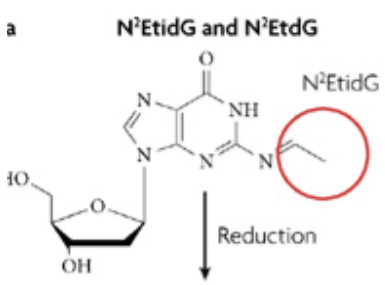

b
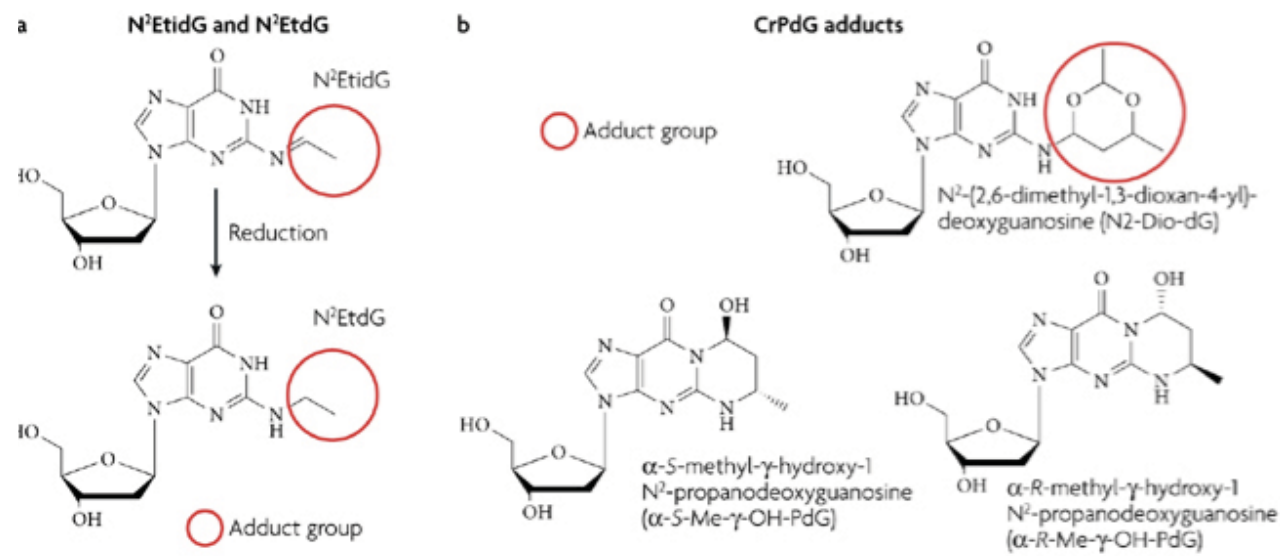

c

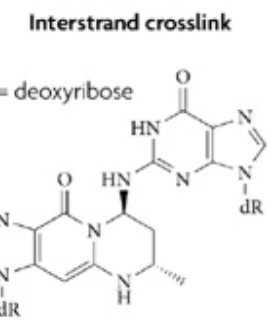

Figure 1-5. DNA Adduct Formation in the Presence of Acetaldehyde
A. Acetaldehyde Adduct Formation. B and C. Formation of Crosslinks. Source: Reprinted with permission. Seitz HK, and F Stickel. "Molecular Mechanisms of Alcohol-mediated Carcinogenesis." Nature Reviews. Cancer 7 (8)(August): 599-612. Copyright 2007 Nature Publishing Group. 
Japanese deficient in ALDH2 (Shimoda et al. 1996). In the rat gastrointestinal system, high acetaldehyde levels in the stomach, small intestine, and colon from chronic intoxication cause hypertrophy of gastric mucosa and intestinal crypts (Pronko et al. 2002). It contributes to neuronal death and cognitive deficits in alcoholics (Haorah et al. 2008). Acetaldehyde promotes lipid peroxidation and oxidative stress in the liver, resulting in collagen production (Lieber 2005). All of these effects of acetaldehyde are due to its metabolism and its adduct-forming capacity with proteins, lipids, and DNA.

The gastrointestinal epithelium is exposed to acetaldehyde from mouth to rectum in chronic alcoholics. This exposure results in an increased risk of cancers of the mouth, pharynx, esophagus, stomach, colon, and rectum (Homann et al. 2000; Akhter et al. 2007; Seitz and Meier 2007; Salaspuro 2009). The bacterial inhabitants of the mouth and colon have been shown to contribute to higher acetaldehyde levels in these areas than in the bloodstream of alcoholics (Salaspuro 1996; Homann et al. 2000). Higher levels of exposure to acetaldehyde result in detrimental effects to these parts of the body.

The detrimental effects of acetaldehyde may be focused on the junctional complexes of gastrointestinal epithelia. These large protein complexes serve as a gate for paracellular passage of ions and large molecules as well as a fence to preserve apicalbasolateral polarity (Schneeberger and Lynch 2004). Acetaldehyde disrupts tight junctions, resulting in penetration of colonic bacterial endotoxins to the bloodstream (Rao, Seth, and Sheth 2004). Because the mechanism of tight junction disruption is poorly understood, it deserves examination in more detail. .

\section{Tight Junctions}

\section{Historical Data}

Tight junctions were first viewed by light microscopy in 1895, assumed to be bars sealing the space between epithelial cells (Bonnet 1895). With advances in electron microscopy, tight junctions were seen as fusions of cell membranes, binding epithelial cells together in a manner similar to the mortar between bricks in a brick wall by sealing the paracellular space between them with interwoven strands of protein (Figure 1-6) (Farquhar and Palade 1963; Tamura et al. 2008). The discovery that some epithelia have high resistance to the passage of ions, while others are "leaky", led to the discovery of zonula occludens 1 (ZO-1) (Stevenson et al. 1986), a structural protein, and occludin, the first trans-membrane protein of the tight junction to be discovered (Furuse et al. 1993). A focus on the tight junction as a regulator of epithelial permeability has resulted in the discovery of over 40 proteins interacting in a highly flexible and dynamic protein complex (González-Mariscal, Tapia, and Chamorro 2008). Tight junctions are far more than mere sealing sites between cells; they are active sites of protein-protein interaction.

Epithelial tight junctions serve to regulate the passage of ions and molecules between cells, and to mark the division between apical and basolateral surfaces of cells in 


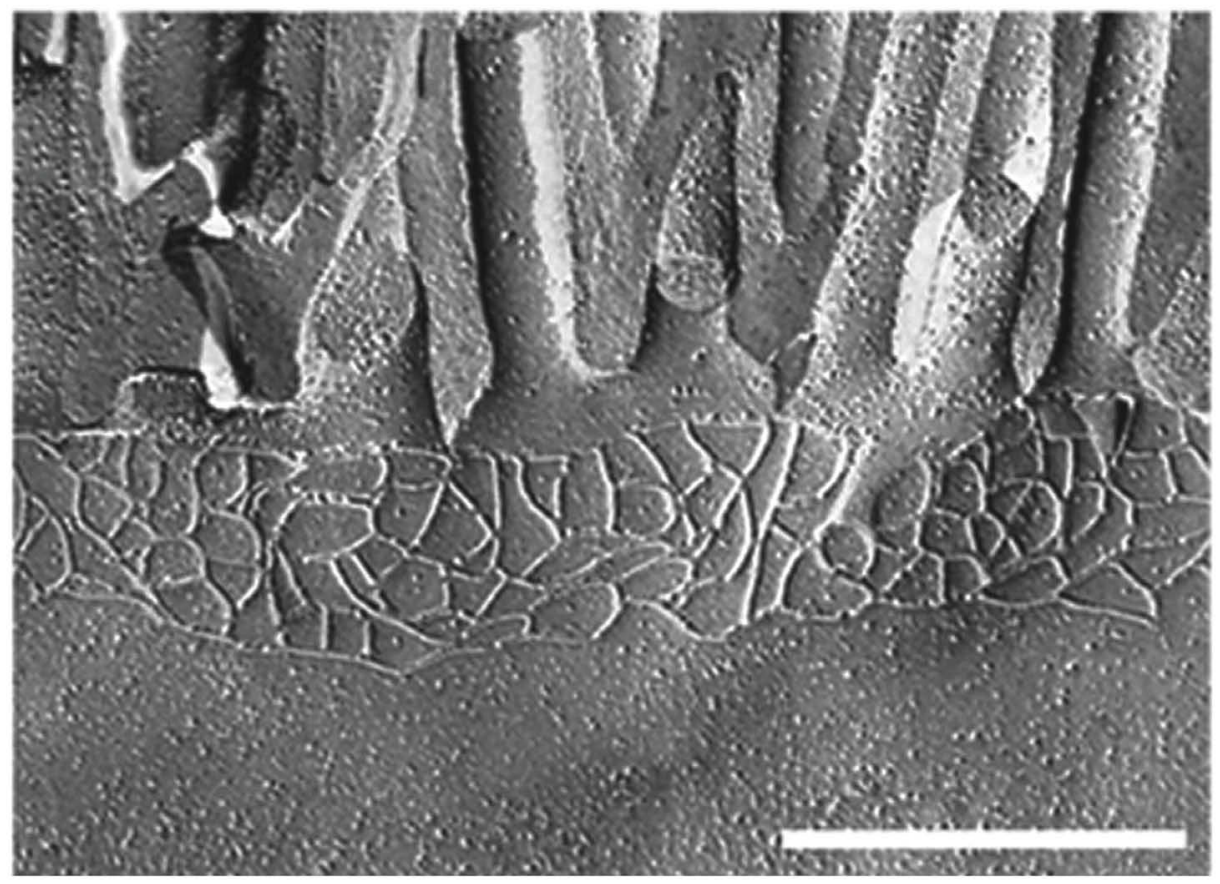

Figure 1-6. Electron Micrograph of the Tight Junction

Anastamosing strands of tight junction proteins in mouse upper small intestine are seen by freeze-fracture and electron microscopy. Bar is one micron.

Source: Reprinted with permission. Tamura A, Y Kitano, M Hata, T Katsuno, K Moriwaki, H Sasaki, H Hayashi, et al. 2008. "Megaintestine in Claudin-15-Deficient Mice.” Gastroenterology 134 (2) (February): 523-534. 
cellular differentiation (Matter et al. 2005). Passage of ions and molecules is regulated by to the actin cytoskeleton, allowing for changes in cytoskeletal arrangements as intercellular contacts change (Hartsock and Nelson 2008). Each of these protein families is critical to the overall function of the tight junction.

The claudin family of transmembrane proteins, which can homo- or heterodimerize to form pores of varying selectivity (Colegio et al. 2002). Apical-basolateral separation of populations of proteins is critical to the maintenance of polarity and differentiation status of epithelial cells (Matter et al. 2005), and is maintained by tight junctions. Expression of a truncated version of occludin inhibited the ability of MDCK cells to maintain fluorescently-marked lipids in their normal location on the apical surface of the cell (Balda et al. 1996). Thus, the disruption of intestinal epithelial tight junctions has two undesirable consequences: unwanted substances such as endotoxins are allowed into the body, and depolarization of cells may be promoted (Laurent-Puig, Blons, and Cugnenc 1999; Rao, Seth, and Sheth 2004).

\section{Protein Classes}

Tight junctions are complex assemblies of transmembrane proteins (occludin, claudins, tricellulin, junctional adhesion molecules) (Aijaz, Balda, and Matter 2006), scaffolding proteins (zonula occludens family, including ZO-1) (Fanning et al. 1998), and signaling proteins such as protein kinases (Andreeva et al. 2006) and protein phosphatases (Seth et al. 2007). ZO-1 and other scaffolding proteins attach this complexto the actin cytoskeleton, allowing for changes in cytoskeletal arrangements as intercellular contacts change (Hartsock and Nelson 2008). Each of these protein families is critical to the overall function of the tight junction (Figure 1-7).

The first proteins of the tight junction to be discovered were the zonula occludens proteins, including ZO-1 as the first member. ZO-1 is a $225 \mathrm{KDa}$ protein found in a variety of epithelial cells, acting as a scaffolding protein to connect transmembrane proteins to the actin cytoskeleton (Stevenson et al. 1986; Fanning et al. 1998). ZO-1 is part of the membrane-associated guanylate kinase (MAGUK) family of proteins (Fanning et al. 1998). The proteins of this family contain PDZ, SH3, and GK binding domains, enabling them to bind and interact with a variety of other proteins. ZO-1 also has a long carboxy-terminal tail to enable further interactions. ZO-1 interacts with claudins and junctional adhesion molecules through its PDZ domains, with occludin through its GK binding domain, and with actin through its carboxy-terminal tail. It also binds ZONAB, a Y-box transcription factor released to the nucleus when the claudin-ZO-1 association is disrupted (Pannequin et al. 2007). ZO-1 is a vital scaffolding protein providing multiple binding sites for a host of tight junction proteins, as well as binding factors that communicate with the nucleus to drive transcription of factors increasing cell proliferation when cell-cell contacts through tight junctions are disrupted.

Occludin is a $65 \mathrm{KDa}$ transmembrane protein with four transmembrane domains, two extracellular loops, and intracellular N-terminal and C-terminal tails 


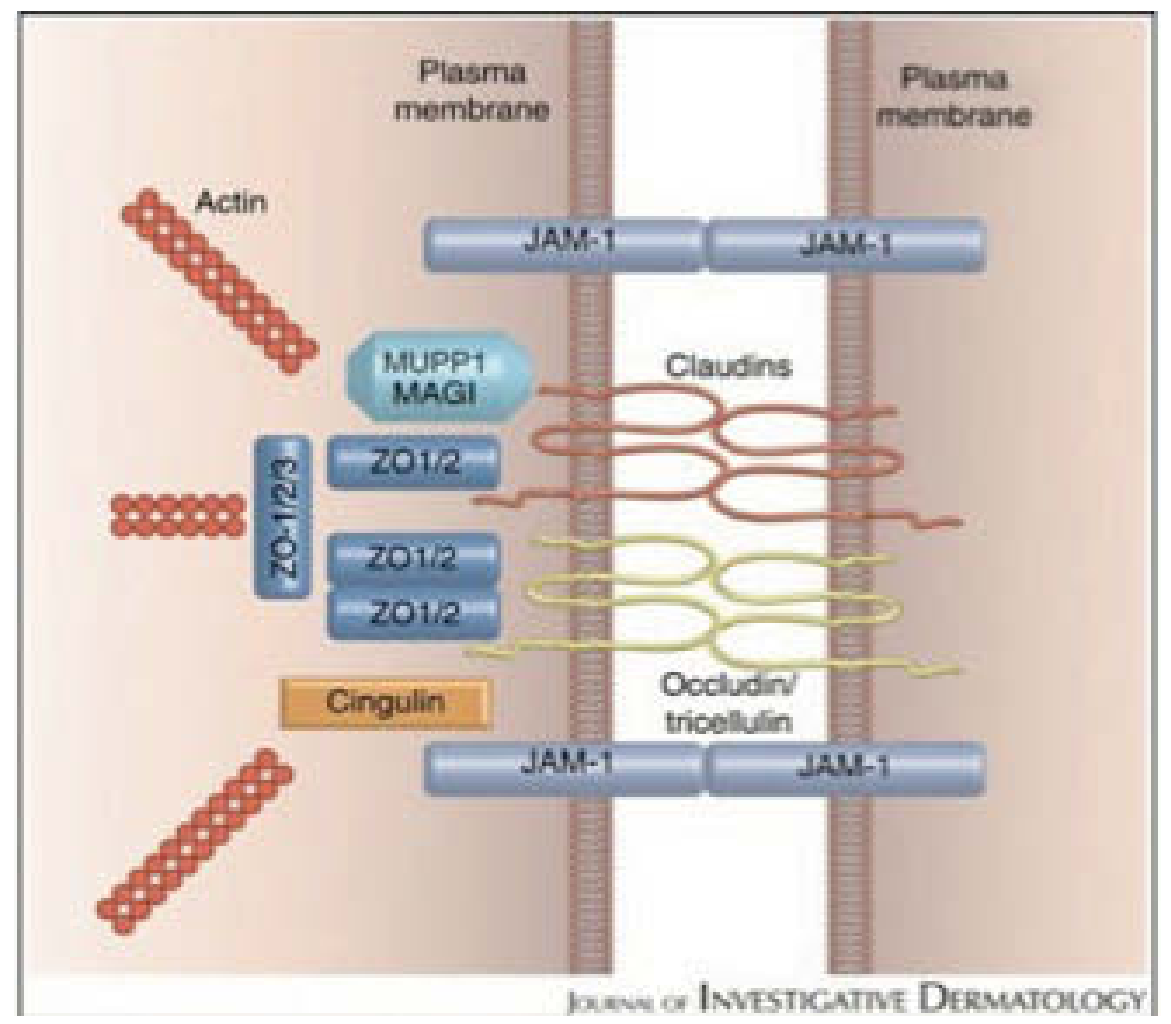

Figure 1-7. Tight Junction Basic Structure

Transmembrane proteins include occludin, claudins, and JAM-1. Scaffolding proteins include the ZO-1 family. These proteins provide binding sites for the transmembrane proteins and actin.

Source: Reprinted with permission. Niessen CM. 2007. "Tight Junctions/Adherens Junctions: Basic Structure and Function.” Journal of Investigative Dermatology 127 (11) (November 1): 2525-2532. Copyright 2007 Nature Publishing Group. 
(Furuse et al. 1993; Feldman, Mullin, and Ryan 2005). Multiple phosphorylation and binding sites on the C-terminal tail allow for interactions with ZO-1, kinases and phosphatases (Chen et al. 1997). As the first transmembrane protein of the tight junction to be discovered, it is known to increase tight junction integrity when over-expressed and to play an important role in tight junction regulation. However, its functional role in the junction was complicated by a study in which occludin null mice were generated (Saitou et al. 2000). Tight junctions in these mice appeared normal, but the mice showed growth retardation, chronic inflammation, gastric hyperplasia, brain calcification, and reproductive abnormalities. Occludin does not appear to be essential for tight junction formation, but does seem to be important in a variety of instances for regulation of absorptive and secretory functions (Saitou et al. 2000). It also seems important in regulating epithelial differentiation and senescence in breast and colon cancers (Osanai et al. 2007; Luque-García et al. 2010). Because tight junctions can develop and appear structurally normal without occludin, but tissues lacking it show abnormalities, its role in tight junction regulation and maintenance is still under active investigation.

The transmembrane protein family that seems critical for tight junction pore formation is the claudins, a group of 24 proteins. Claudins bear no sequence homology to occludin, despite having similar transmembrane domains, extracellular loops, and regulatory and binding domains (Furuse et al. 1998). They are smaller than other tight junction proteins, with a molecular weight ranging from 20-27 KDa (Van Itallie and Anderson 2006). Claudins homo- or hetero-dimerize to form paracellular pores of differing charge and size, allowing for paracellular passage of small ions (Van Itallie and Anderson 2006). Appropriate pore formation has been shown to be critical in promoting the normal barrier function of the intestinal epithelium, and pathologies of claudin expression have been associated with gastrointestinal diseases such as colorectal cancer (Huo et al. 2009; Kinugasa et al. 2010).

The interactions among these molecules keep the tight junctions intact (Shin, Fogg, and Margolis 2006). For example, occludin attaches to the N-terminal half of the scaffolding protein ZO-1 via its carboxy-terminal cytoplasmic domain (Furuse et al. 1994; Fanning et al. 1998). Several different protein kinases facilitate this interaction by phosphorylating the C-terminal tail of occludin (Andreeva et al. 2001). Dephosphorylation of tight junction proteins by protein phosphatases result in their internalization (Nunbhakdi-Craig et al. 2002). The interactions of transmembrane proteins, scaffolding proteins, kinases, and phosphatases are essential to the functions of the tight junction.

Recently these interactions have been discovered to be even more complex than previously imagined. The tight junction complex appears to be highly dynamic, with occludin diffusing within cell membranes to areas of photobleaching in steady-state cells, with recovery of fluorescence on the timescale of 5-6 minutes (Shen, Weber, and Turner 2008). Claudin-1, in contrast, does not recover fluorescence at all, suggesting stabilization and lack of exchangeability. ZO-1 shows an intermediate ability to move into a photobleached area, and that mostly from intracellular pools (Shen, Weber, and Turner 2008). Actin exchanges rapidly, showing increased exchange time only in 3-day- 
old as opposed to 1-day-old and 10-day-old MDCK monolayers. New and fully mature monolayers seem to show dynamic protein interactions with movement of different tight junction molecules among unique cellular pools by different mechanisms.

\section{Phosphorylation and Function of Occludin and Claudins}

With such a dynamic system, modes of regulation are critical to understanding how the tight junction adjusts to different environmental stimuli. It is well known that tight junctions may be disrupted in vitro by a variety of stimuli including phorbol esters, calcium depletion, oxidative stress, and hydrogen peroxide. Studies have indicated changes in the phosphorylation states of tight junction proteins, and their association with each other, as a result of these disrupting factors. Changes in phosphorylation of tight junction proteins happen prior to endocytosis of tight junction proteins and often mirror changes in TER (Farshori and Kachar 1999). For example, claudins form chargeselective pores allowing for paracellular permeability that results in measurable changes in transepithelial resistance (Van Itallie et al. 2006). Phosphorylation of claudins 1 and 4 by PKCs has been shown to promote tight junction formation and barrier function, as does inhibition of PP2A (González-Mariscal, Garay, and Quirós 2010). Other tight junction proteins also show significant patterns of phosphorylation and dephosphorylation during tight junction formation and disassembly.

Serine, threonine, and tyrosine phosphorylation of occludin have been shown to be important for tight junction assembly; a low-molecular weight, dephoshorylated form of occludin does not go to the cell surface for tight junction assembly (Sakakibara et al. 1997; Wong 1997; Farshori and Kachar 1999). Phosphorylation of occludin by PKC $\zeta$ on threonines 403, 404, 424, and 438 of the $\mathrm{C}$-terminal tail promotes tight junction assembly (Jain et al. 2011). PKC $\eta$ has also been shown to phosphorylate threonines 403 and 404 (Suzuki et al. 2009). Tyrosine phosphorylation via c-Src, in contrast to threonine phosphorylation, is present only in occludin from disrupted tight junctions, as in cells exposed to hydrogen peroxide (Basuroy et al. 2010). The interplay of these kinases and others in phosphorylating different occludin residues is important for the assembly, function, and disassembly of tight junctions (Andreeva et al. 2006).

Dephosphorylation by protein phosphatases has been shown to be important as well. For example, acetaldehyde disrupts tight junctions by activating the dephosphorylation of tight junction proteins by PP2A and PP1 (Seth et al. 2007). PP2A and PP1 bind to the cytoplasmic C-terminal tail of occludin in the presence of acetaldehyde, dephosphorylating it and causing its translocation from the tight junction to the cytoplasm (Seth et al. 2007). This process is part of the destabilization of the tight junction and loss of cell-cell contact, which can lead to aberrant cell growth (Polette et al. 2007). Phosphorylation and dephosphorylation of tight junction proteins allow for assembly and disassembly of tight junctions. 


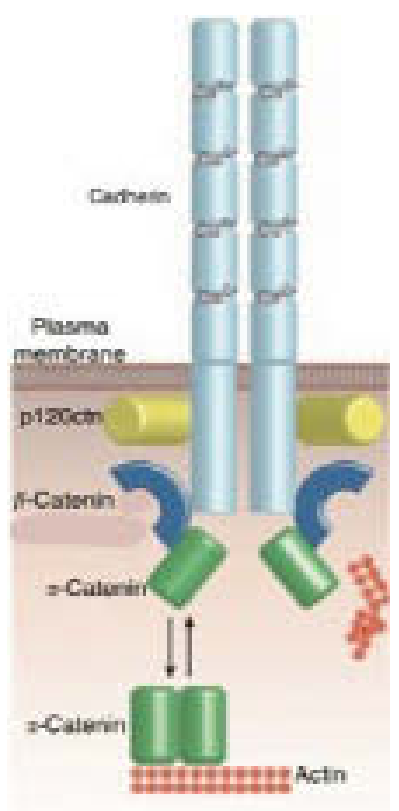

\section{Figure 1-8. Adherens Junction Proteins}

Adherens junctions are important for cell-cell adhesion and signaling. They contain cadherins, catenins, kinases, and phosphatases. For the sake of simplicity only the structural proteins are shown here. Cadherins are calcium-dependent transmembrane proteins bound to members of the catenin family, which serve as a scaffold to link the adherens junction to the cytoskeleton.

Source: Reprinted with permission. Niessen CM. "Tight Junctions/Adherens Junctions: Basic Structure and Function." Journal of Investigative Dermatology 127 (11)

(November 1): 2525-2532. Copyright 2007 Nature Publishing Group. 


\section{Adherens Junctions}

The adherens junction, located just below the tight junction, is critical for cell-cell contact and communication (Figure 1-8). It forms and maintains contact between cells so that the tight junction can assemble (Hartsock and Nelson 2008). Two primary proteins, beta catenin, a scaffolding protein, and E-cadherin, a calcium-dependent transmembrane protein, interact with the actin cytoskeleton and various kinases and phosphatases in a manner similar to occludin and ZO-1 in tight junctions (Niessen 2007). The adherens junction contributes stability to the tight junction, and factors disrupting one will often disrupt the other.

Beta catenin localization has been a subject of active investigation for many years, as nuclear localization of beta catenin causes activation of the usually-embryonic Wnt signaling pathway, causing proliferation and stem-cell-like characteristics in cancer cells (Fodde and Brabletz 2007). Dissociation of beta catenin from the adherens junction and accumulation in the cytoplasm and nucleus is associated with increased disease severity and metastasis in colorectal adenocarcinomas (Herter et al. 1999). Beta catenin is also known to accumulate in the cytoplasm of cultured cells with reduced expression at the cell membrane during cell migration assays (Polette et al. 2007). Once in the nucleus, beta catenin binds to transcriptional activators LEF1 and TCF to activate expression of

genes for growth factors, cell proliferation markers, and components of the Wnt signaling pathway, creating a feed-forward loop that encourages dedifferentiation and proliferation (Klaus and Birchmeier 2008). The disruption of adherens junctions by a variety of factors may dislodge beta catenin from its membrane-bound complex, enabling it to change the functions and expression levels of proteins within the cell.

\section{PP2A}

\section{Structure and Function}

PP2A is a ubiquitous protein serine/threonine phosphatase, acting on a variety of proteins in cell signaling pathways throughout the cell. In some cells, it comprises up to $1 \%$ of the total protein (Shi 2009). It negatively regulates the G2/M transition in mitosis by inhibiting cyclin-dependent-kinase-activating kinase (Janssens and Goris 2001). Inactivation of some of its regulatory subunits, or interaction with viral oncoproteins to replace regulatory subunits, may result in cellular transformation by activating signaling pathways involving, c-Myc, Wnt, and phosphoinositide-3-kinase (Sablina et al. 2010). It also interacts with several proteins in the tight and adherens junctions to regulate cell-cell adhesion and epithelial barrier properties (Seth et al. 2007; Nita-Lazar et al. 2010).

The activity and substrate specificity of PP2A are determined by it structure and post-translational modifications to that structure. PP2A has three subunits: the A or scaffolding subunit, the $\mathrm{B}$ or regulatory subunit, and the $\mathrm{C}$ or catalytic subunit (Arroyo and Hahn 2005; US Cho and $\mathrm{Xu}$ 2007). The A and $\mathrm{C}$ subunits each have two isoforms, 


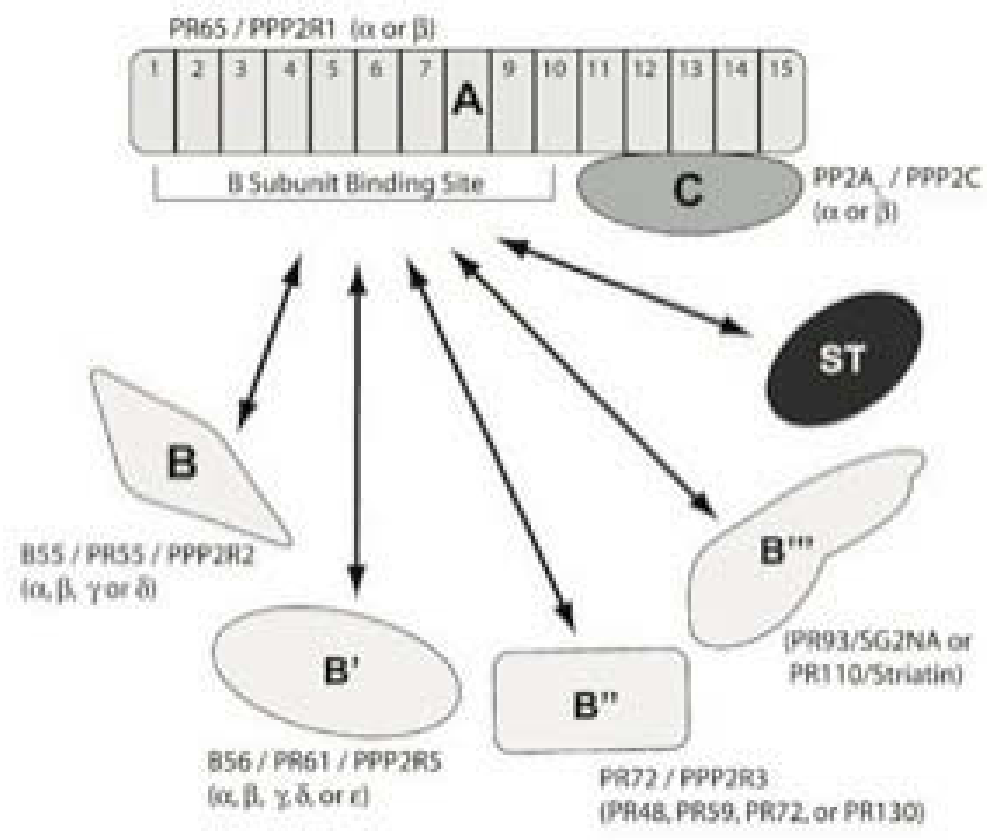

Figure 1-9. PP2A Subunits

The three subunits of PP2A are shown with their isoforms as named under different naming systems. The A subunit is a scaffolding subunit to which the others bind. The $\mathrm{C}$ is the catalytic subunit. Different B (B, B', B", B"') subunits determine localization and substrate specificity. The ST is a viral protein that can replace the B subunit to change the activity of PP2A.

Source: Reprinted with permission. Arroyo JD, and WC Hahn. 2005. "Involvement of PP2A in Viral and Cellular Transformation." Oncogene 24 (52): 7746-7755. Copyright 2005 Macmillan Publishers. 
and an $\mathrm{AC}$ dimer forms soon after protein translation (Janssens, Longin, and Goris 2008). The B subunit has several isoforms including B55 $(\alpha, \beta, \gamma, \delta), \mathrm{B} 56(\alpha, \beta, \gamma 1, \gamma 2, \gamma 3, \delta)$, and PR72 (Janssens and Goris 2001), each of which confers different substrate specificity on the catalytic subunit (Figure 1-9). Post-translational modification of the conserved TPDYFL tail of the catalytic subunit by methylation via leucine carboxymethyltransferase 1 enhances binding of some B subunits, but not others(Stanevich et al. 2011). Phosphorylation of Tyrosine 307 inactivates the enzyme (Janssens and Goris 2001).

\section{Inhibition Strategies}

Cells regulate the amount and activity of PP2A so tightly that some techniques normally used to explore protein function are difficult to achieve. Overexpression of the catalytic subunit of PP2A is tightly regulated at the translational level (Janssens and Goris 2001). Over-expressing the A subunit causes rat fibroblasts to become multinucleated and disrupts the cell cycle (Wera et al. 1995). Knockdown of the A (scaffolding) subunit or the catalytic subunit results in cell death in a variety of mammalian cell types (Strack, Cribbs, and Gomez 2004). Knockout of the C- $\alpha$ subunit is embryonic lethal in mice even when the C- $\beta$ subtype is still present and active (Götz et al. 1998). The inability to knock down or overexpress subunits of PP2A without serious impact on cell viability limits effective use of RNAi techniques normally used to examine protein function.

To solve the problem of tight cellular regulation in exploring PP2A function, pharmacological inhibitors and a recently-discovered peptide inhibitor were used. Natural inhibitors exist, mostly from marine dinoflagellates, cyanobacteria, marine sponges, and Streptomyces (Swingle, Ni, and Honkanen 2007). These compounds act by inhibiting catalytic activity, enabling studies otherwise made difficult by tight cellular regulation of PP2A expression.

Fostriecin is an antitumor phosphorus-containing compound isolated from medium exposed to Streptomyces pulveraceus sp. fostreus (Stampwala et al., 1983). Though its structure is similar to okadaic acid (another PP2A inhibitor), it is different in several important respects, which make it a more specific inhibitor of the serine-threonine kinase PP2A. The phosphate group on fostriecin binds the manganese ions in the active site of PP2A directly. Fostriecin binds covalently to the cysteine-269 residue of PP2A (Takeuchi et al. 2009). A nearby methyl group mimics the methyl group of the substrate phosphothreonine. An unsaturated lactone may help to alkylate a cysteine on the active site loop of PP2A (Buck, et al., 2003). These specific interactions enable fostriecin to be a potent, specific inhibitor of PP2A (Swingle et al. 2009) (Figure 1-10).

Cell viability (as evaluated by growth inhibition using a cell count reagent) in L1210 cells is unaffected with treatment of up to $10 \mu \mathrm{M}$ biotinylated Fst for 72 hours. This was a much greater concentration than that usually required (IC50 of $0.21 \mathrm{ug} / \mathrm{ml}$ ) (Leopold et al. 1984) for PP2A inhibition, so short-term viability of cells treated with 


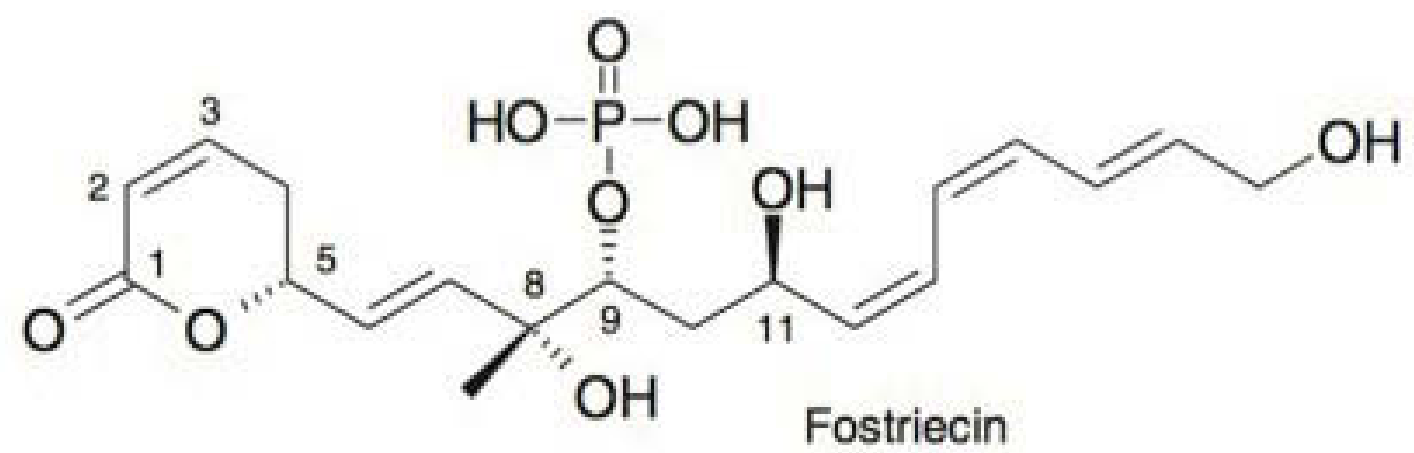

Figure 1-10. Structure of Fostriecin

Fostriecin is a PP2A inhibitor.

Source: Reprinted with permission. Swingle S, L Amable, BG Lawhorn, SB Buck, CP Burke, P Ratti, KL Fischer, DL Boger, and RE Honkanen. 2009. "Structure-Activity Relationship Studies of Fostriecin, Cytostatin and Key Analogues, with PP1, PP2A, PP5, and (\{beta $\} 12-\{$ beta $\} 13)$-chimeras (PP1/PP2A and PP5/PP2A) Provide Further Insight Into Inhibitory Actions of Fostriecin Family Inhibitors." The Journal of Pharmacology and Experimental Therapeutics 331 (1) (July 10): 45-53. 
fostriecin is not an issue.

\section{Significance and Hypotheses}

Acetaldehyde accumulates in the colonic lumen at high concentrations due to the activity of alcohol dehydrogenase (ADH) expressed by luminal microflora. Chronic ethanol consumption, with resulting production of acetaldehyde, elevates the risk for colon cancer. A mounting body of evidence indicates that acetaldehyde disrupts adherens junctions and tight junctions of the intestinal epithelium, which involves Thrdephosphorylation of occludin, a major tight junction protein. My studies show that acetaldehyde disrupts adherens junctions and tight junctions leading to barrier dysfunction by a mechanism that involves the activity of PP2A. Additionally, my data indicate that acetaldehyde inhibits migration of Caco-2 cells on cluster plates. It also has a negative effect on differentiation of Caco- 2 cells into polarized epithelial cells when grown in a 3-dimensional model on Matrigel. All these studies strongly support the hypothesis that acetaldehyde destabilizes tight junctions and adherens junctions in the intestinal epithelium by a PP2A-dependent mechanism.

The long-range goal of this project is to elucidate the mechanisms involved in ethanol-induced increase in risk for colon cancer, and if such information can be utilized to design therapeutics to prevent cancer promotion and tumor metastasis. As an initial step toward this goal I investigated the role of PP2A in acetaldehyde-mediated disruption of tight junctions and adherens junctions and evaluated the effect of acetaldehyde on the morphology of cells during three-dimensional culture in Matrigel. .

Specific Aim 1: To determine the role of PP2A and Thr-dephosphorylation of occludin in acetaldehyde-induced disruption of tight junctions and adherens junctions. Sub-aims include the following:

A) Acetaldehyde disrupts tight junctions and adherens junctions by a PP2Adependent mechanism.

B) Acetaldehyde induces PP2A translocation by a tyrosine kinase-dependent mechanism.

C) PP2A-mediated Thr-dephosphorylation of occludin is involved in acetaldehydeinduced disruption of tight junctions and adherens junctions.

Specific Aim 2: To determine that acetaldehyde alters migration and differentiation by a PP2A-dependent mechanism. To reach this goal we will determine that:

A) Acetaldehyde promotes cell migration by a mechanism that involves PP2A and Thr-dephosphorylation of occludin.

B) Acetaldehyde alters morphology of cells grown in Matrigel in a dose-dependent manner. 


\title{
CHAPTER 2. METHODS AND MATERIALS
}

\author{
Cell Culture and Transfection
}

\section{Cell Types Used}

Caco-2 cells were purchased from the American Type Culture Collection (Manassas, VA). Caco-2 cells were first isolated from a lung metastasis of a colon adenocarcinoma in a 72-year-old man (Fogh 1975). After the cells were grown and passaged in nude mice, the cells appeared to differentiate in vitro. They expressed brush border enzymes and microvilli at the apical surface of the cell when fully differentiated, at about day 20, in a similar manner to intestinal epithelia in vivo (Hidalgo, Raub, and Borchardt 1989). These cells are used as a model system for the intestinal epithelium in pharmaceutical as well as academic research applications (Hidalgo, Raub, and Borchardt 1989; Yamashita et al. 2000; Yamashita et al. 2002) . Cell growth and differentiation may be carefully manipulated to mimic different stages of in vivo development of epithelia via changes in medium and pH (Yamashita et al. 2000; Ranaldi et al. 2003; Moyes, Morris, and Carr 2010). Because of the similarities between Caco-2 cell monolayers grown on permeable polycarbonate membranes and intestinal epithelial cells in vivo, these monolayers have become a prominent model for studying intestinal permeability and cell signaling in the simplified in vitro environment.

Caco-2 cells were grown under standard culture conditions until seeding on transwells for experiments. In summary, cells were grown in DMEM supplemented with $10 \%$ fetal bovine serum. Additional supplementation with $100 \mathrm{IU} / \mathrm{ml}$ penicillin, 100 $\mu \mathrm{g} / \mathrm{ml}$ streptomycin, and $50 \mathrm{mg} / \mathrm{ml}$ gentamicin was also necessary at first due to laboratory and building conditions outside our control. After a period of persistent repeated contamination incidents, $1 \mathrm{mg} / 10 \mathrm{ml}$ Primocin, a proprietary non-cytotoxic broad spectrum antimicrobial, antibiotic, and antimycoplasma solution became necessary for work to continue. Experimental results showed that there was no loss of protein expression or change in immunofluorescence staining due to this intervention.

\section{Cells Grown in Transwells}

Cells from passages 9-40 were used. Previous data indicated that cells in this passage range express stable brush border enzymes, have predictable growth and differentiation patterns, and produce reliable trans-epithelial resistance (Briske-Anderson, Finley, and Newman 1997). Cells were grown on polycarbonate membranes for 7-11 days (6.5 mm Transwells), 11-14 days (12 mm Transwells) or 17-19 days (24 mm Transwells) prior to incubation and experiments. These cells have been shown to differentiate on permeable membranes within 2-3 weeks post-seeding, so these times of growth post-seeding are well aligned with those in common use (Yamashita et al. 2000; Yamashita et al. 2002; Behrens and Kissel 2003). 


\section{Investigating the Role of PP2A}

\section{Inhibition of PP2A Activity with Fostriecin}

Fostriecin is a potent antitumor antibiotic first isolated from a Streptomyces pulveraceus culture in in 1983 (Tunac, Graham, and Dobson 1983; Stampwala et al. 1983). It was thought to act against murine leukemias by inhibiting DNA topoisomerase II, but was later found to inhibit DNA, RNA, and protein production by inhibiting protein phosphatase 2A (Walsh, Cheng, and Honkanen 1997). It inhibits PP2A by binding covalently to the Cys-269 residue of the catalytic subunit (Takeuchi et al. 2009).

Fostriecin is advantageous for use because it is more selective for PP2A compared to PP1 than other similar compounds (Swingle, Ni, and Honkanen 2007). For example, okadaic acid, the most commonly used PP2A inhibitor, inhibits PP2A at an $\mathrm{IC}_{50}$ of 0.1 to 0.3 nanomolar. Okadaic acid inhibits $\mathrm{PP} 1$ at an $\mathrm{IC}_{50}$ of $15-50 \mathrm{nM}$. In contrast, fostriecin inhibits PP2A at 1.5 to $5.5 \mathrm{nM}$, but PP1 at $45000-58000 \mathrm{nM}$. Fostriecin is more selective than other available PP2A inhibitors, allowing a wider dose range for optimization and reduced risk of inhibiting undesired phosphatases (Table 2-1).

Fostriecin is also able to enter cells grown under typical cell culture conditions more readily than okadaic acid. Okadaic acid is hydrophobic, enabling it to penetrate the cell membrane with ease. However, that very hydrophobicity can cause it to pool on top of the cell culture media, isolated from the cells below. Fostriecin, a water soluble compound incorporated into cells through the reduced folate transporter, can be delivered to living cells in culture with more confidence of the actual dose accessible by the cells than okadaic acid and other hydrophobic inhibitors (Swingle, Ni, and Honkanen 2007).

Cells were incubated with $50 \mathrm{nM}$ fostriecin in Dulbecco's Modified Eagle's Medium (DMEM) in apical and basal wells for 16.5 hours before each experiment. Cells were washed with DMEM, and fostriecin was reapplied at the beginning of each experiment to maintain PP2A inhibition.

Table 2-1. $\mathrm{IC}_{50}$ for Fostriecin and Okadaic Acid

\begin{tabular}{llllll}
\hline Compound & PP1 & PP2A & PP4 & PP5 & PP7 \\
\hline okadaic acid & $15-50$ & $0.1-0.3$ & 0.1 & 3.5 & $>1000$ \\
fostriecin & $45,000-$ & $1.5-5.5$ & 3.0 & $50,000-$ & not \\
& 58,000 & & & 70,000 & determined \\
\hline
\end{tabular}

Source: Data used with permission. Swingle MS, L Ni, and RE Honkanen. 2007. "Smallmolecule Inhibitors of Ser/thr Protein Phosphatases: Specificity, Use and Common Forms of Abuse." Methods in Molecular Biology (Clifton, N.J.) 365: 23-38. . 


\section{Knockdown of PP2A-Ca by SiRNA Transfection}

Small interfering RNAs (siRNAs) are used to knock down expression of a target gene for 3-5 days (Fewell and Schmitt 2006). These contain 19-22 base pairs to avoid the cellular interferon response to long dsRNA viral sequences and subsequent global downregulation of protein translation, which may lead to apoptosis (Paddison et al. 2002). These constructs knock down gene expression by mimicking an intermediate in an endogenous gene expression regulatory pathway (Krol, Loedige, and Filipowicz 2010).

In the natural system, about 800 different small dsRNAs have been discovered in humans (more in plants), which fine-tune the expression of a variety of proteins by binding to mRNA using the miRNA induced silencing complex (miRISC). This binding removes the poly-adenylyl cap of the mRNA and prepares it for degradation (Krol, Loedige, and Filipowicz 2010). SiRNA mimics the last intermediate of this process, which binds the miRISC complex to downregulate mRNA translation of the protein of interest.

Caco-2 cells (approximately 125,000 cells/well) were seeded in six-well cluster plates. After 24 hours of growth, cells were incubated in serum-free, antibiotic-free DMEM for an hour. Cells were transfected using $100 \mu \mathrm{L}$ Optimem, $12 \mu 1$ Plus reagent, and $7 \mu$ oligofectamine with $150 \mu \mathrm{DMEM}$ and incubated for 6-8 hours. Medium containing $10 \%$ serum was added, and cells were incubated at $37^{\circ} \mathrm{C}$ until the next day. Cell monolayers were trypsinized and seeded onto Transwell inserts. TER was monitored daily, and experiments were conducted on days 3 or 4, when TER stabilized at levels indicating a confluent monolayer.

\section{Peptide Inhibition of PP2A}

TPDYFL is a universally conserved epitope at the C-terminal tail of the catalytic subunit of PP2A (Xing et al. 2008). Methylation of the C-terminal leucine and phosphorylation of tyrosine 306/307 help to determine regulatory B-subunit binding, and thus activity, substrate specificity, and localization of PP2A (Bryant, Westphal, and Wadzinski 1999; Deshmukh, Blunt, and Hofmann 2007; Longin et al. 2007). TPDYFL peptide seems to interfere with binding of the B subunit with the AC dimer, thus inhibiting activity and changing subcellular localization of PP2A (Deshmukh, Blunt, and Hofmann 2007).

A delivery system for the inhibitory peptide had to be optimized for the Caco-2 cell line. The $\beta$-escin based transfection system used for cardiac myocytes (Deshmukh, Blunt, and Hofmann 2007) caused Caco-2 cells to detach from the underlying substrate, rendering them unusable for experiments. Instead we used the Chariot transfection reagent system (Figure 2-1), a non-cytotoxic peptide-based system which allows peptides or proteins to be transfected into cells without harsh reagents or electroporation (Morris et al. 2001; Gros et al. 2006). The peptide of choice is incubated with the Chariot 


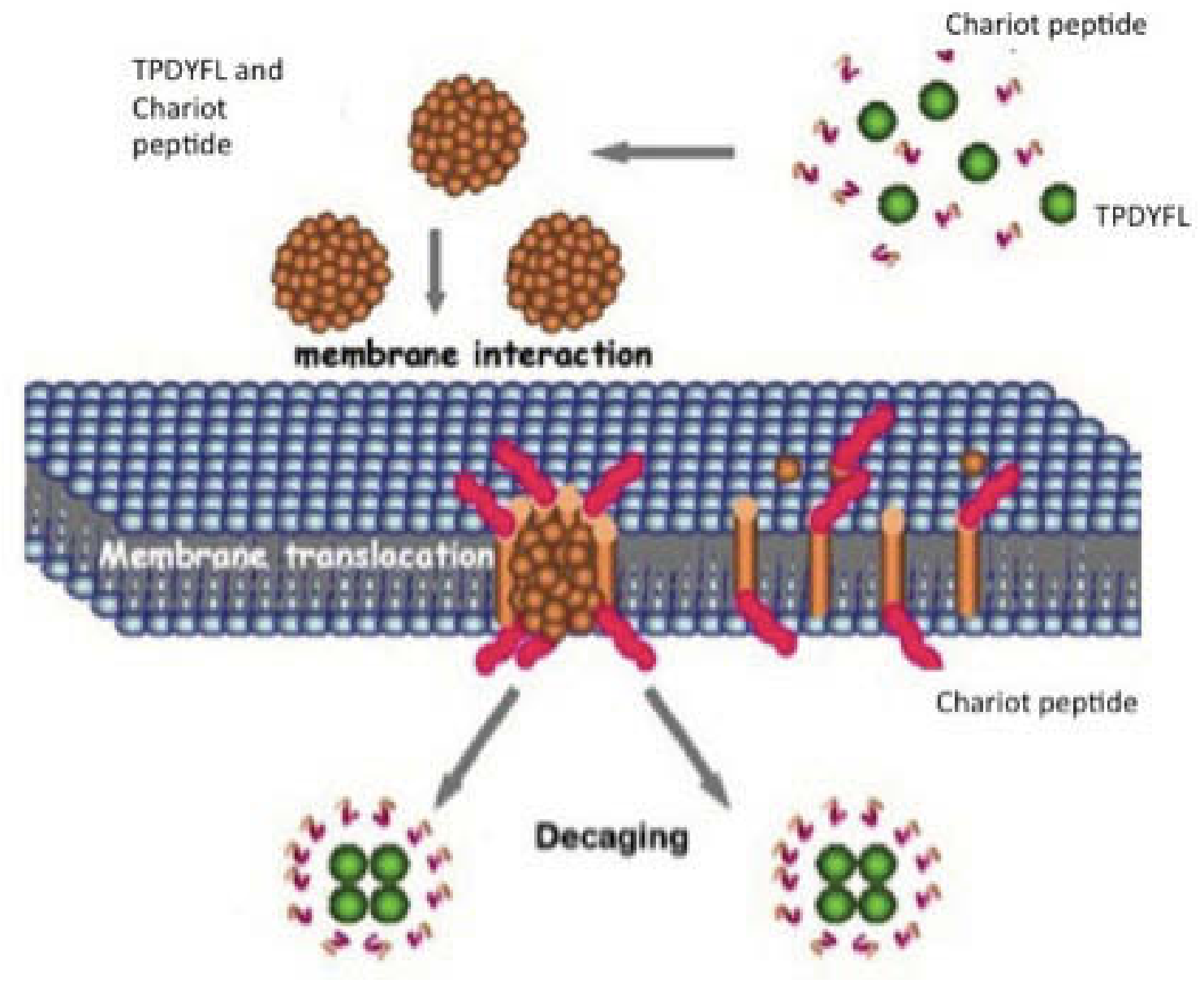

Figure 2-1. TPDYFL Transfection and Chariot Peptide

The chariot peptide reversibly binds the peptide to be transfected into the cell, allowing it to pass through the cell membrane and to release for use on the other side.

Source: Reprinted with permission. Gros E, S Deshayes, MC Morris, G Aldrian-Herrada, J Depollier, F Heitz, and G Divita. 2006. "A Non-covalent Peptide-based Strategy for Protein and Peptide Nucleic Acid Transduction." Biochimica Et Biophysica Acta 1758 (3) (March): 384-393. Copyright 2006 Elsevier. 
reagent for 30 minutes, forming a complex at concentrations dependent on the size of the well in which the cells are contained. A simple titration is used to determine the optimal amount of peptide and Chariot. An early trial involving Chariot and FITC-inulin indicated nearly universal, low-level transfection, though transfecting fully confluent monolayers is not recommended (Gros et al. 2006). The Chariot reagent itself had no effect on barrier function or cell viability. TPDYFL inhibitory peptide and scrambled peptide were added at a concentration of $600 \mathrm{ng} /$ transfection using the Chariot transfection reagent system in fully confluent monolayers on transwells two hours before experiments were conducted.

\section{Acetaldehyde Treatment}

Acetaldehyde was administered to cells as previously described (Rao 1998), in a technique based on previous research in bovine bronchial epithelia (Sisson and Tuma 1994). In summary, cells were pre-incubated in PBS containing $1.2 \mathrm{mM} \mathrm{CaCl}_{2}$ and $1 \mathrm{mM}$ $\mathrm{MgCl}_{2}$, bovine serum albumin, and glucose for one hour. In cases such as peptide transfection, in which the albumin might affect results by binding the peptide, DMEM without antibiotics was used for pre-incubation. Transwells were placed in the center wells of a cluster plate. Acetaldehyde solution was placed in the outer wells. and the plate was quickly sealed. Control plates were sealed as well, and showed no signs of changes in TER or flux due to oxygen depletion. The cells were exposed to vapor-phase acetaldehyde at 200-600 $\mu \mathrm{M}$ concentration as described previously (Rao 1998) for time periods ranging from 15 minutes to 5 hours, depending on the experiment.

\section{Measurement of Barrier Function}

\section{Measurement of TER}

Trans-epithelial electrical resistance (TER) was measured using a Millicell-ERS Electrical Resistance System (Millipore, Bedford, MA). TER was demonstrated to correlate to the permeability and morphology of the zonula occludens, now known as the tight junctional protein complex, in the 1970s (Claude 1978). Total TER represents both the transcellular and the paracellular resistance to the passage of small ions. Under normal conditions in a confluent monlayer, TER depends on the packing of the cells, space available between them, total surface area of the monolayer, and the probability that pores (now known to be composed of claudin molecules) are open or closed (Claude 1978). "Normal" values determined from previous experience in the laboratory with control cells from specific cell lines were used as a rough measure of monolayer integrity before experiments began, and were used to monitor progress as well as determine the effects of acetaldehyde. Calculations were completed using the following equation:

Resistance $_{\text {measured }}=\left(\Delta \mathrm{V}_{\mathrm{t}} / \Delta \mathrm{I}_{\mathrm{t}}\right) / \mathrm{A}-$ Resistance $_{\text {membrane and medium }}$ 
(Wills, Reuss, and Lewis 1996). In practice, the resistance of an empty well with medium was subtracted from the resistance of experimental wells with confluent monolayers. Percent change over the course of an experiment was used to determine efficacy of treatment.

Trans-epithelial resistance is not always a reliable measure of paracellular permeability. Because TER measures both transcellular and paracellular permeability, cellular adaptations can mask the effects of stress on tight junctions. In addition, high TER values may or may not correlate to other measures of paracellular permeability in Caco-2 cells (Briske-Anderson, Finley, and Newman 1997). When occludin is overexpressed, TER increases while paracellular flux of small particles also increases, perhaps through the influence of pore-forming claudins (Balda et al. 1996). Therefore, other measures of paracellular permeability are necessary. .

\section{Unidirectional FITC-inulin Flux}

Flux of molecules including mannitol, polyethylene glycol, and FITC-inulin from one side of a layer of cells to the other has been used to measure the integrity of epithelial monolayers and evaluate their suitability for modeling transport of pharmaceuticals for decades (Munck and Rasmussen 1977; Ghandehari et al. 1997). FITC-inulin has a molecular weight of 3000-6000, and is not actively transported into or across cells. Thus it is used as an indicator of tight junction integrity, as less than $0.5 \%$ of the inulin will move across a healthy, differentiated, confluent monolayer (Ghandehari et al. 1997). When the monolayer is compromised, gaps open between the cells through which large molecules can pass, creating a leaky barrier (Rao 1998).

Mature cell monolayers on Transwells were incubated in different experiments with $0.5 \mathrm{mg} / \mathrm{ml} \mathrm{FITC-inulin} \mathrm{in} \mathrm{the} \mathrm{basal} \mathrm{well.} \mathrm{At} \mathrm{the} \mathrm{end} \mathrm{of} \mathrm{incubation} \mathrm{with} \mathrm{or} \mathrm{without}$ acetaldehyde and/or inhibitors, $100 \mu \mathrm{l}$ each of medium from the apical and basal wells were sampled, and fluorescence was measured using a Flx-800 microplate fluorescence reader (BioTEK instruments, Winooski, VT). Flux into the apical well was calculated as the percentage of total basal well fluorescence $/ \mathrm{cm}^{2}$ surface area.

\section{Immunofluorescence Confocal Microscopy}

After incubation and exposure to acetaldehyde, cell monolayers were fixed in 4\% paraformaldehyde in TBST (20 mM Tris, $\mathrm{pH} 7.2$, and $150 \mathrm{mM} \mathrm{NaCl}$ ) for 15 minutes at room temperature or in acetone methanol (1:1) on ice for 5 minutes. Monolayers were permeabilized with $0.2 \%$ Triton-X 100 for 5 minutes. They were blocked in $4 \%$ milk in TBST( $20 \mathrm{mM}$ Tris. $\mathrm{pH} 7.2,150 \mathrm{mM} \mathrm{NaCl}$ ) for one hour. They were incubated with primary antibodies for one hour and thirty minutes. They were washed and incubated with secondary antibodies for one hour. Fluorescence was visualized using a Zeiss LSM 5 laser scanning confocal microscope, and images from $1 \mu \mathrm{m}$-thick $\mathrm{x}-\mathrm{y}$ sections were collected. Images were stacked using Image J software [NIH (National Institutes of 
Health), Bethesda, MD], and processed using Adobe Photoshop (Adobe Systems, San Jose, CA).

\section{Cell Viability Assay: Lactate Dehydrogenase Release}

The Promega 96-well cytotoxicity assay was adapted to larger wells and used to determine the degree of cell lysis in control and experimental cell monolayers. When cell viability is compromised, cells release lactate dehydrogenase, which converts a tetrazolium salt to a red formazan product. Changes in color are measured using a 96well plate reader at $\mathrm{OD}_{450}$. Color change is proportional to cell lysis, making the lactate dehydrogenase assay a good measure of effects of cell treatments on cell viability (Legrand et al. 1992).

\section{Biochemical Analyses}

\section{Preparation of Cytoskeletal Fractions}

Cell monolayers were washed twice with PBS, then incubated with lysis buffer CS (Tris buffer containing 1.0\% Triton-X100, $2 \mu \mathrm{g} / \mathrm{ml}$ leupeptin, $10 \mu \mathrm{g} / \mathrm{ml}$ aprotinin, 10 $\mu \mathrm{g} / \mathrm{ml}$ bestatin, $10 \mu \mathrm{g} / \mathrm{ml}$ pepstatin-A, $1 \mathrm{mM}$ vanadate and $1 \mathrm{mM}$ PMSF) for 15 minutes on ice. If fractions were to be used to measure PP2A activity, vanadate was not included in the lysis buffer. Extracts were centrifuged at $15,600 \mathrm{x}$ g for 4 minutes at $4{ }^{\circ} \mathrm{C}$ to sediment the high-density actin cytoskeleton and associated proteins. The pellet was resuspended in lysis buffer CS. Cytoskeletal fractions were mixed with Laemmli's sample buffer and heated at $100{ }^{\circ} \mathrm{C}$ for 5 minutes.

\section{Immunoprecipitation}

After acetaldehyde treatment, the cells were washed with cold $20 \mathrm{mM}$ Tris- $\mathrm{HCl}$, $\mathrm{pH} 7.4$, and proteins were extracted using lysis buffer $\mathrm{N}$ ( $20 \mathrm{mM}$ Tris, $\mathrm{pH} 7.4$, containing $150 \mathrm{mM} \mathrm{NaCl}, 10 \mu \mathrm{g} / \mathrm{ml}$ leupeptin, $10 \mu \mathrm{g} / \mathrm{ml}$ pepstatin A, $10 \mu \mathrm{g} / \mathrm{ml}$ aprotinin, $10 \mu \mathrm{g} / \mathrm{ml}$ bestatin, and $0.1 \mathrm{mM}$ PMSF). Cell monolayers were extracted in $750 \mu l$ lysis buffer $\mathrm{N}$, then two monolayers per experimental condition were pooled for immunoprecipitation. $400 \mu \mathrm{g}$ protein per condition was incubated with antibodies overnight. The next day, protein complexes were precipitated with protein A/G sepharose beads. For activity assays, beads were kept on ice until the assay (a few hours at most). For immunoblot analysis, beads were heated at $100^{\circ} \mathrm{C}$ for 10 minutes with Laemmli's sample buffer to release complexes. The sample buffer was frozen at $-20^{\circ} \mathrm{C}$ until analysis could be done. 


\section{Analysis of Phosphothreonine}

Cells were lysed in lysis buffer $\mathrm{D}(0.3 \% \mathrm{SDS} w / \mathrm{v}, 10 \mathrm{mM}$ Tris-HCl, $\mathrm{pH} 7.4$, containing $10 \mu \mathrm{g} / \mathrm{ml}$ leupeptin, $10 \mu \mathrm{g} / \mathrm{ml}$ pepstatin A, $10 \mu \mathrm{g} / \mathrm{ml}$ aprotinin, $10 \mu \mathrm{g} / \mathrm{ml}$ bestatin, and $0.1 \mathrm{mM} \mathrm{PMSF}$ ) at $100{ }^{\circ} \mathrm{C}$. After repeated pipetting to homogenize samples, samples were heated at $100{ }^{\circ} \mathrm{C}$ for 10 minutes. $400 \mu \mathrm{g}$ protein per sample was incubated with anti-phosphothreonine antibodies overnight, Protein complexes were immunoprecipitated with protein A sepharose beads and samples processed as described above.

\section{PP2A Activity Assay}

PP2A was assayed by a method adapted from (Fathi et al. 2002). Detergentinsoluble fractions or immunocomplexes were resuspended in PPase buffer $(50 \mathrm{mM}$ HEPES, pH7.2, $60 \mathrm{mM} \mathrm{NaCl}, 60 \mathrm{mM} \mathrm{KCl}$, and protease inhibitors) to a volume of $20 \mu \mathrm{l}$. These samples were incubated at $30^{\circ} \mathrm{C}$ for 10 minutes with $5 \mu \mathrm{l}(1 \mu \mathrm{g} / \mu \mathrm{l})$ of KRpTIRR phosphopeptide substrate. Free phosphate was assayed by adding $100 \mu \mathrm{l}$ malachite green reagent to each sample in a 96-well microtiter plate and incubating at room temperature for 15 minutes . Absorbance was measured at $620 \mathrm{~nm}$ wavelength in a microplate reader (SpectraMax 190, Molecular Devices, Sunnydale, CA). Assay was performed in the presence or absence of $300 \mathrm{nM}$ fostriecin and $100 \mathrm{nM}$ okadaic acid. Units of PP2A activity represent pmol free phosphate generated under assay conditions.

\section{Immunoblot Analysis}

Proteins were separated by SDS-polyacrylamide gel (4-12\% gradient) electrophoresis and transferred to nitrocellulose PVDF membranes. Membranes were blotted for different proteins using specific antibodies in combination with HRPconjugated anti-mouse IgG or HRP-conjugated anti-rabbit IgG antibodies. The blots were developed using ECL chemiluminescence method (Amersham, Arlington Heights, IL). The bands were quantitated by densitometric analysis using Image J software (NIH).

\section{Animal Studies}

\section{Animals}

These studies were conducted using an IACUC approved protocol. Adult male mice (C57BL/6; 12 weeks old) were used for these studies. C57BL/6 mice are the preferred strain for alcohol studies, as they consume alcohol willingly when not deprived of food or water, and they have an active complement of alcohol-processing enzymes (Middaugh et al. 1999; Westerlund et al. 2005). 


\section{Acetaldehyde Treatment of Mouse Ileum}

Segments of ileum were flushed and slit open longitudinally to prepare intestinal sheets. These tissues were incubated in DMEM at $37^{\circ} \mathrm{C}$ with or without $50 \mathrm{nM}$ fostriecin for 15 minutes, followed by incubation with acetaldehyde $(400 \mu \mathrm{M})$ for one hour as described previously for transwell-grown cells. Tissues were cryofixed in OCT.

\section{Preparation of Detergent-insoluble Fractions from Mouse Ileum}

Mouse ileal mucosal scrapings were incubated for 15 min with lysis buffer CS. Cell lysates were centrifuged at low speed $(15,600 \mathrm{xg})$ for $4 \mathrm{~min}$ at $4 \mathrm{C}$ to sediment the high-density actin cytoskeleton (detergent-insoluble fraction). Supernatant was used as detergent-soluble fraction. The pellet was suspended in $200 \mu \mathrm{l}$ of lysis buffer-CS and sonicated to homogenize the actin cytoskeleton. Protein contents in different fractions were measured by the BCA method (Pierce Biotechnology Inc, Rockford, IL). Tritoninsoluble and triton-soluble fractions were mixed with equal volume of Laemmli's sample buffer $\left(2 \mathrm{x}\right.$ concentrated) and heated at $100^{\circ} \mathrm{C}$ for $5 \mathrm{~min}$.

\section{Immunofluorescence Staining of Cryosections}

$10 \mu \mathrm{m}$ cryosections were stained for occludin and ZO-1 by immunofluorescence staining method as described above for transwell-grown cells.

\section{Statistical Analyses}

Comparison between two groups was made by Student's $t$-tests for grouped data. Significance in all tests was set at $95 \%$ or greater confidence level. Sets with multiple comparisons were checked by ANOVA as applicable using AnalystSoft Inc., StatPlus:mac LE, version 2009. See www.analystsoft.com.

\section{Three-dimensional Cell Culture}

\section{Matrigel Cell Culture}

Cells were cultured in Matrigel according to a protocol assembled from several sources (Zhang et al. 2003; Debnath, Muthuswamy, and Brugge 2003; Xiang and Muthuswamy 2006). Caco-2 cells were cultured under normal cell culture conditions to confluency. Cells were trypsinized and pipetted gently to eliminate clumps. Matrigel was thawed overnight on ice in a $4{ }^{\circ} \mathrm{C}$ refrigerator before use. It was preserved in aliquots at $20{ }^{\circ} \mathrm{C}$ to minimize freeze-thaw cycles. Each aliquot was thawed on ice before use and preserved on ice during use. Matrigel solidifies in minutes at room temperature. 
Plates were pre-coated with cold $100 \%$ matrigel before cells were deposited. Plates were allowed to solidify in the incubator for 20 minutes before seeding. Avolume of cell suspension in complete medium containing 2500-20,000 cells with $100 \mathrm{uL}$ of Matrigel, ice cold (for a $0.7 \mathrm{~cm}^{2}$ surface), was gently dripped onto the plate, aiming for even coverage. Plates were placed in a $37{ }^{\circ} \mathrm{C}$ incubator immediately for gel to solidify. When gel was solid (time varied by lot, about 20 minutes to one hour), cells were overlaid with $0.2 \mathrm{ml}$ DMEM with $10 \%$ FBS and primocin. New medium was added every other day by manual aspiration of old medium, taking care not to aspirate the gel, and gentle deposition of new medium.

\section{Treatment of Matrigel Cultures with Acetaldehyde}

Acetaldehyde treatment by vapor deposition every other day was modified from Rao, 2008. In summary, cells were seeded in the central wells of a transwell or cluster plate. At day 3 (to observe effects on differentiation) or day 7 (to observe effects on growth), cells were treated with concentrations of acetaldehyde ranging from $0.003 \%$ to $0.2 \%$, pipetted as a solution in PBS-BSA-glucose in the outer wells of the plate $(24 \mathrm{ml}$ per plate). The plate was sealed and set in a dedicated $37^{\circ} \mathrm{C}$ incubator with $5 \% \mathrm{CO}_{2}$ for one hour. Then cells and plate were rinsed with PBS. Cells were fed new complete medium and allowed to continue to grow. Cells were treated and photographed by phase contrast microscopy every other day.

\section{Fixation of Matrigel Cultures}

Cells are stained in situ in the gel, so the process takes a longer time than in monolayers grown on membranes, because the antibodies must diffuse through the extracellular matrix. Nonspecific staining may also be a problem, if washing is not done properly or staining is rushed. The protocols for 3D culture and processing were adapted and optimized from previously published protocols in kidney and breast epithelial cell models (Pollack, Runyan, and Mostov 1998; K Shaw, Wrobel, and Brugge 2004). During all aspiration, manual techniques were used to avoid aspirating the gel.

Cultures were rinsed with PBS, $\mathrm{pH} 7.4$, containing $1 \mathrm{mM} \mathrm{CaCl}_{2}$ and $0.5 \mathrm{mM}$ $\mathrm{MgCl}_{2}\left(\mathrm{PBS}^{+}\right)$after experiments. Cells were fixed with $4 \%$ paraformaldehyde in $\mathrm{PBS}^{+}$for 30 minutes. Cells were washed with PBS twice, then stored in PBS plus sodium azide, $0,05 \%$ until staining.

\section{Immunofluorescence for Matrigel Cultures}

Sections of membrane with gel and cells attached were carefully excised from wells of a transwell plate and placed in a 24-well cluster plate. Cells were permeabilized with $0.02 \%$ Tween- 20 in PBS IF for 30 minutes. Cells were blocked with $4 \%$ milk in TBST for 2 hours. Then primary antibody was added at normal concentration for 
immunofluorescence in $4 \%$ milk in TBST. Plates were sealed with tape and placed in cold room or $4^{\circ} \mathrm{C}$ refrigerator overnight.

On the next day, cells were washed three times (10 minutes for each wash) with $1 \%$ milk. Secondary antibodies at manufacturer-recommended concentrations were added and TO-PRO-3 in 4\% milk. Resulting solutions were incubated 2 hours. Cells were washed (10 min each) with IF-PBS.

Gels were mounted on pre-labeled Superfrost microscope slides. The gel was gently removed from the membrane and placed in a drop of mounting fluid on the slide, then a few more microliters of mounting solution were placed on top, then the coverslip. Slides were sealed with fingernail polish, allowed to air dry, and stored at $4^{\circ} \mathrm{C}$ in the dark. Due to challenges in sealing the slides with thick and/or uneven gels, slides were evaluated as soon as possible after preparation.

\section{Cell Migration Assays}

\section{Background}

When the intestinal epithelial barrier is breached by injury, a rapid process called intestinal restitution ensures that exposure of the sterile internal environment to intestinal contents is minimized. Then long-term healing processes can take place safely. Intestinal restitution is of interest because of its function in wound healing after acute trauma and its action in pathologies such as necrotizing enterocolitis, inflammatory bowel disease, and Crohn's disease. In vitro and in vivo studies have found that a sequence of steps occurs, including secretion of cytokines and growth factors, cell migration, and cell differentiation. The restoration of barrier function is followed by a longer, slower process of functional restoration via differentiation.

Cell migration is an essential part of the restitution process. Restoration of intestinal epithelial barrier function after exposure to bile salts in porcine intestine happens for large molecules within 30 minutes, with ion transport restored after 90 minutes to 2 hours (Argenzio, Henrikson, and Liacos 1988), a process too fast for cell proliferation to play a role. Within 8 minutes, flattened cells were seen covering the wounded surfaces, recovering their normal columnar morphology within 2 hours. Cell movement is known to be dependent on actin skeletal reorganization and microtubule formation, but the signals to and among cells engaging in migration are still under investigation. A complex mixture of cytokines and growth factors is involved in the process, and debate continues concerning the sequence and relative importance of these factors, especially in the clinical setting.

The complex milieu of the large intestine also complicates matters. Cells are exposed to a variety of commensal and pathogenic bacteria, immune cells and their secretions, chemicals, and waste products as they migrate. Understanding which 
components of this milieu accelerate and which ones inhibit the healing process is important for clinical applications in the treatment of necrotizing enterocolitis and Crohn's disease.

In order to achieve an understanding of the normal and pathological processes of wound healing, in vitro models of cell migration have been used to isolate and characterize the migrating cells. These wound healing models usually involve growing epithelial cells in a monolayer, then scratching or puncturing the monolayer to create a hole. The cells can be observed during migration, and the cellular environment can be altered or fully characterized much more easily than in a whole animal.

Wound healing in vitro proceeds according to certain predictable patterns, dependent on cell type and culture conditions. In gastric epithelia, migrating cells reorganize their actin cytoskeletons to form lamellipodia ("ruffles"), which can extend into the wounded area. Cells extend these lamellipodia or pseudopods into the wound. Then integrin molecules at the leading edge of the cell interact with extracellular matrix molecules to form focal adhesions (Decaestecker et al. 2007). Matrix metalloproteinases and serine proteases cleave proteins to allow the cells to continue moving forward. Growing actin filaments push the membrane forward, as disassembly at the rear allows for cell migration (Rafelski and Theriot 2004). Actin filaments are stabilized and contracted by myosin and other contractile proteins of the cell. When the wound is closed, the cells proliferate to normal cell density and reassume their normal shape and function.

Cells of different types migrate in different ways and at different speeds. Immune cells such as neutrophils may move individually in an amoeboid manner at speeds of 1520 microns per minute (Entschladen et al. 2005). Fibroblasts and tumor cells are dependent on focal adhesion and move at $0.2-1 \mathrm{micron} / \mathrm{min}$ or $0.1-0.3 \mathrm{micron} / \mathrm{min}$, respectively (Entschladen et al. 2005). Colon and other epithelial cells migrate collectively, moving slowly while maintaining intercellular junctions (Decaestecker et al. 2007). This collective movement contributed to the "purse-string" pattern of healing in circular wounds (Tétreault et al. 2008). The different movement patterns and speeds of different cell types contribute to complexity in migration studies.

\section{Acetaldehyde Treatment}

Migration was assayed using common methods, adapted from Liang, et al., 2007. Cells were trypsinized from a confluent flask and seeded at uniform density in the center two wells of six-well cluster plates. Upon reaching confluence (48-72 hours), the monolayer was serum-starved overnight to reduce cell proliferation. Inhibitors of PP2A were applied one hour before treatment. Cells were treated with acetaldehyde by vapor deposition at varying concentrations for one or two hours, as described above. Wells were washed thoroughly with PBS after treatment to remove acetaldehyde, then cell monolayers were scratched with a razor blade or a 200 ul pipette tip. Holes were 
photographed at three hour intervals until $60-80 \%$ closure was achieved. Phase contrast images were collected.

\section{Analysis and Quantitation}

Digital images were processed in Metamorph 7 or NIS-Elements (Nikon) software. Measurement of 4-5 damaged areas per experimental condition in at least three experiments was completed using Image $J$ software. The average rate of migration was calculated in Microsoft Excel by subtracting the area at the conclusion of the experiment (after 6 or 12 hours) from the area at the beginning of the experiment, and calculating a percent of area covered.

\section{Sources of Materials}

\section{Reagents}

Dulbecco's modified Eagle's medium (DMEM), fetal bovine serum, and other cell culture reagents were purchased from Invitrogen and Fisher Scientific. FITC-inulin, leupeptin, aprotinin, bestatin, pepstatin A, phenylmethylsulfonyl fluoride, Triton-X-100, Malachite green and protein-A sepharose were purchased from Sigma. Fostriecin and okadaic acid were purchased from Calbiochem. PPase substrate phosphopeptide (KRpTIRR) was purchased from Millipore (Upstate). All other chemicals were purchased from Sigma or Fisher.

\section{Antibodies}

Mouse monoclonal PP2A $\alpha$ and mouse monoclonal anti-e-cadherin were purchased from BD Transduction (Franklin Lakes, NJ). Mouse monoclonal anti-occludin, rabbit polyclonal anti-ZO-1, HRP-conjugated anti-occludin, rabbit polyclonal anti-pThr, and anti-pSer antibodies were purchased from Zymed (San Francisco, CA). Alexa-fluor 488-conjugated anti-mouse IgG antibody was purchased from Invitrogen. Cy3conjugated anti-rabbit IgG antibodies were from Sigma. Rabbit anti-caspase 3 was purchased from Chemicon. PP2A Aalpha antibody and goat anti-rat secondary HRP were purchased from Santa Cruz.

\section{SiRNA}

Scrambled control RNA and siRNA specific to human PP2A-C $\alpha$ (sequence unavailable) were purchased from Dharmacon (Lafayette, $\mathrm{CO}$ ). 


\section{Peptide Inhibitor}

Inhibitory peptide TPDYFL and scrambled peptide were custom-synthesized by Genscript (Piscataway, NJ). Control scrambled peptide TPAYFA was also synthesized by Genscript.

\section{Matrigel}

Matrigel was purchased from BD Biosciences ( Bedford, MA). All other reagents were of analytical grade and were purchased either from Sigma or Fisher Scientific. 


\section{CHAPTER 3. RESULTS}

\section{Specific Aim 1: To Determine the Role of PP2A and Thr-dephosphorylation of Occludin in Acetaldehyde-induced Disruption of Tight Junctions and Adherens Junctions}

\section{Acetaldehyde Disrupts Tight Junctions and Adherens by a PP2A-dependent Mechanism}

Previous studies have shown that acetaldehyde in doses in the range used throughout this thesis, 600 micromolar or less, are not cytotoxic to epithelial cells for the time exposure (5 hours or less) used in our experiments (Grafström et al. 1994; Koivisto and Salaspuro 1998; Rao 1998).

Cells were exposed to acetaldehyde at concentrations of 200-600 $\mu \mathrm{M}$ for 5 hours. A lactate dehydrogenase assay for cytotoxicity was also performed for the same conditions, with comparison to a positive control of cells incubated with $0.05 \%$ Triton X100 for 10 minutes.

TER declined and inulin flux increased in a time-dependent manner, indicating that acetaldehyde disrupts tight junctions (Figure 3-1A, B). LDH assay confirmed that levels of cell lysis were comparable to untreated controls and several-fold lower than positive controls (Figure 3-2).

\section{Acetaldehyde Disrupts Barrier Function in Caco-2 Cell Monolayers by a Mechanism That Involves PP2A}

Previous studies showed that acetaldehyde disrupts intestinal epithelial barrier function, which was associated with dephosphorylation of occludin on Thr residues (Rao 2008; Sheth et al. 2007). PP2A was shown to regulate the Thr-phosphorylation of occludin and tight junction integrity under calcium-switch conditions of tight junction dis-assembly and reassembly (Seth et al. 2007). To determine whether the role of PP2A was similar to that under calcium switch, I evaluated the effect of a PP2A inhibitor, fostriecin, on acetaldehyde-induced barrier dysfunction in Caco-2 cell monolayers.

Caco-2 cell monolayers were pretreated with $50 \mathrm{nM}$ fostriecin for 16 hours followed by incubation with 200-400 $\mu \mathrm{M}$ acetaldehyde for $4 \mathrm{hrs}$. TER and inulin permeability were measured at the end of incubation. TER was not affected by fostriecin, nor did fostriecin ameliorate effects of acetaldehyde on TER (data not shown). However, fostriecin did prevent acetaldehyde-induced increases in inulin flux (Figure 3-3). Recent studies have indicated that the tight junction mechanisms responsible for the passage of small ions and larger molecules are different. 

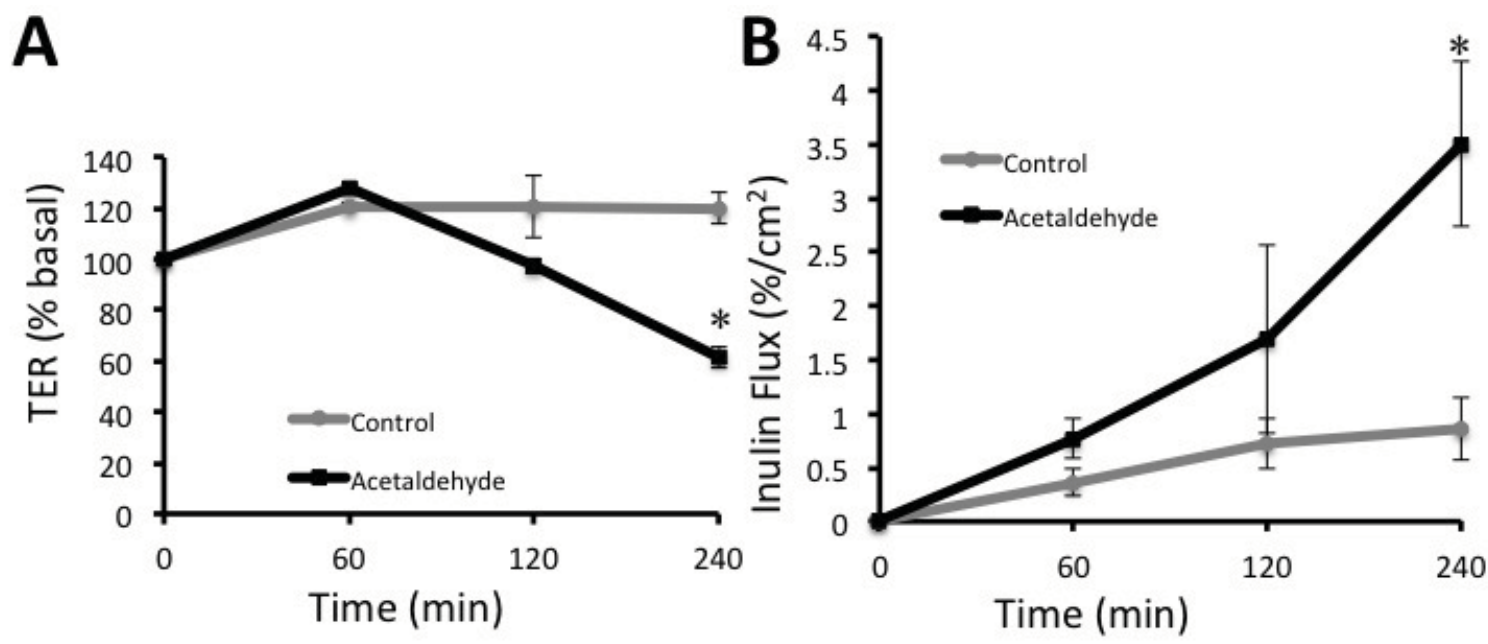

Figure 3-1. TER and FITC-inulin Flux in Acetaldehyde-treated Cells

TER was measured from Caco- 2 cell monolayers treated with $200 \mu \mathrm{M}$ acetaldehyde over a time course of four hour or from control cells. B. Inulin flux was measured the same sets of cells over the course of four hours. 


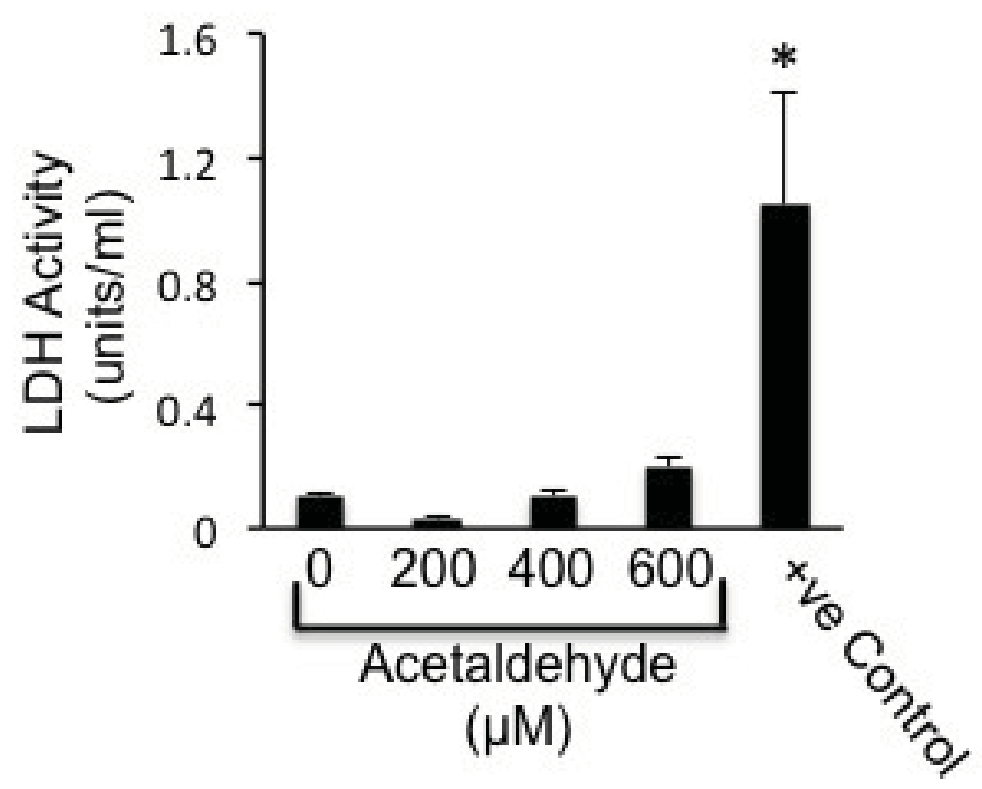

Figure 3-2. Effects of Fostriecin on Acetaldehyde-induced Tight Junction Disruption

The lactate dehydrogenase assay indicates degree of cell lysis by measuring activity of lactate dehydrogenase released into culture medium from cells. Activity was measured in cells treated with acetaldehyde for five hours. Values for $0,200,400$, and $600 \mu \mathrm{M}$ were not significantly different. Positive control was cells treated with TritonX-100 for 10 minutes. 


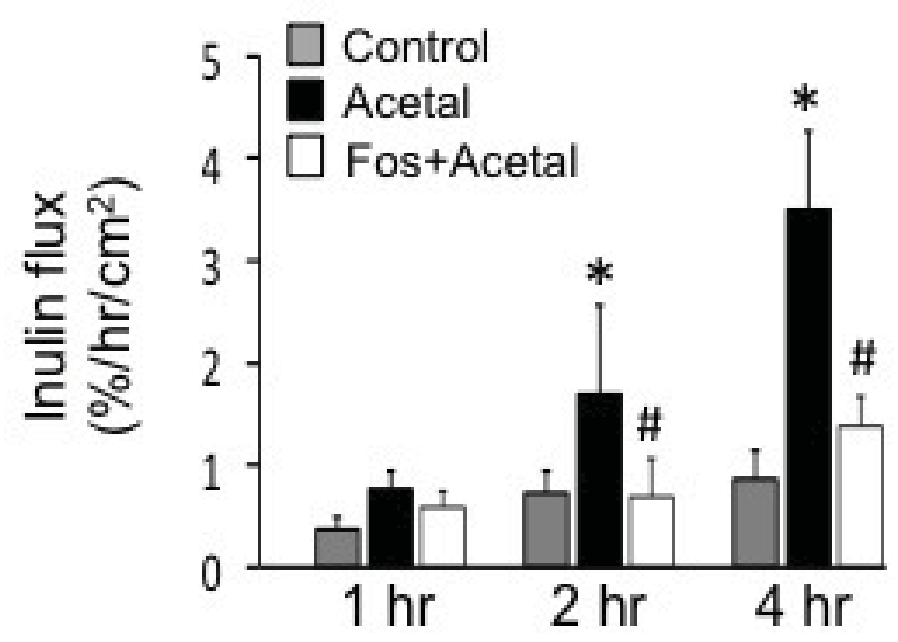

Figure 3-3. Effects of Fostriecin on Acetaldehyde-induced Tight Junction Disruption

Cells with or without pre-treatment with fostriecin were sealed in cluster plates with or without $200 \mu \mathrm{M}$ acetaldehyde for up to four hours.* indicates statistically significant difference in flux for treated cells versus control. \# indicates statistically significant difference in flux with fostriecin pretreatment from flux in acetaldehyde-treated cells without fostriecin. 
For small ions, claudins form size-and-charge selective pores. For larger molecules, temporary openings form between cells, perhaps regulated by occludin, in ways that are not size or charge-dependent. For this reason, results for TER and FITCinulin flux are not always similar (Anderson and Van Itallie 2009). These results indicate that acetaldehyde disrupts epithelial barrier function, as measured by passage of large molecules, by a PP2A-dependent mechanism.

\section{Acetaldehyde Disrupts Tight Junctions in Caco-2 Cell Monolayers by a Mechanism That Involves PP2A}

Acetaldehyde induces barrier dysfunction by disrupting the tight junctions without affecting the cell viability. Results from TER and flux were contradictory, so we evaluated the effect of pharmacological PP2A inhibition on the acetaldehyde-induced redistribution of tight junction proteins.

Caco-2 cell monolayers were treated with fostriecin and acetaldehyde as described above. Fixed cell monolayers were double labeled for occludin/ZO-1 by immunofluorescence; images were collected by using a confocal microscope.

Occludin and ZO-1 were co-localized at the intercellular junctions in control cell monolayers, indicating the presence of intact tight junctions (Figure 3-4). Acetaldehyde treatment induced redistribution of occludin and $\mathrm{ZO}-1$ from the intercellular junctions. However, pretreatment of cells with fostriecin attenuated this effect of acetaldehyde. PP2A inhibition protected tight junction protein localization.

\section{Acetaldehyde Disrupts Adherens Junctions in Caco-2 Cell Monolayers by a PP2A- dependent Mechanism}

Acetaldehyde has also been shown to induce disruption of adherens junctions (Samak, Aggarwal, and Rao 2011). This disruption causes internalization of occludin and ZO-1. Adherens junction stability has been shown to influence tight junction stability (Nita-Lazar et al. 2010). For these reasons I examined the effects of acetaldehyde and PP2A inhibition on adherens junctions.

Caco-2 cell monolayers were treated with $50 \mathrm{nM}$ fostriecin and $200 \mu \mathrm{M}$ acetaldehyde as described above. Fixed cell monolayers were double-labeled for Ecadherin and $\beta$-catenin by immunofluorescence; images were collected using a confocal microscope.

Acetaldehyde treatment induced redistribution of E-cadherin and $\beta$-catenin from the intercellular junctions. E-cadherin and $\beta$-catenin wew internalized by the cell in a similar manner to occludin and ZO-1 at the tight junction. Fostriecin attenuated the disruptive effect of acetaldehyde (Figure 3-5). These results demonstrate that acetaldehyde disrupts adherens junctions by a PP2A-dependent mechanism. 


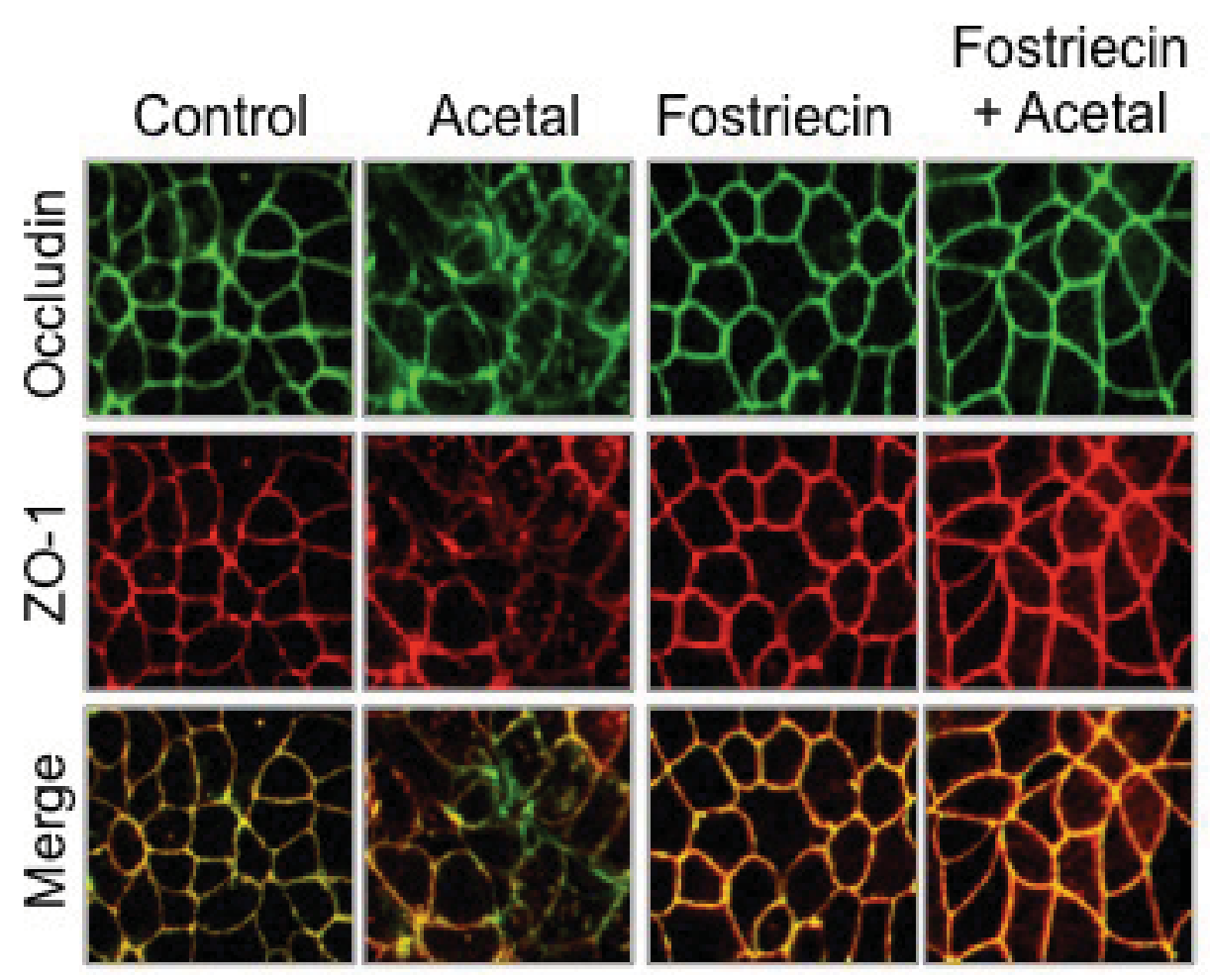

Figure 3-4. Confocal Images of Tight Junction Effects of Acetaldehyde and Fostriecin

Caco-2 cells were pretreated with fostriecin for 16 hours, then treated with $200 \mu \mathrm{M}$ acetaldehyde for four hours. The cells were fixed with $4 \%$ paraformaldehyde and immunostained for occludin and ZO-1. 


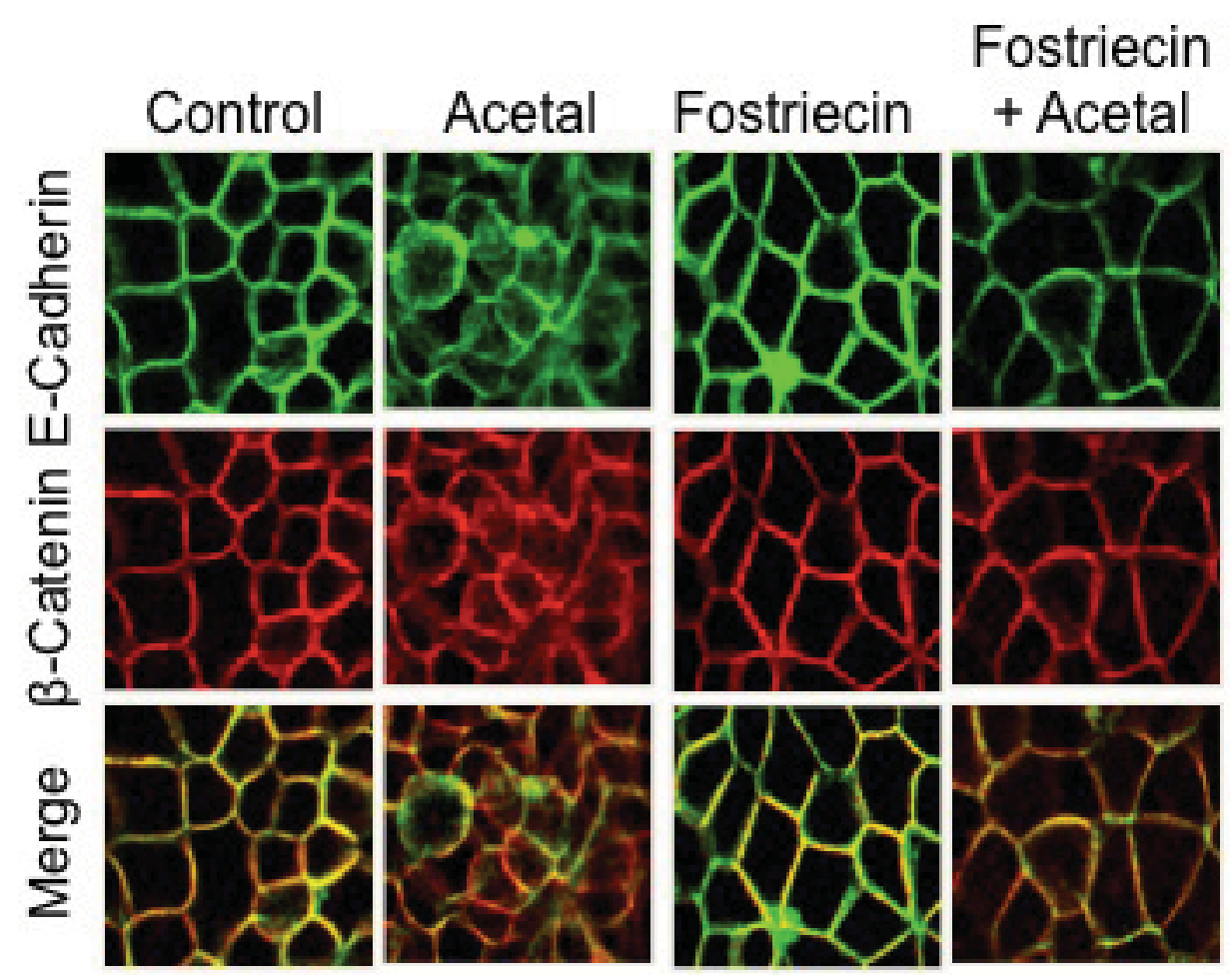

Figure 3-5. Effects of Acetaldehyde and Fostriecin on Adherens Junctions

Caco-2 cells were pretreated with fostriecin for 16 hours, then treated with $200 \mu \mathrm{M}$ acetaldehyde for four hours. The cells were fixed with $4 \%$ paraformaldehyde and immunostained for beta-catenin and e-cadherin.

\section{Acetaldehyde Disrupts Tight Junctions and Adherens Junctions in Mouse Ileum by a PP2A-dependent Mechanism}

Chronic alcohol consumption has been shown to promote colon cancer in rat and mouse models by exposure to acetaldehyde in the gastrointestinal tract (Pronko et al. 2002). Since tight junction disruption may be part of the process of tumor promotion, we decided to examine the effects of acetaldehyde on tight junctions in mouse ileum to confirm our in vitro results. In vivo exposure to acetaldehyde is difficult to measure, so an ex vivo experiment was performed to control the acetaldehyde administration.

We exposed mouse ileal segments to acetaldehyde at $300 \mu \mathrm{M}$ for 60 minutes. Tissues were cryofixed in OCT. They were sectioned and stained by immunofluorescence for occludin and ZO-1 in a manner similar to that used for cell culture monolayers.

Tight junctions were disrupted by acetaldehyde, but not by fostriecin alone (Figure 3-6). Treatment with fostriecin alleviated tight junction disruption, indicating that PP2A is involved in acetaldehyde-induced disruption of tight junctions in mouse tissues as well as in human cell culture. 


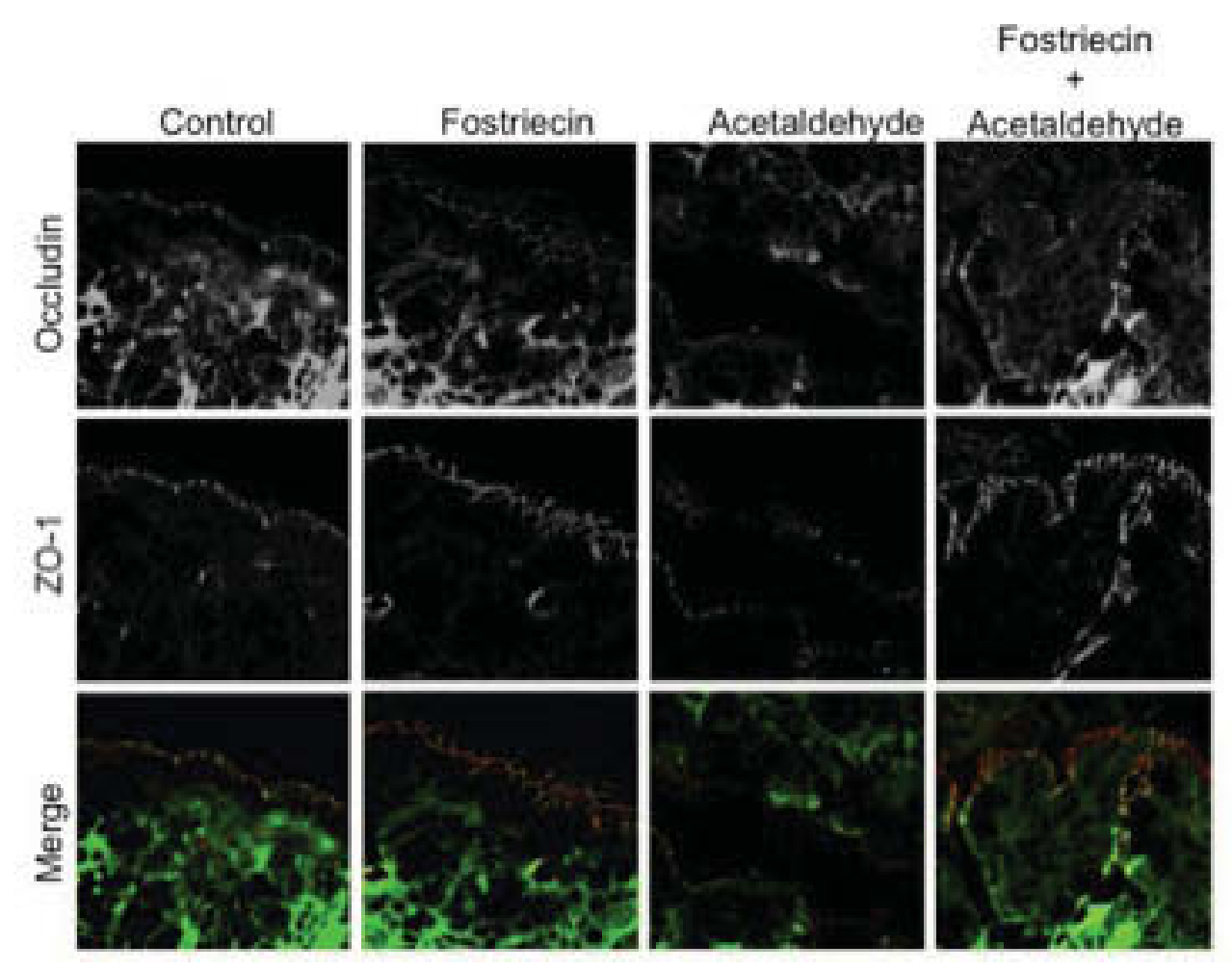

Figure 3-6. Effects of Acetaldehyde and Fostriecin on Mouse Ileum

Mouse ileum samples were treated with $300 \mu \mathrm{M}$ acetaldehyde ex vivo in the presence or absence of $50 \mathrm{nM}$ fostriecin. Cryosections were stained for occludin (green) and ZO-1 (red). 


\section{Knock Down of PP2A Attenuates Acetaldehyde-induced Barrier Dysfunction and Tight Junction Disruption}

Although fostriecin is a selective inhibitor of PP2A, it also inhibits PP4 and other

phosphatases at high concentrations. Therefore, we evaluated the effect of knockdown of PP2A-C $\alpha$ on acetaldehyde-induced barrier dysfunction. Caco-2 cells were transfected with non-specific RNA or siRNA specific for PP2A-C $\alpha$. Transfected cells grown on transwell inserts were exposed to acetaldehyde. Barrier function was analyzed by measuring TER and inulin flux and tight junction integrity assessed by confocal microscopy for occludin.

Immunoblot analysis showed that siRNA effectively reduced the level of PP2A$\mathrm{C} \alpha$ in Caco- 2 cells by roughly $25 \%$. PP1 levels varied, with some experiments showing no change and others showing an increase, perhaps as a cellular effort to compensate for the knockdown of PP2A (Figure 3-7A). Acetaldehyde-induced increase in inulin permeability in siRNA-transfected cell monolayers was significantly lower than that in control-RNA-transfected cells (Figure 3-7B). Acetaldehyde-induced redistribution of occludin from the junctions was attenuated in siRNA-transfected cells (Figure 3-7C). These results confirm that PP2A plays a crucial role in acetaldehyde-induced disruption of tight junctions.

\section{Acetaldehyde-induces PP2A Translocation by a Tyrosine Kinase-dependent Mechanism}

Previous studies in our laboratory have shown that acetaldehyde -induced disruption of tight junctions and adherens junctions increases tyrosine phosphorylation of junctional proteins and reduced protein tyrosine phosphatase 1B(PTP-1B) activity (Atkinson and Rao 2001; Sheth et al. 2007). Tyrosine phosphorylation and carboxymethylation of PP2A on a terminal leucine are known to affect localization and activity of PP2A by affecting the binding of B (regulatory) subunits. The following series of experiments was undertaken to explore the effects of acetaldehyde on association of PP2A and tight junction proteins, and to explore possible mediators of increased PP2A association and activity.

\section{Acetaldehyde Increases Association of PP2A with Occludin}

It has been previously shown that PP2A associates with occludin when tight junctions are disrupted by calcium depletion and in the presence of hydrogen peroxide (Seth et al. 2007; Sheth et al. 2009). We investigated the association of PP2A with occludin in the presence of acetaldehyde as a possible mechanism for acetaldehydemediated tight junction disruption. Cells were exposed to acetaldehyde for time periods ranging from 15-60 minutes, based on initial trials of up to 2 hours, indicating that the association peaked and faded within the first hour of treatment, before disruption was apparent. 

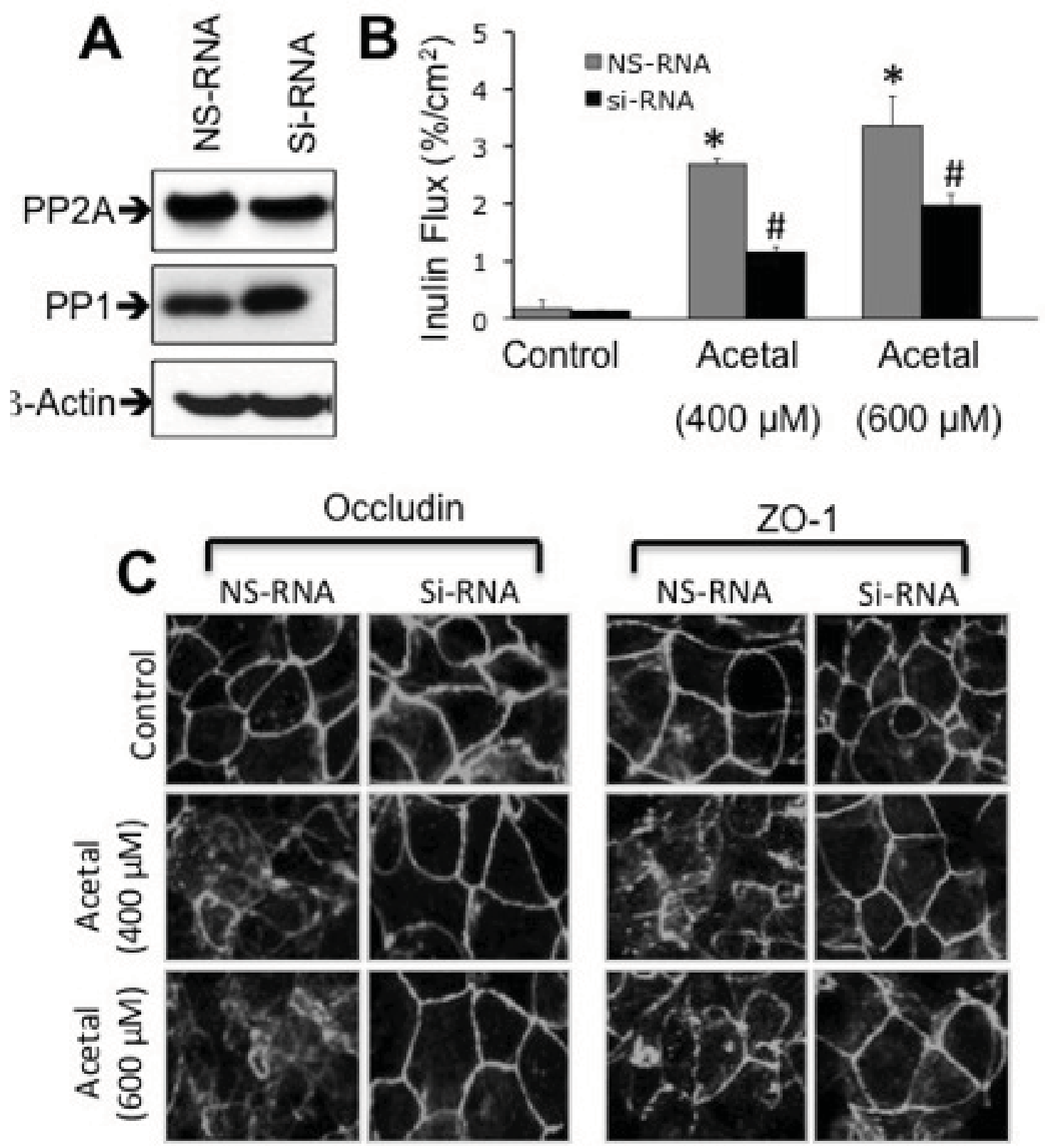

Figure 3-7. SiRNA Knockdown of PP2A Attenuates Effects of Acetaldehyde

A. Western blot and immunostaining from total cell lysate indicate levels of PP2A, PP1, and actin in cells treated with siRNA. B. Inulin flux in cells exposed to $400 \mu \mathrm{M}$ or 600 $\mu \mathrm{M}$ acetaldehyde for 5 hours. * indicates significant difference in flux $(\mathrm{p}<0.02)$ vs. control. \# indicates significant effect of acetaldehyde in cells with PP2A siRNA $(p<0.05)$ vs. cells with scrambled siRNA. C. Cells were exposed to acetaldehyde for five hours at two different acetaldehyde concentrations, then stained by immunofluorescence for occludin and ZO-1. 
Immunoprecipitation of occludin from actin-cytoskeletal-associated fractions of cell lysates followed short time course experiments. Half of each sample was used immediately for PP2A activity assay, while the other half was used for immunoblot analysis to determine occludin-PP2A association. PP2A activity was measured using the substrate KRpTIRR and malachite green color change in the presence of free phosphate. PP2A activity associated with occludin increased over time of acetaldehyde treatment (Figure 3-8A). PP2A physical association with occludin peaked between 30 and 60 minutes after initiation of acetaldehyde exposure, corresponding roughly to activity data (Figure 3-8B, C). These results indicate that PP2A association with occludin rises with activity upon exposure of cultured human epithelial cells to acetaldehyde.

\section{PP2A Translocation Inhibitor Attenuates Acetaldehyde-induced Barrier Dysfunction and Tight Junction Disruption}

Previous PP2A inhibition had shown attenuation of acetaldehyde-induced disruption of barrier function, but siRNA knockdown of PP2A was unimpressive and the pharmacological inhibitor could also inhibit PP4 and PP6. Another method of inhibition was needed. TPDYFL is an inhibitory peptide previously used by another researcher in our department in a study of cardiac myocytes (Deshmukh, Blunt, and Hofmann 2007). Cells were treated with TPDYFL using the Chariot system to carry the peptide into the cell. After two hours of pre-treatment, cells were treated with $200 \mu \mathrm{M}$ acetaldehyde for four hours. TER and flux were measured. Cells were fixed with paraformaldehyde and stained for occludin and ZO-1. FITC-inulin flux data indicate that pre-treatment with TPDYFL to inhibit PP2A alleviated the usual acetaldehyde-induced increase in flux (Figure 3-9A). As with fostriecin treatment, short-term PP2A inhibition did not affect TER (data not shown). Occludin-PP2A co-immunoprecipitation indicates that the usual increase in PP2A association with acetaldehyde is attenuated by TPDYFL (Figure 3-9B). Confocal images confirm that tight junctions appear to be more stable in the presence of acetaldehyde in cells subject to TPDYFL PP2A inhibition (Figure 3-9C).

\section{Tyrosine Kinase Activity Mediates Acetaldehyde-induced PP2A Translocation}

Previous studies have shown that tyrosine phosphorylation on Y309 is important for activation and localization of PP2A (Deshmukh, Blunt, and Hofmann 2007). Because tyrosine phosphorylation has been previously shown to increase in tight junction proteins in the presence of acetaldehyde, resulting in tight junction disruption, we examined the effect of genistein, a known tyrosine kinase inhibitor, on the association between PP2A and occludin.Cells were exposed to $200 \mu \mathrm{M}$ acetaldehyde in the presence or absence of $100 \mu \mathrm{M}$ genistein for one hour. In the presence of acetaldehyde, PP2A association with occludin is increased within the first hour (Figure 3-10). With genistein treatment, the association of PP2A and occludin did not increase with acetaldehyde treatment. A representative blot is not available because these values were normalized to expression of actin. 

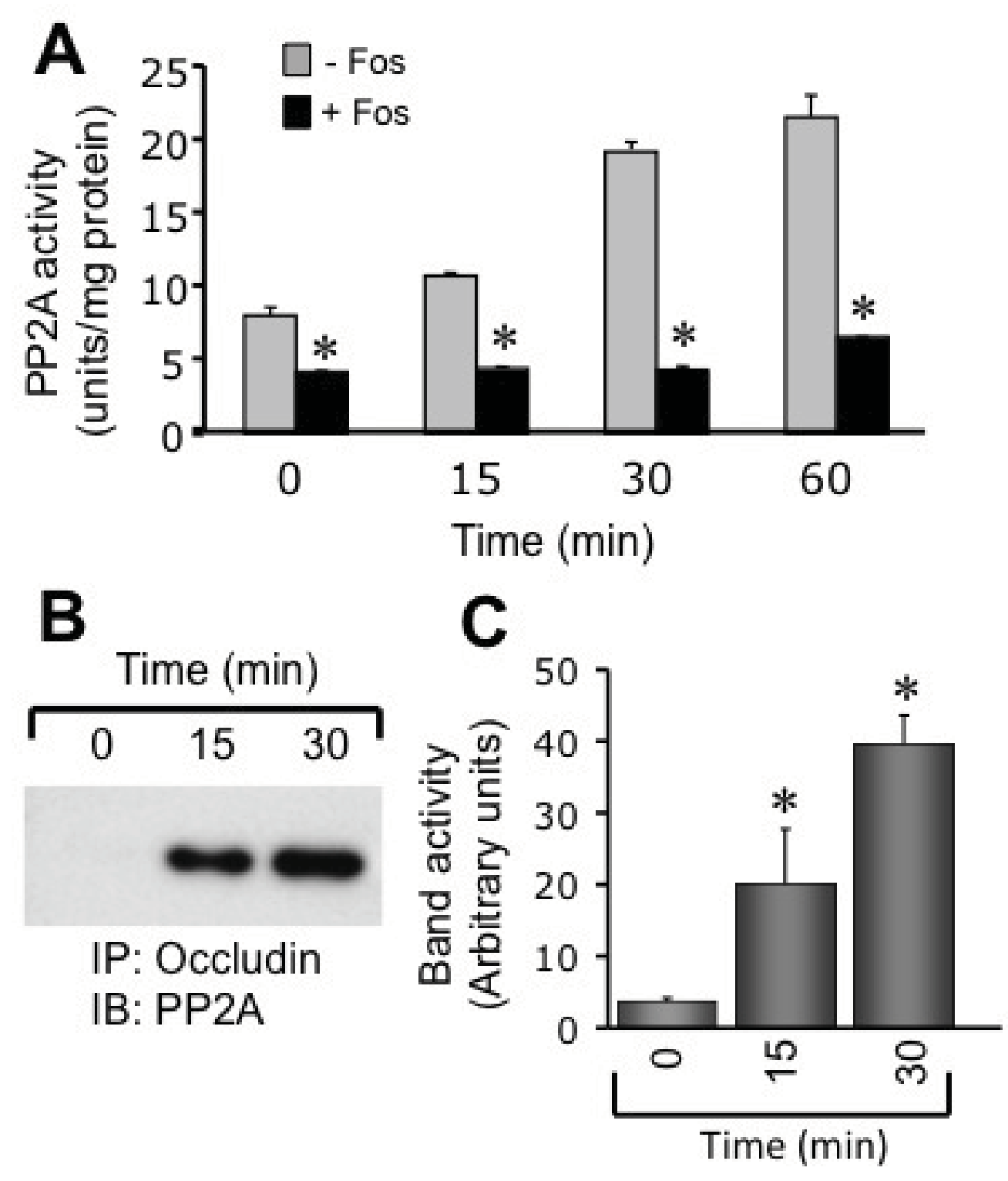

Figure 3-8. Effects of Acetaldehyde on PP2A Activity and Association with Occludin

A. In vitro PP2A activity assay from occludin immunoprecipitate in the presence of 200 $\mu \mathrm{M}$ acetaldehyde for exposure times up to one hour with or without fostriecin. * represents significant change in PP2A activity $(\mathrm{p}<0.02)$ compared to controls. B. Coimmunoprecipitation of occludin and PP2A from same cell lysates as the activity assay confirms increased association as well as activity. C. Densitometric analysis of several co-immunoprecipitations confirms representative blot. * indicates significant difference in PP2A-occludin association compared to controls $(\mathrm{p}<0.05)$. 

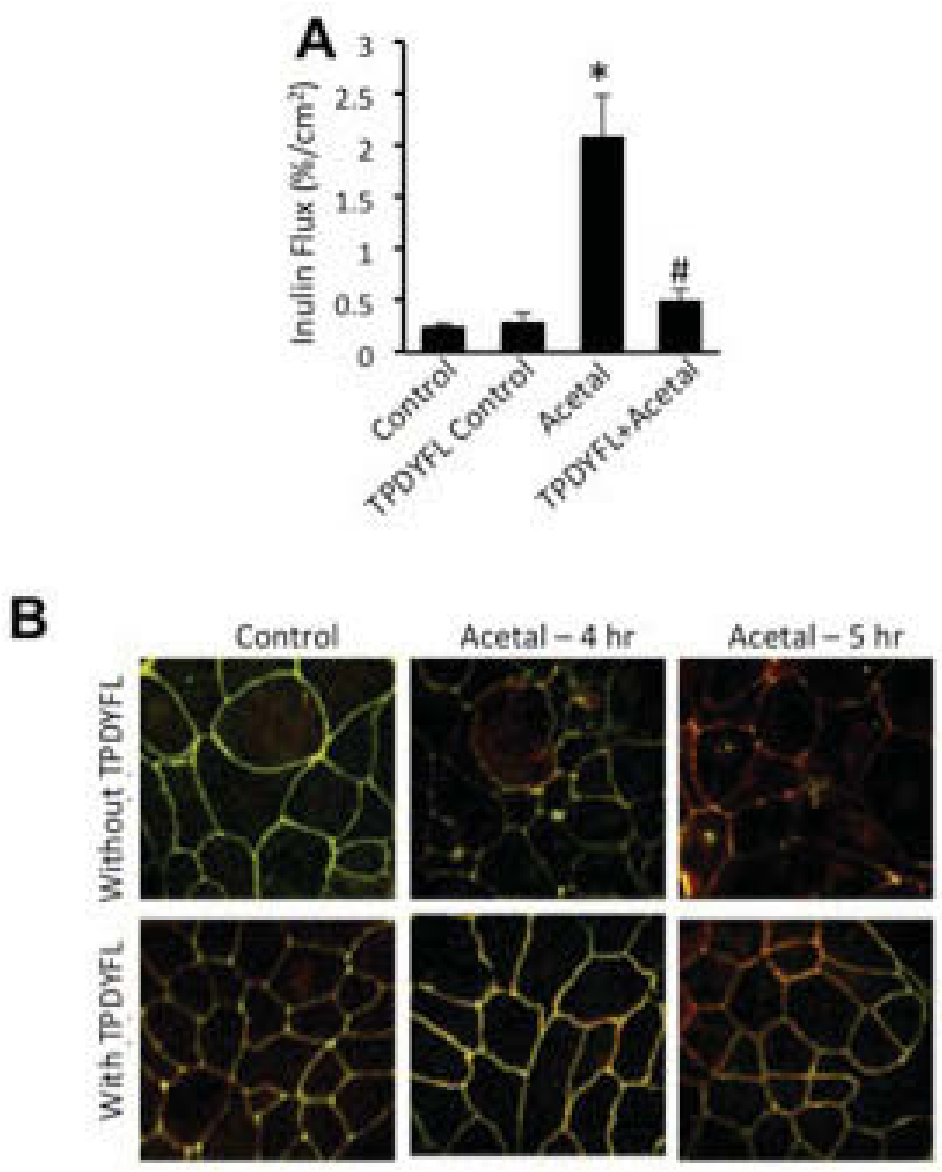

Figure 3-9. Effects of Peptide Inhibition on Acetaldehyde-induced Tight Junction Disruption

A. FITC-inulin flux with TPDYFL pretreatment in the presence or absence of $200 \mu \mathrm{M}$ acetaldehyde for four hours. * indicates significant difference in inulin flux compared to control. \# indicates significant attenuation of acetaldehyde effect. B. Cells treated with acetaldehyde were fixed in $4 \%$ paraformaldehyde and immunostained for occludin and $\mathrm{ZO}-1$. 


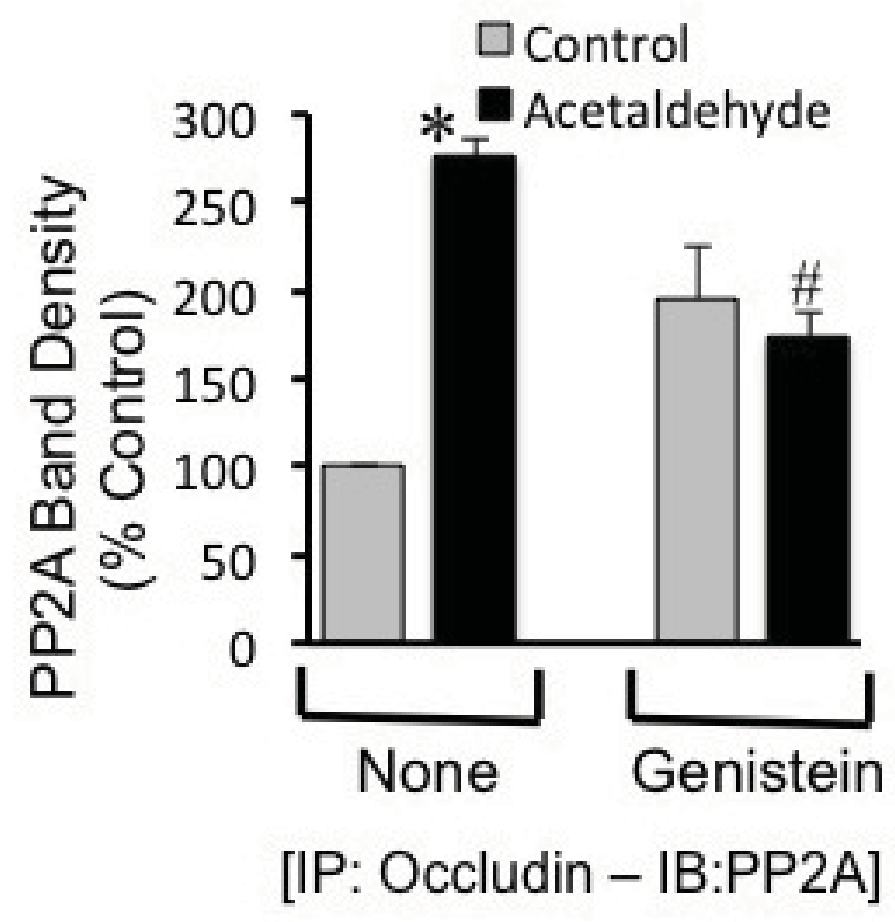

Figure 3-10. Genistein Effect on PP2A Association with Occludin

Densitometric analysis of three experiments with co-immunoprecipitation of PP2A and occludin from cells pre-treated with $100 \mu \mathrm{M}$ genistein, and treated with $200 \mu \mathrm{M}$ acetaldehyde. * indicates significant increase of association of PP2A with occludin in the presence of acetaldehyde. \# indicates significant decrease of association in the presence of genistein compared to acetaldehyde-treated controls. 


\section{Acetaldehyde Dephosphorylates Occludin on Threonine Residues by a PP2A- dependent Mechanism}

Threonine dephosphorylation of occludin, and involvement of PP2A, have been demonstrated in previous studies in our laboratory examining the disassembly and reassembly of tight junctions in the presence of altered calcium concentrations in cell media (Seth et al. 2007). In this series of experiments, we explored the threonine phosphorylation status of occludin in the presence of acetaldehyde treatment. Cells were exposed to $200 \mu \mathrm{M}$ acetaldehyde for time periods ranging from 15 to 60 minutes, after initial studies indicating that threonine dephosphorylation occurred within the first hour. Occludin was dephosphorylated on threonine residues, with maximum dephosphorylation occurring between thirty and sixty minutes after initiating acetaldehyde treatment (Figure 3-11).

\section{PP2A Translocation Inhibitor Blocks Acetaldehyde-induced Threonine Dephosphorylation}

Previous studies have shown that PP2A dephosphorylates occludin on threonine residues as described above. We used TPDYFL, a specific peptide inhibitor, to examine the effects of inhibiting PP2A translocation on threonine dephosphorylation. After two hours of pretreatment with $500 \mathrm{ng}$ peptide, the confluent monolayers were exposed to 200 $\mu \mathrm{M}$ acetaldehyde for time periods up to one hour. Results shown are for the 30-minute time point, correlating with earlier data for fostriecin protection. Inhibition of PP2A using a specific peptide inhibitor protects the phosphorylation of threonine residues of occludin in the presence of acetaldehyde (Figure 3-12).

\section{Tyrosine Kinase Activity Mediates Acetaldehyde-induced Occludin Dephosphorylation}

Previous studies of PP2A regulation have indicated that phosphorylation of Y307 is part of the activation of PP2A (Gentry et al. 2005). Since tyrosine phosphorylation of tight junction and adherens junction proteins has been shown to be altered in the presence of acetaldehyde (Atkinson and Rao 2001), we examined the effects of genistein (a known tyrosine kinase inhibitor) on PP2A dephosphorylation of threonine in the presence of acetaldehyde. Cells were pre-treated with $100 \mu \mathrm{M}$ genistein for one hour. They were then exposed to $200 \mu \mathrm{M}$ acetaldehyde for one hour. Cells were lysed and the actin cytoskeleton-associated fraction was subjected to immunoprecipitation for threoninephosphorylated proteins. Immunoblot analysis for occludin and claudins followed.

In the presence of acetaldehyde, occludin threonine phosphorylation declines (Figure 3-13A, B), but genistein protects occludin from dephosphorylation. Claudin-5, another tight junction transmembrane protein, is also threonine-dephosphorylated in a manner independent of tyrosine kinase inhibition (Figure 3-13A). 


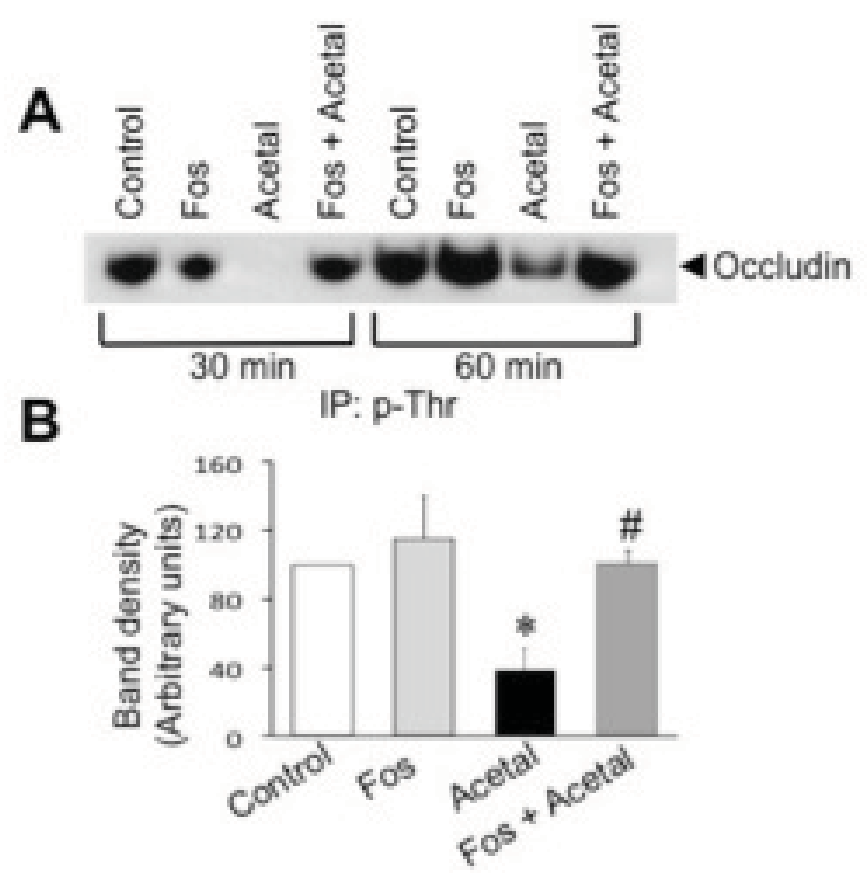

Figure 3-11. Effects of Acetaldehyde and Fostriecin on Threonine Phosphorylation of Occludin

A. Cells were pre-treated with fostriecin for 16 hours, then sealed into cluster plates in the presence or absence of acetaldehyde for up to one hour. Immunoprecipitates of threonine-phosphorylated proteins from actin-cytoskeleton-associated cell lysates were immunoblotted for occludin. B. Densitometric analysis of three experiments is shown at the 30 minute time point. $*$ indicates significant difference in threonine phosphorylation compared to control. \# indicates difference in threonine phosphorylation with fostriecin pretreatment. 


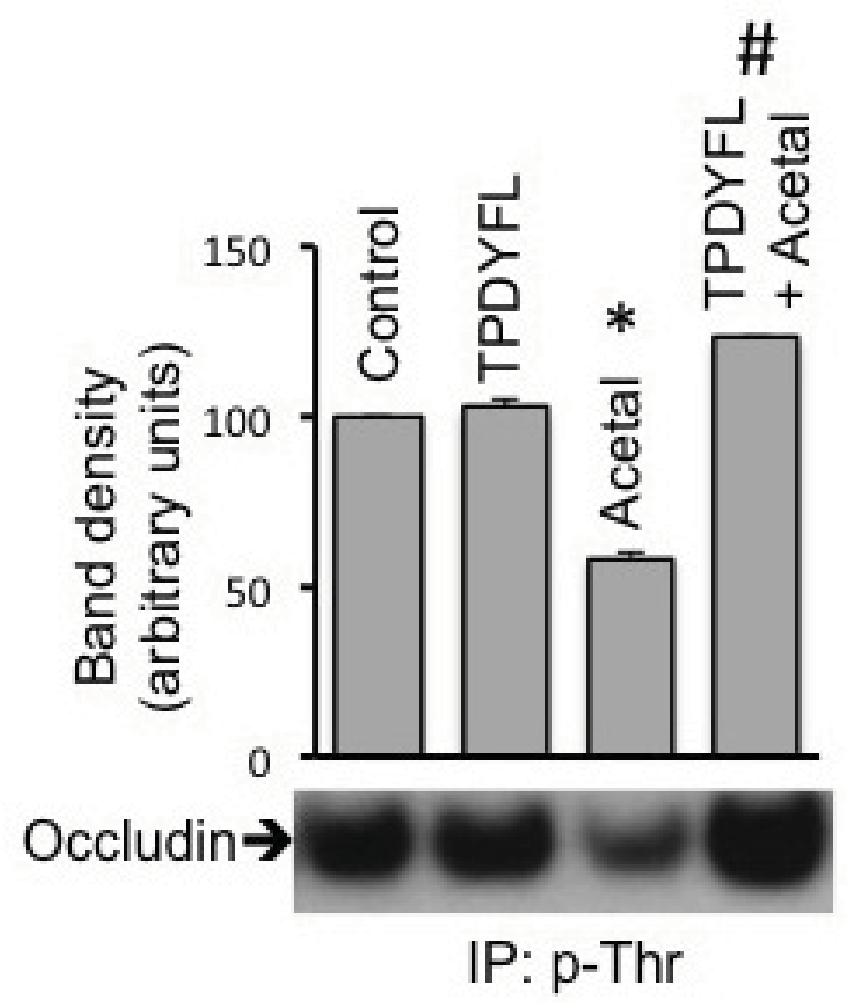

Figure 3-12. PP2A Inhibition with TPDYFL Restores Threonine Phosphorylation of Occludin

Cells were pretreated with 500 ng TPDYFL for two hours before 30 miniutes of treatment with acetaldehyde. Threonine-phosphorylated proteins were immunoprecipitated from actin-cytoskeleton-associated cell lysates and immunoblotted for occludin. * indicates significant difference $(\mathrm{p}<0.02)$ in threonine phosphorylation with acetaldehyde treatment. \# indicates significant difference $(\mathrm{p}<0.02)$ with pretreatment with TPDYFL compared to acetaldehyde-treated cells without pretreatment. 


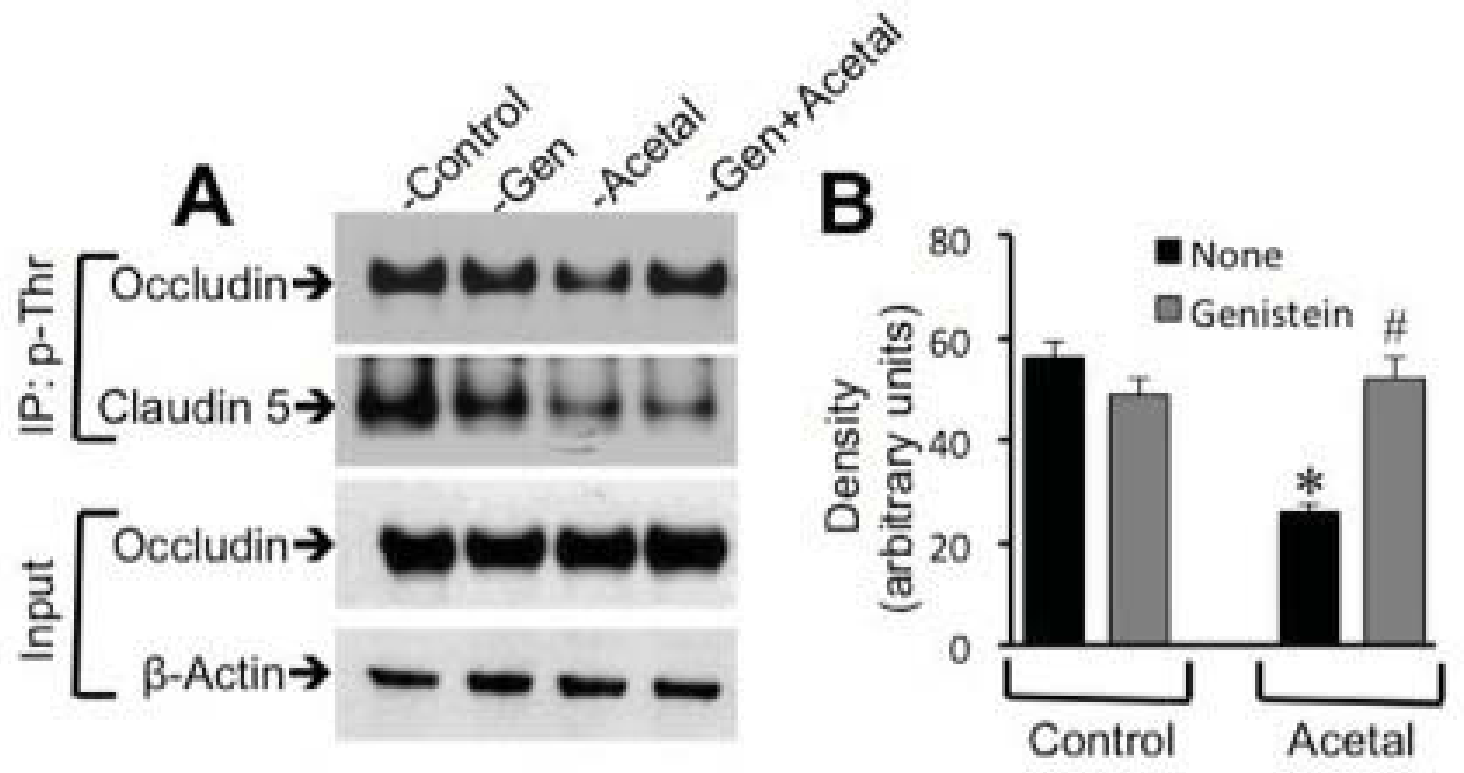

Figure 3-13. Effects of Tyrosine Kinase Inhibition with Genistein on Acetaldehyde induced Threonine Dephosphorylation of Occludin

A. Cells pre-treated with $100 \mu \mathrm{M}$ genistein or control cells were exposed to $200 \mu \mathrm{M}$ acetaldehyde for one hour. Immunoprecipitation of threonine-phosphorylated proteins and immunoblot for occludin and claudin-5 followed. Loading controls ("input") from total cell lysate for occludin and actin are included. B. Densitometry for threonine phosphorylation of occludin in the presence or absence of $200 \mu \mathrm{M}$ acetaldehyde and 100 $\mu \mathrm{M}$ genistein. * indicates significant difference $(\mathrm{p}<0.05)$ in threonine dephosphorylation of occludin compared to control. \# indicates significant difference $(p<0.05)$ from acetaldehyde-treated cells. 


\section{Acetaldehyde-induced Activity of PP2A Does Not Depend on Changes in PP2A Methylation Status}

Studies of the regulation of PP2A activity have shown that terminal carboxymethylation of L309 is important for substrate specificity and localization of PP2A (Bryant, Westphal, and Wadzinski 1999; Xing et al. 2008). However, other studies have shown that carboxymethylation is not necessary for B-subunit binding and PP2A activity in all cases (Ikehara et al. 2007). Therefore we examined whether acetaldehyde induced an increase in the methylation of PP2A as an explanation of its increased binding and activity. Cells were treated with $200 \mu \mathrm{M}$ acetaldehyde for one hour. Total cell lysate was immunoblotted for methylated PP2A C- $\alpha$. Acetaldehyde treatment did not change the amount of methylated PP2A as demonstrated by Western blot (Figure 3-14) at the thirty minute or one hour time points, when PP2A was activated and translocated in previous experiments. After repeatedly generating this result, we believe that methylation of PP2A is not influenced by acetaldehyde.

\section{Specific Aim 2: To Determine That Acetaldehyde Alters Migration and Differentiation by a PP2A-dependent Mechanism}

\section{Acetaldehyde Promotes Cell Migration by a Mechanism That Involves PP2A and Thr-dephosphorylation of Occludin}

Two types of cell migration assays were attempted: scratch wounding and transmigration. Transmigration did not work (data not shown) because the Caco- 2 cells did not pass through the 8-micron pores of a permeable filter upon acetaldehyde stimulation. Caco-2 cells are used as a monolayer through which immune cells pass in models of gastrointestinal immune function (Rescigno et al. 2001). They are also used as a model for the invasion of Candida albicans by intra- and intercellular migration (Weide and Ernst 1999). Other types of cells can migrate through membranes with a confluent monolayer of Caco- 2 cells, but the Caco- 2 cells themselves do not move. The transmigration model was attempted, but Caco- 2 cells do not migrate across membranes upon acetaldehyde stimulation.

Several types of scratch wounding were attempted. First, using a razor blade to scratch away a large portion of the monolayer was used for experiments examining the effect of hydrogen peroxide on FAK and Src signaling. In these experiments, I noted difficulty with reproducibility because the blade often gouges the underlying plastic, leaving small valleys the cells cannot cross in the migration process. I optimized the technique using collagen coating of the plates prior to seeding, but the reproducibility issues remained. I then attempted other scratch techniques from the literature including using a fine metal-toothed comb (stippling, scraping, and stippling with rotation), stippling or scraping with a gel-loading pipette tip, placing a tiny drop of acid on the monolayer, and suction using a Pasteur pipette. Of all these techniques, the one yielding 


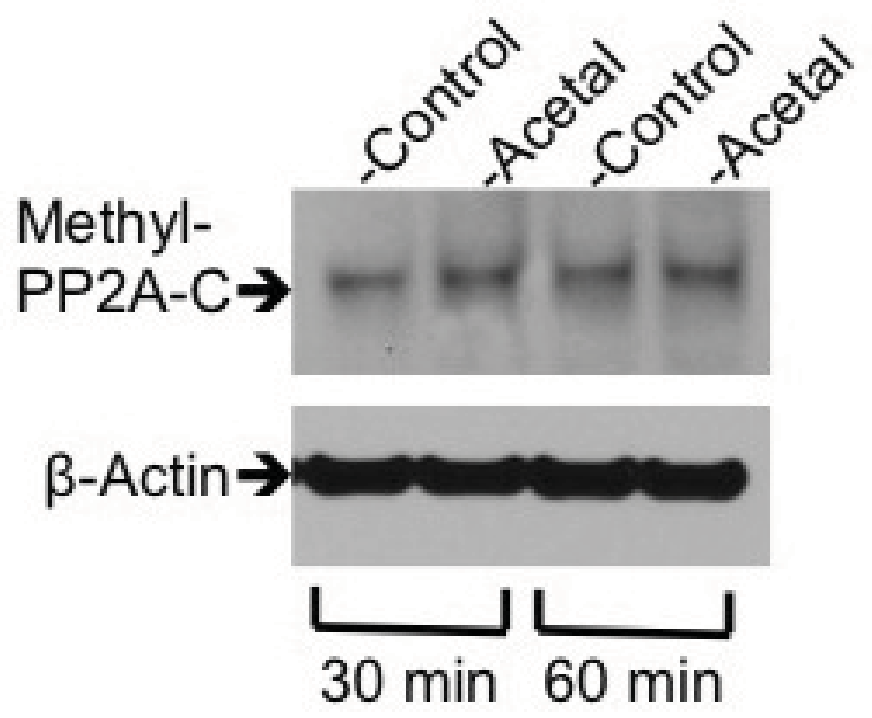

Figure 3-14. Methylation Status of PP2A in the Presence of Acetaldehyde

Cells were exposed to $200 \mu \mathrm{M}$ acetaldehyde for 30 minutes or one hour. Total cell lysate was immunoblotted for methylated PP2A C- $\alpha$, with $\beta$-actin loading control. 
the most consistent results was stippling small holes with a gel-loading pipette tip. Scraping a linear hole and watching the cells migrate to close it over time, as is done in many other wound-healing models (Bindschadler and McGrath 2007), does not work with Caco-2 cells due to their strong intercellular connections. A large or ragged hole, or one ripped quickly and with force, increases the probability that the monolayer will detach from the substratum, rendering it useless for cell migration purposes. Several experiments using small round holes were conducted.

\section{Acetaldehyde Inhibits Cell Migration in Caco-2 Cells at Low Concentrations}

Acetaldehyde is known to disrupt tight junctions, and disrupted cell-cell junctions have been previously demonstrated to promote cell migration. These experiments were completed in an attempt to show that acetaldehyde promoted cell migration. Cells were seeded in six-well cluster plates. After five hours of acetaldehyde treatment, confluent cell monolayers were scratched with a pipette tip to form small holes (Figure 3-15A). After six to twelve hours, scratches were examined for closure. Photomicrographs of phase contrast images were saved as TIFs or JPEGs using Metamorph 8 or NIkon NISElements software. Images were compared from time zero to ending time points. Percent closure was calculated by drawing outlines of the holes using Image $J$ and calculating changes in enclosed area with Microsoft Excel.

At concentrations several-fold lower than those used for typical Transwell experiments, acetaldehyde did not promote cell migration. At the six hour time point displayed, the lowest concentration of acetaldehyde inhibited migration (Figure 3-15B). At normal concentrations used in Transwell experiments, cells detached (data not shown). These results indicated that acetaldehyde may delay wound healing in gastrointestinal epithelia.

\section{Inhibition of Migration by Acetaldehyde Exposure is Not PP2A-dependent}

Acetaldehyde exposure at high concentration has been previously shown in my experiments to cause disruption of tight and adherens junctions in confluent cell monolayers. Promotion of cell migration in the presence of this disruption was expected based on previous studies in other contexts. Cells were exposed to acetaldehyde concentrations including those typically used for acute exposure experiments in the laboratory $(100-300 \mu \mathrm{M})$. Initial experiments in which these higher concentrations of acetaldehyde tended to cause cell detachment led to experiments with a range of much

lower concentrations, as displayed below. After five hours of exposure to acetaldehyde in sealed cluster plates, cell monolayers were scratched with a pipette tip and migration was observed over the course of the next twelve hours.

All concentrations of acetaldehyde inhibited migration in a dose-dependent manner, with inhibition not significantly rescued by fostriecin at any concentration (Figure 3-16). Cells exposed to concentrations of acetaldehyde above $100 \mu \mathrm{M}$ tended to 

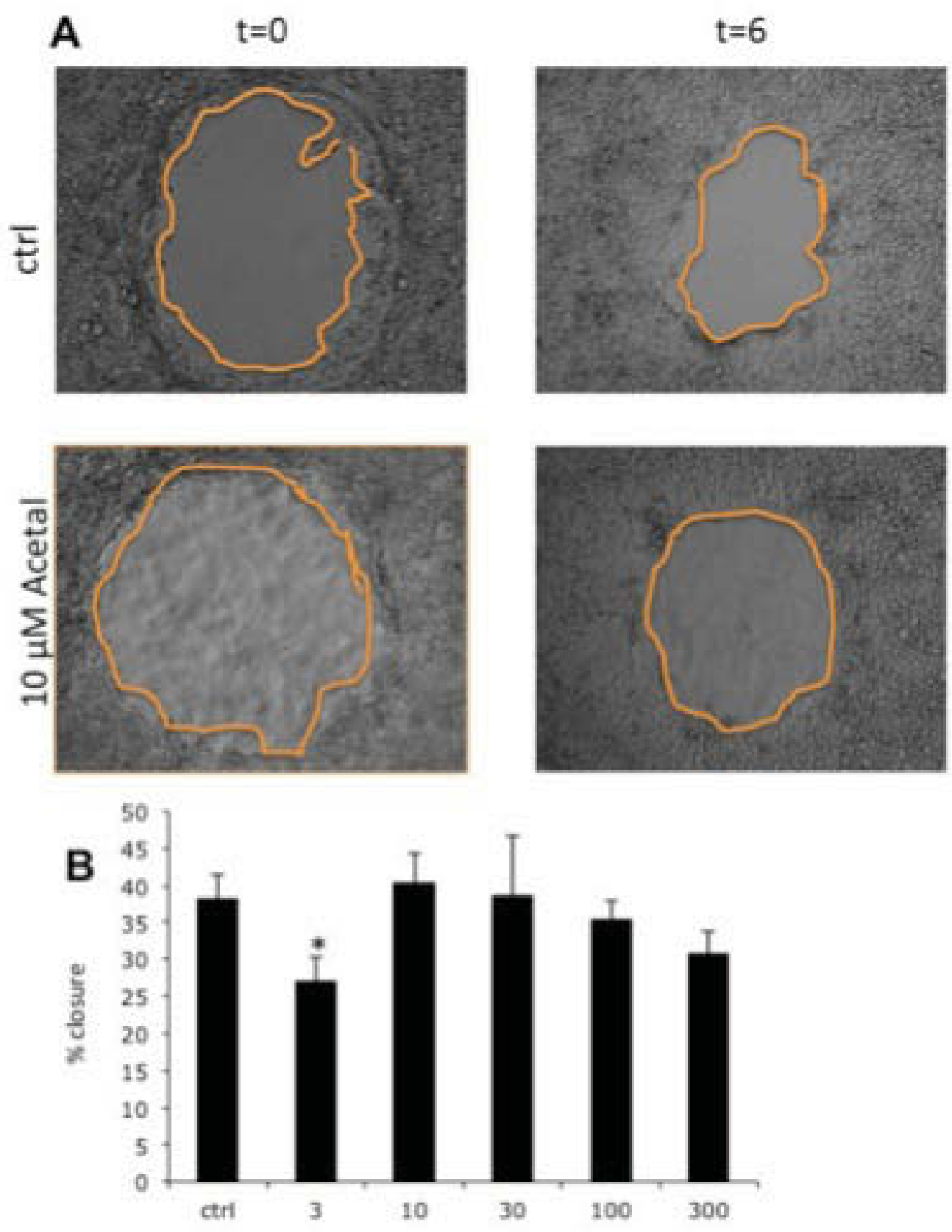

Concentration Acetaldehyde ( $\mu \mathrm{M})$

Figure 3-15. Cell Migration Dose Response in the Presence of Acetaldehyde

A. Representative scratches and measurement technique are shown. Image $\mathbf{J}$ was used to calculate each encircled area, with changes over time graphed in Microsoft Excel as percent closure. B. Data from several dose-response experiments with treatment of cells with acetaldehyde for five hours, followed by six hours of observation, are shown. * is significantly different from control $(\mathrm{p}<0.2)$. 


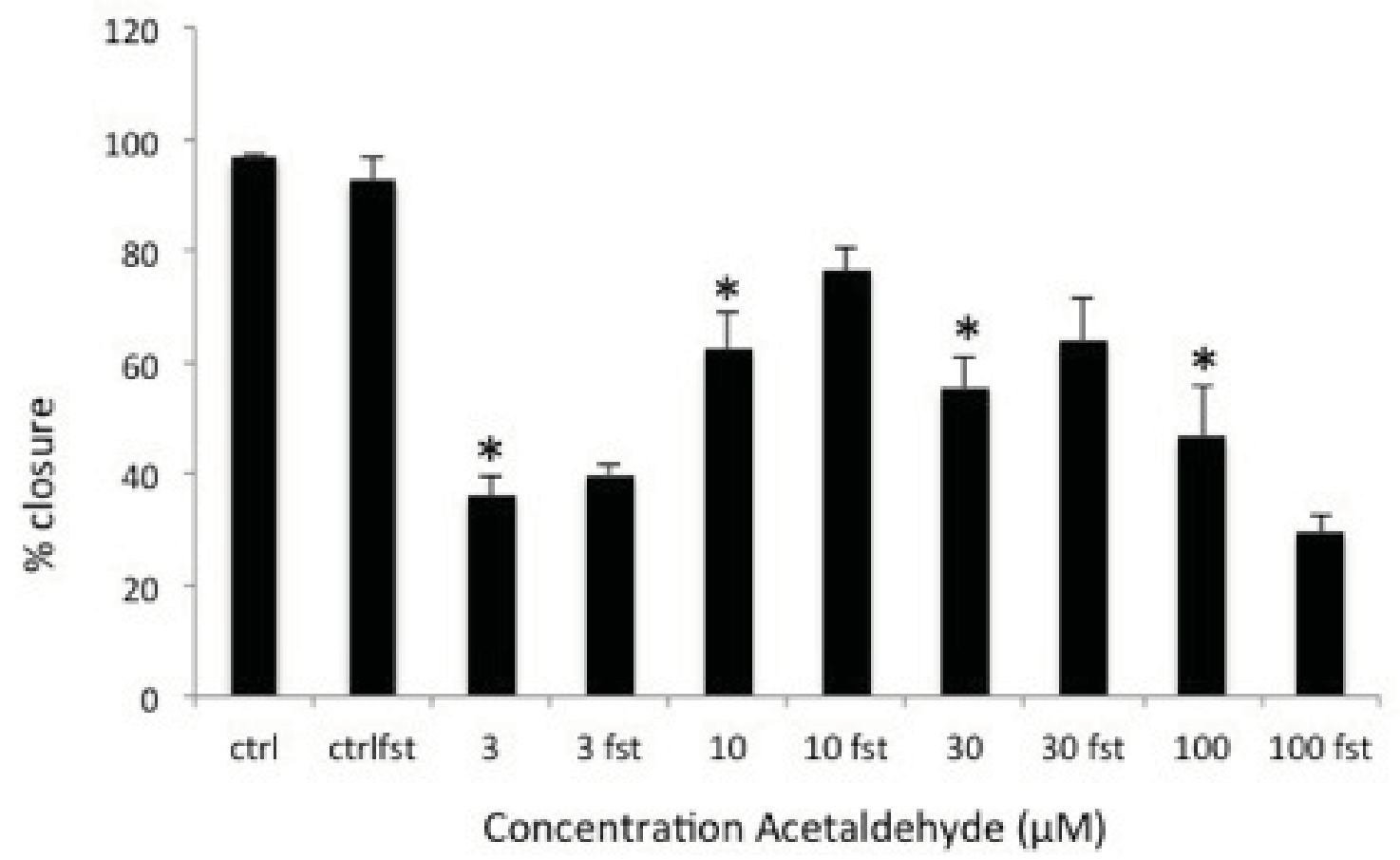

Figure 3-16. Effects of Fostriecin at Range of Concentrations of Acetaldehyde

Cells in monolayers grown on cluster plates were treated with a range of concentrations of acetaldehyde, with or without pretreatment with $50 \mathrm{nM}$ fostriecin. * indicates wound closure significantly different from control $(\mathrm{p}<0.02)$ after five hours acetaldehyde treatment, wounding, and twelve hours wound closure. 
detach. Inhibition of wound healing by acetaldehyde at any concentration is probably not PP2A-dependent.

\section{Acetaldehyde Affects Growth and Differentiation of Caco-2 Cells by a PP2A- dependent Mechanism}

As discussed in the introductory chapter, alcohol consumption increases the risk for colon cancer (Salaspuro 2009). Acetaldehyde formation seems to play a crucial role in this effect of ethanol. Our studies described above show that acetaldehyde disrupts both tight junctions and adherens junctions. Since the dissociation of tight junctions and adherens junctions may result in morphological changes in cells, we investigated whether acetaldehyde affected the epithelial differentiation of Caco-2 cells when grown in a 3dimensional model. Caco-2 cells were grown on Matrigel as described in the Methods chapter. After 3 days of growth, cells were exposed to acetaldehyde $(200 \mu \mathrm{M})$ for one hour every day. The control group was treated similarly without acetaldehyde. On day nine of growth, phase contrast images were collected. Cells were fixed with $4 \%$ paraformaldehyde and immunostained for occludin and ZO-1.

Caco-2 cells on Matrigel grew to form a three-dimensional cyst-like structure, consisting of a monolayer of polarized epithelial cells enclosing a central cavity. Phase contrast images show that acetaldehyde at concentrations normally used for acute exposure experiments attenuated the differentiation into cysts; rather, the cells appeared dispersed without polarization. This was confirmed when the distribution of occludin and ZO-1 was visualized by confocal microscopy. In control cells, occludin and ZO-1 were co-localized at the apical end (facing the cavity) of the epithelial cells (Figure 3-17), while such organization of occludin and ZO-1 was absent in acetaldehyde-treated cells. These results indicate that acetaldehyde attenuates epithelial differentiation of Caco-2 cells.

\section{Acetaldehyde-induced Differentiation Problems Are PP2A-dependent}

Our studies described above show that acetaldehyde disrupts both tight junctions and adherens junctions. Since the dissociation of junctions and adherens junctions may result in morphological changes in cells, we investigated whether fostriecin influenced the effect of acetaldehyde on morphological changes in differentiation, and whether a lower dose of acetaldehyde would have an effect. Cells were grown in Matrigel following previously-described protocols. Treatment with acetaldehyde started at day three, and continued every other day until day twelve. Cells were pre-treated for one hour with 50 $\mathrm{nM}$ fostriecin.

Fostriecin attenuated the acetaldehyde-induced prevention of epithelial

differentiation. Fostriecin-treated cells with or without acetaldehyde showed organization of cells into polarized epithelium in a cyst-like structure, similar to control cells 

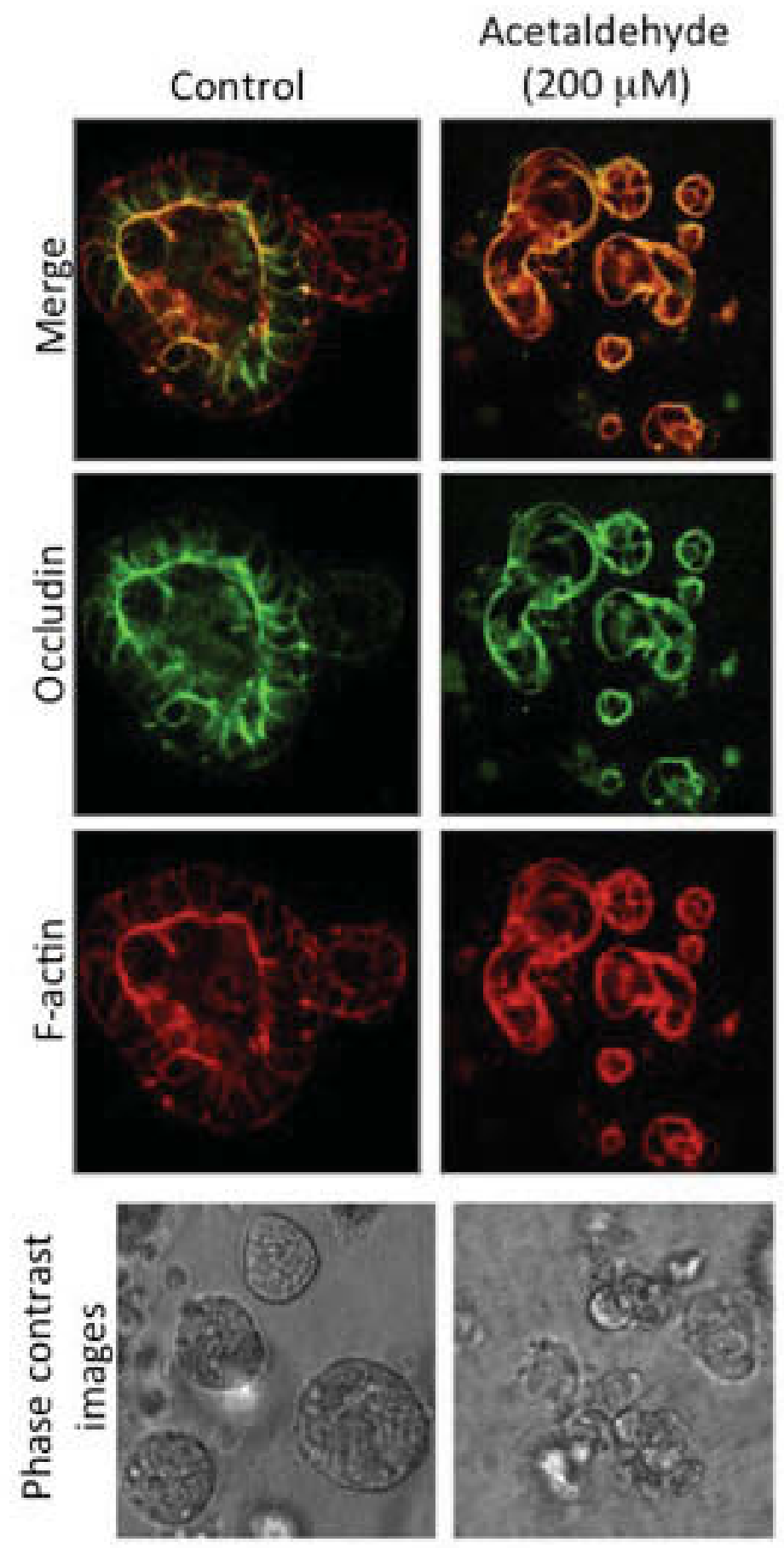

Figure 3-17. Effects of Acetaldehyde at High Concentration on Growth in Matrigel

Cells exposed to $200 \mu \mathrm{M}$ acetaldehyde for one hour, daily, are compared to control cells. Phase contrast of cells at day 12 post-seeding is displayed with immunostaining for occludin and ZO-1. 
(Figure 3-18A). Localization of occludin and ZO-1 were also affected (Figure 3-18B). This study suggests that PP2A activity may play a role in acetaldehyde-induced attenuation of epithelial differentiation 
Figure 3-18. Cells Exposed to Reduced Acetaldehyde Concentrations in the Presence or Absence of Fostriecin

Cells were exposed to $25 \mu \mathrm{M}$ acetaldehyde with or without pretreatment for one hour with $50 \mathrm{nM}$ fostriecin. A. Phase contrast images are shown at day 12. B. Cells were fixed and stained for occludin and ZO-1. 
A

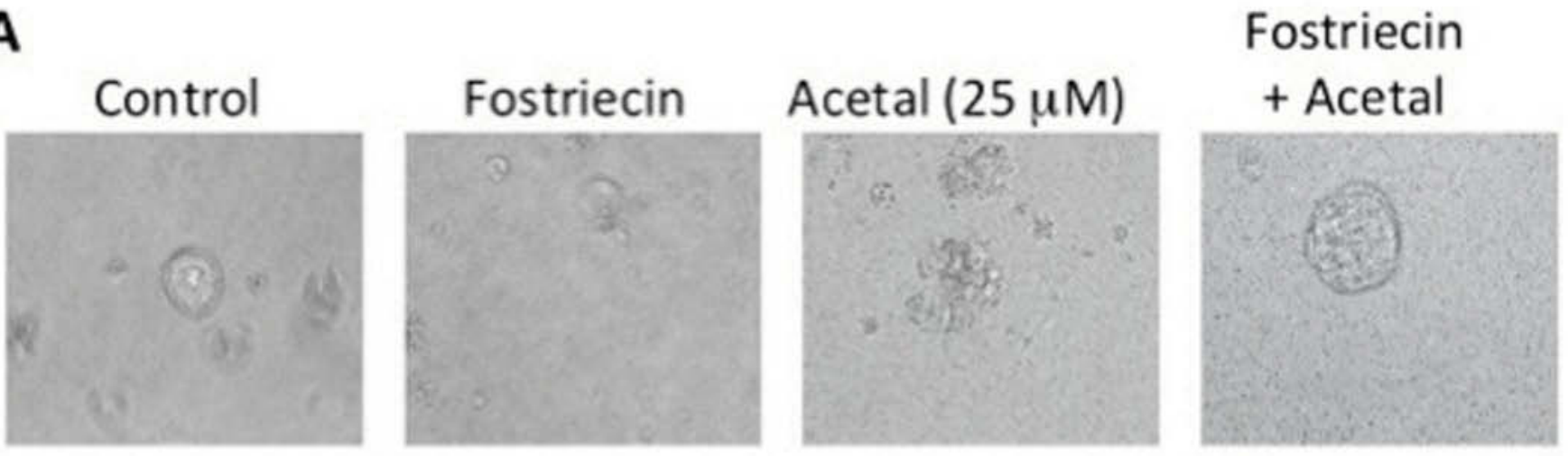

B

Control

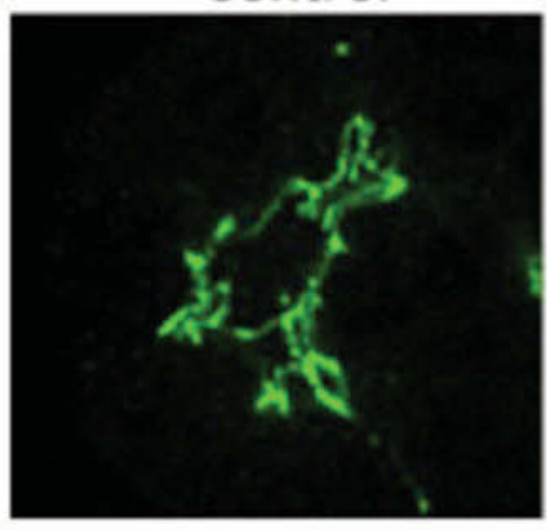

Acetaldehyde

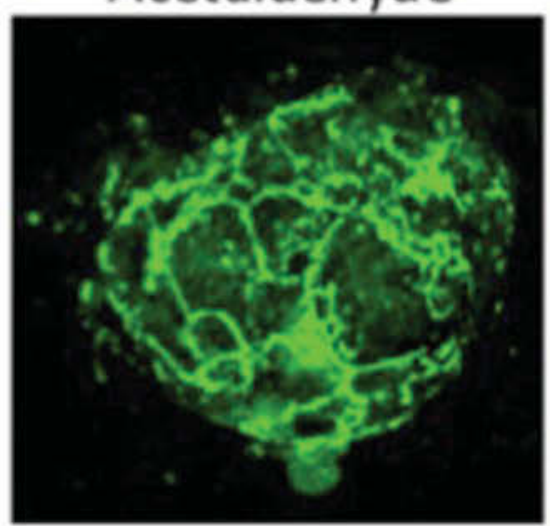

Fostriecin + Acetal

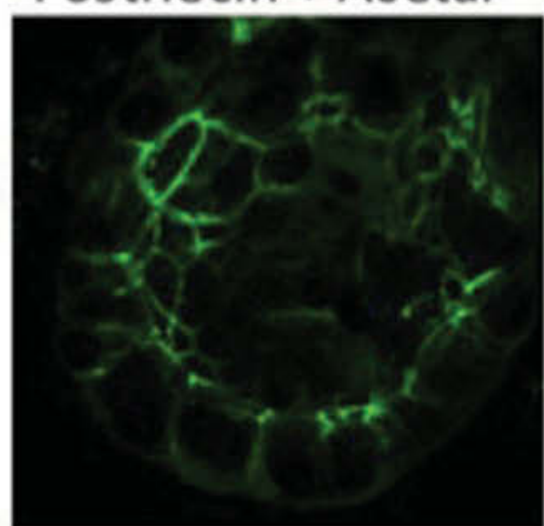




\section{CHAPTER 4. DISCUSSION}

\section{Acetaldehyde Disrupts Apical Junctional Complexes and Barrier Function in Intestinal Epithelium by a PP2A-dependent Mechanism}

Acetaldehyde, the most toxic product of ethanol metabolism, is involved in tissue injury in several organ systems. Although acetaldehyde is well known to disrupt intestinal epithelial tight junctions and increase paracellular permeability (Rao 1998; Atkinson and Rao 2001; Rao 2008), the mechanism involved in this process of tight junction disruption is poorly understood. Understanding the mechanism is important because junctional-complex disruption contributes to liver disease in alcoholics, with remediation by glutamine administration (Rao, Seth, and Sheth 2004), and is suspected to contribute to the increased risk of aerodigestive cancers in alcoholics (Salaspuro 2009).

Our present studies show that concentrations of acetaldehyde used in our laboratory disrupt tight junctions, but do not cause cell lysis in the time course used. LDH assay indicated no more lactate dehydrogenase release in cells treated for five hours at three of our highest concentrations than in controls. However, tight junctions and adherens junctions were disrupted as indicated by FITC-inulin flux, TER, and the redistribution of tight and adherens junction molecules as seen by immunostaining and confocal microscopy. These results correlate with those obtained in earlier published work from our laboratory and others (Rao 2008; Fisher, Swaan, and Eddington 2010)

Inhibiting the serine/threonine dephosphorylation of tight and adherens junction proteins may help to protect the tight junctions. PP2A is known to interact with tight and adherens junction proteins to dephosphorylate them (Seth et al. 2007; Nita-Lazar et al. 2010), so inhibition of PP2A was investigated in the context of acetaldehyde-induced junctional complex disruption by three methods: pharmacological inhibition with fostriecin, peptide inhibition with TPDYFL, and siRNA knockdown.

Fostriecin is a selective inhibitor of PP2A activity (Swingle, Ni, and Honkanen 2007). Our present study shows that pretreatment of Caco-2 cell monolayers with fostriecin significantly lessens acetaldehyde-induced barrier dysfunction, as indicated by TER and FITC-inulin flux. Attenuation of acetaldehyde-induced redistribution of occludin, ZO-1, E-cadherin and $\beta$-catenin by fostriecin indicates that inhibiting PP2A keeps apical junctional complexes intact in the presence of acetaldehyde.

The adherens junction is not a physical barrier to macromolecular transport across the epithelium. However, it is known to indirectly regulate the integrity of tight junctions, and therefore influence the barrier function. Previous studies indicated that redistribution of e-cadherin and $\beta$-catenin plays a crucial role in acetaldehyde-induced barrier dysfunction in Caco-2 cell monolayers (Sheth et al. 2007). The current study indicates that the redistribution of e-cadherin and beta-catenin may be PP2A-dependent.

Because fostriecin inhibits PP4 and PP6 as well as PP2A, a non-cytotoxic, specific inhibitor of PP2A was sought. The TPDYFL peptide, from a universally 
conserved motif at the c-terminal end of the catalytic subunit, met this need. After determination and optimization of an appropriate delivery method, experiments to clarify the role of PP2A and confirm the fostriecin data commenced. These studies were conducted to seek insight into the mechanism of acetaldehyde-induced PP2A translocation. Sub-cellular translocation of PP2A is known to be regulated by posttranslational modification at the C-terminal sequence TPDYFL (Ogris, Gibson, and Pallas 1997; Bryant, Westphal, and Wadzinski 1999; Gentry et al. 2005). Previous studies demonstrated that a synthetic peptide with this sequence altered PP2A translocation and activity in cardiac myocytes (Deshmukh, Blunt, and Hofmann 2007). Our study demonstrated that TPDYFL prevented acetaldehyde-induced tight junction disruption and barrier dysfunction, as indicated by attenuation of FITC-inulin flux in the presence of acetaldehyde and confirmed by immunofluorescence microscopy. These results confirmed co-immunoprecipitation and PP2A activity data from the fostriecin studies, indicating that PP2A translocation is an essential step in the mechanism of acetaldehyde-induced tight junction disruption. Details of this mechanism remain to be investigated.

Previous studies showed that overexpression of PP2A disrupted tight junction integrity in MDCK cells (Nunbhakdi-Craig et al. 2003). Disruption of tight junctions by calcium depletion involved increased association of PP2A with the tight junction protein complex, and calcium-mediated reassembly of tight junctions was associated with dissociation of PP2A from tight junctions in Caco-2 cell monolayers (Seth et al. 2007). Inhibition of PP2A activity or knockdown of PP2A-C $\alpha$ resulted in acceleration of calcium-induced tight junction assembly (Seth et al. 2007). Furthermore, PP2A activity was found to be involved in hydrogen peroxide-mediated disruption of tight junctions in Caco-2 cell monolayers (Sheth et al. 2009). These previous studies led us to believe that PP2A involvement in the acetaldehyde-induced disruption of tight junctions could be productively investigated by PP2A knockdown with siRNA.

PP2A knockdown, however, is not without its disadvantages. Appropriate expression of the A (scaffolding) subunit is critical for survival, and knocking it down significantly, even in an inducible manner, causes cell death by apoptosis and necrosis (Strack, Cribbs, and Gomez 2004). Suppression of the PP2A C $\alpha$ subunit by more than $50 \%$ causes apoptosis and poor proliferation (Sablina et al. 2010). Suppression of the B56y subunit recapitulates some, but not all, of the transforming features of the SV-40 small $\mathrm{T}$ antigen. PP2A suppression by siRNA must be used with caution, especially when cell viability is important.

The role of PP2A in acetaldehyde-induced tight junction regulation was confirmed by knockdown of PP2A using PP2A-C $\alpha$-specific siRNA. Though PP2A was only knocked down by $20-25 \%$ in our experiments, knockdown of PP2A dampened the effects of acetaldehyde on inulin permeability. It attenuated redistribution of occludin and ZO-1 from the intercellular junctions. Our present study demonstrates by multiple methods that PP2A is involved in acetaldehyde-induced disruption of tight junctions. However, we do not know important details about PP2A in the context of the tight junction. We do not know which B-regulatory subunits are involved in PP2A 
translocation to the tight junctions. Initial attempts to determine which B-regulatory subunits of PP2A were involved in acetaldehyde-mediated tight junction disruption were unsuccessful due to transfection problems with shRNA constructs. Trying again with different constructs or a more tractable cell line may result in more detailed knowledge about the specific PP2A B-regulatory subunits involved.

To establish the physiological relevance of the role of PP2A in tight junction regulation in the presence of acetaldehyde, we determined the effect of acetaldehyde and fostriecin on tight junction integrity in mouse intestine. Acetaldehyde induced redistribution of occludin and ZO-1 from the intercellular junctions of epithelial monolayers in mouse ileum incubated ex vivo with acetaldehyde, indicating that acetaldehyde disrupts tight junctions in mouse intestinal epithelium. The presence of occludin and ZO-1 at the tight junctions in mouse ileum treated with fostriecin demonstrated that acetaldehyde-induced tight junction disruption in mouse intestinal epithelium is also mediated by PP2A activity. Because lack of PP2A causes cell death, and overexpression of PP2A also causes severe problems, genetic study of the role of PP2A in acetaldehyde-induced disruption of intestinal epithelial junctions in vivo in mice would probably be difficult. The inhibitors could offer a way around the problem, but dosing would have to be carefully optimized to minimize morbidity.

\section{Acetaldehyde Dephosphorylates Occludin on Thr Residues by a PP2A-dependent Mechanism}

A significant body of evidence indicates that tight junctions are regulated by protein phosphorylation. Occludin is phosphorylated on serine and threonine residues, and this phosphorylation is regulated by protein kinases such as c-Src, c-Yes, PKC $\eta$, PKC $\zeta$ and CK (Suzuki et al. 2009; Jain et al. 2011) and protein phosphatases such as PTP1B, PP1 and PP2A (Seth et al. 2007; Sheth et al. 2007; Sheth et al. 2009).

Previous studies showed that PP2A binds to the C-terminal domain of occludin (Seth et al. 2007; Sheth et al. 2009). Our co-immunoprecipitation studies demonstrated that acetaldehyde increased the association of PP2A with occludin, indicating an enhanced interaction of PP2A with the tight junction protein complex. PP2A activity associated with occludin also increased on approximately the same time scale. Therefore, it is likely that acetaldehyde enhances the direct interaction between occludin and PP2A, enhancing PP2A's ability to dephosphorylate occludin and perhaps other proteins in the tight junction complex. How this interaction is enhanced is currently unknown.

Our data show that acetaldehyde induces a rapid dephosphorylation of occludin and other tight junction proteins on threonine residues. The occludin dephosphorylation was effectively blocked by fostriecin, indicating that PP2A played a role in this effect of acetaldehyde. The peptide TPDYFL also blocked dephosphorylation in the presence of acetaldehyde, confirming the data from the fostriecin studies. PP2A translocation and interaction with tight junction proteins is important for dysregulation in the presence of acetaldehyde. 
The best-known means of PP2A activation and regulation are methylation of the carboxy-terminal leucine of the C-subunit, and phosphorylation of Y307 (Ogris, Gibson, and Pallas 1997). These interactions enable specific B-regulatory subunits to bind to the A-C trimer, determining substrate specificity and subcellular localization. Previous studies demonstrated that tyrosine kinase activity is involved in acetaldehyde-induced tight junction disruption (Atkinson and Rao 2001). In the present study, the prevention of occludin dephosphorylation on threonine by genistein indicates that tyrosine kinase activity does play a role in acetaldehyde-induced PP2A translocation. According to previous studies, phosphorylation of PP2A on Y307 negatively regulates its interaction with the B-subunit (Ogris, Gibson, and Pallas 1997). Y307E mutation of PP2A Csubunit leads to loss of its interaction with the B-subunit and alters its substrate specificity. Therefore, we speculate that tyrosine kinase activity and tyrosine phosphorylation of PP2A may increase its affinity for occludin via binding of a Bregulatory subunit, causing dephosphorylation of occludin on threonine residues. Our study also shows that acetaldehyde induces dephosphorylation of claudin-5 on threonine residues. However, genistein failed to prevent this dephosphorylation, indicating that the mechanism of claudin-5 dephosphorylation is distinct from that of occludin dephosphorylation, and independent of the tyrosine phosphorylation of PP2A.

Prevention of acetaldehyde-induced tight junction disruption by TPDYFL suggested that the acetaldehyde-induced PP2A translocation may be mediated by tyrosine phosphorylation or carboxy-methylation. Methylation of L309 may be required for the interaction of PP2A C-subunit with the B-subunit (Bryant, Westphal, and Wadzinski 1999). Our studies show that methylated PP2A is present in the untreated Caco-2 cells, but acetaldehyde failed to alter the level of methyl-PP2A. This failure indicates that methylation is not involved in the mechanism of acetaldehyde-induced PP2A translocation, occludin dephosphorylation or tight junction disruption.

Further studies in this area are needed to determine how acetaldehyde activates tyrosine kinase activity. Whether the actions of acetaldehyde are due to adduct formation or activation of signaling pathways in the cell is unknown. Measurement of changes in mass of occludin, claudins, PP2A, and other tight junction proteins could be used to determine whether acetaldehyde causes direct adduct formation with these proteins. Electrophoretic separation of proteins in a two-dimensional gel could be used to detect changes in protein mass with acetaldehyde treatment. Mass spectrometry of isolated proteins could be used to confirm changes found.

\section{Acetaldehyde Inhibits Cell Migration by a Mechanism That Does Not Involve PP2A}

Earlier studies have shown that chronic acetaldehyde treatment alters the proliferation, adhesion, and differentiation properties of Caco-2 cells (Koivisto and Salaspuro 1998). In the presence of low, non-cytotoxic levels of acetaldehyde (less than 1 $\mathrm{mM}$ ) for up to 5 weeks, proliferation slowed, but continued to occur at half the pace of untreated cells. Adhesion to collagens I and IV was altered, so that cells exposed to $1 \mathrm{mM}$ acetaldehyde could not be passaged due to low adhesion rates. Production of sucrase was 
altered, indicating problems with differentiation (Koivisto and Salaspuro 1998). These studies suggested that acetaldehyde alters a variety of characteristics of Caco-2 cells, which could be further investigated in our laboratory. With decreased differentiation and altered cell-cell contact, we expected acetaldehyde to promote cell migration in a manner that would be dependent on PP2A activity for the weakening of tight junctions. Previous studies in migrating cells exposed to hydrogen peroxide had indicated accelerated migration, so we expected faster migration with acetaldehyde exposure (Basuroy et al. 2010).

Two types of cell migration assays were attempted: scratch wounding and transmigration. Transmigration did not work (data not shown) because the Caco-2 cells did not pass through the 8-micron pores of a permeable filter upon acetaldehyde stimulation. Caco-2 cells are used as a monolayer through which immune cells pass in models of gastrointestinal immune function (Rescigno et al. 2001). They are also used as a model for the invasion of Candida albicans by intra- and intercellular migration (Weide and Ernst 1999). Other types of cells can migrate through membranes with a confluent monolayer of Caco- 2 cells, but the Caco- 2 cells themselves do not move. The transmigration model was attempted, but Caco- 2 cells do not migrate across membranes upon acetaldehyde stimulation, even when freshly-seeded, immature cells are used.

Scratch-wounding assays were attempted using a variety of methods. Scratchwounding assays involving a razor blade and scratching away a large cell surface resulted in reproducibility issues due to scratching of the underlying plastic. A subsequent trial of creating holes by various methods from the literature (small linear scratch, small circular scratch, acid, suction) resulted in the selection of the small round hole cut with a micropipette tip, a method previously used in several papers (Lotz, Rabinovitz, and Mercurio 2000; Farooqui and Fenteany 2005). Due to cohesion of cells, the linear scratch model most commonly in use resulted in ripping of the monolayer, with jagged wound edges. Acid and suction resulted in large holes. The small, round hole technique was not perfect, as compressed cells could block migration, but it was more reproducible than other techniques.

Several experiments using small round holes were conducted. Repeated experiments clearly demonstrated that acetaldehyde at very low $(3 \mu \mathrm{M})$ and high doses $(100 \mu \mathrm{M})$ inhibited cell migration instead of promoting it, with mid-range doses comparable to the migration of controls at time points less than twelve hours postwounding. Caco-2 cells may be acting as a "normal" epithelium under our current culture conditions, in which case our migration assay models wound healing. Acetaldehyde would inhibit wound healing in this case.

Immature monolayers of Caco- 2 cells capable of migration seem to detach from the underlying substrate rather easily. Acetaldehyde is known to alter the adhesion of epithelial cells to underlying substrate in a dose-dependent manner (Koivisto and Salaspuro 1998). This complicates the study of the effects of acetaldehyde on cell migration. The mature monolayers used for other experiments can be exposed to higher concentrations of acetaldehyde without detachment, but they do not migrate. For further 
studies, consideration of very low-concentration acetaldehyde for prolonged chronic use might be appropriate.

The current results are relevant in the context of wound healing in alcoholics. Alcoholics are well known for suffering a variety of surgical risks including delayed wound healing and increased risk of infection (Tønnesen 1999). Acetaldehyde has been shown in our experiments to cause PP2A-independent delays in wound healing, even in an acute-exposure context. With the rise of binge drinking as an important phenomenon among young people and a common cause of behavior-related trauma, understanding the slowed wound healing caused by excessive alcohol consumption and subsequent acetaldehyde exposure is important to optimize approaches to healing in inebriated patients.

\section{Acetaldehyde Alters Morphology of Cells Grown in Matrigel in a Dose-dependent Manner}

Growth of cells in Matrigel or collagen with added growth factors has become a popular method to explore how cells grow and differentiate in a three-dimensional matrix of extracellular proteins similar to those to which they would attach in vivo (Debnath and Brugge 2005). It is used to model growth of cancer cells into tumors (Gudjonsson et al. 2003) and to explore tubulogenesis in renal tubule cells (Pollack, Runyan, and Mostov 1998). It has been used previously in Caco-2 cells to explore the role of integrins in differentiation (Zhang et al. 2003), with differentiation in this context defined as formation of a hollow spheroid of polarized cells, with the apical surfaces toward the interior lumen. We expected that acetaldehyde exposure would disrupt this process by disrupting the "fence" role of the tight junction in separating apical and basolateral populations of membrane proteins.

Attempts to isolate cells after growth in Matrigel for further biochemical analysis were unsuccessful despite use of techniques and buffers found to be productive in multiple other cell lines. The end of the isolation procedure yielded no detectable protein. All cells were lost. No Western blotting for changes in keratins or vimentin was possible.

In short, we know that PP2A influences the process of cell differentiation in the presence of acetaldehyde in a manner we believe to be dose-dependent. However, the difficulties encountered using the techniques required for these studies in the context of our cell line, facilities, and the respiratory sensitization effect of acetaldehyde preclude any conclusive statements or journal publications based on the data at this time.

\section{Summary}

In conclusion, this series of studies adds to the evidence that acetaldehyde exposure affects the basic functions of intestinal epithelial cells in vitro and in vivo in a dose-dependent manner. The negative effects on tight junction maintenance clearly 
involve threonine dephosphorylation of occludin and other tight junction proteins via PP2A, as indicated by the rescue of tight junction localization of occludin in the presence of acetaldehyde by pharmacological inhibition, peptide inhibition, and siRNA. Ex-vivo studies of intact ileum confirm these findings. Migration studies show PP2A-independent inhibition of migration in the presence of acetaldehyde. Differentiation studies remain inconclusive until detailed biochemical analyses can be completed. PP2A affects a variety of cell signaling pathways, and acetaldehyde reacts with a variety of cell constituents. Their juxtaposition is a challenging study. 


\section{LIST OF REFERENCES}

Aijaz S, MS Balda, and K Matter. 2006. "Tight Junctions: Molecular Architecture and Function.” International Review of Cytology 248: 261-98.

Akhter M, S Kuriyama, N Nakaya, T Shimazu, K Ohmori, Y Nishino, Y Tsubono, A Fukao, and I Tsuji. 2007. "Alcohol Consumption Is Associated with an Increased Risk of Distal Colon and Rectal Cancer in Japanese Men: The Miyagi Cohort Study." European Journal of Cancer (Oxford, England: 1990) 43 (2) (January): 383-90.

Anderson JM, and CM Van Itallie. 2009. "Physiology and Function of the Tight Junction." Cold Spring Harbor Perspectives in Biology 1 (2) (August 1).

Andreeva AY, E Krause, EC Müller, IE Blasig, and DI Utepbergenov. 2001. "Protein Kinase C Regulates the Phosphorylation and Cellular Localization of Occludin." The Journal of Biological Chemistry 276 (42) (October 19): 38480-38486.

Andreeva AY, J Piontek, IE Blasig, and DI Utepbergenov. 2006. "Assembly of Tight Junction Is Regulated by the Antagonism of Conventional and Novel Protein Kinase C Isoforms." The International Journal of Biochemistry \& Cell Biology 38 (2) (February): 222-233.

Argenzio RA, CK Henrikson, and JA Liacos. 1988. "Restitution of Barrier and Transport Function of Porcine Colon After Acute Mucosal Injury." The American Journal of Physiology 255 (1 Pt 1) (July): G62-G71.

Arroyo JD, and WC Hahn. 2005. "Involvement of PP2A in Viral and Cellular Transformation." Oncogene 24 (52): 7746-7755.

Atkinson KJ, and RK Rao. 2001. "Role of Protein Tyrosine Phosphorylation in Acetaldehyde-induced Disruption of Epithelial Tight Junctions." American Journal of Physiology. Gastrointestinal and Liver Physiology 280 (6) (June): G1280-G1288.

Balda MS, JA Whitney, C Flores, S González, M Cereijido, and K Matter. 1996. "Functional Dissociation of Paracellular Permeability and Transepithelial Electrical Resistance and Disruption of the Apical-basolateral Intramembrane Diffusion Barrier by Expression of a Mutant Tight Junction Membrane Protein." The Journal of Cell Biology 134 (4) (August): 1031-1049.

Basuroy S, M Dunagan, P Sheth, A Seth, and RK Rao. 2010. "Hydrogen Peroxide Activates Focal Adhesion Kinase and c-Src by a PI 3-Kinase-Dependent Mechanism and Promotes Cell Migration in Caco-2 Cell Monolayers." American Journal of Physiology. Gastrointestinal and Liver Physiology 299(1) (July): G186-195. 
Behrens I, and T Kissel. 2003. "Do Cell Culture Conditions Influence the Carriermediated Transport of Peptides in Caco-2 Cell Monolayers?" European Journal of Pharmaceutical Sciences 19 (5) (August): 433-442.

Best CA, and M Laposata. 2003. "Fatty Acid Ethyl Esters: Toxic Non-oxidative Metabolites of Ethanol and Markers of Ethanol Intake." Frontiers in Bioscience: A Journal and Virtual Library 8 (January 1): e202-217.

Biewald J, R Nilius, and J Langner. 1998. “Occurrence of Acetaldehyde Protein Adducts Formed in Various Organs of Chronically Ethanol Fed Rats: An Immunohistochemical Study." International Journal of Molecular Medicine 2 (4): 389-396.

Bindschadler M, and JL McGrath. 2007. "Sheet Migration by Wounded Monolayers as an Emergent Property of Single-cell Dynamics.” Journal of Cell Science 120 (Pt 5) (March 1): 876-884.

Boffetta P, P Kaihovaara, P Rudnai, A Znaor, J Lissowska, B Swiatkowska, D Mates, T Pandics, and M Salaspuro. 2011. "Acetaldehyde Level in Spirits from Central European Countries." European Journal of Cancer Prevention: The Official Journal of the European Cancer Prevention Organisation (ECP) 20 (6) (November): 526-529.

Bonnet R. 1895. “Ober Die 'Schlussleisten Der Epithelien'.” Deutsche Medizinische Wochenschrift 21: 58-73.

Bootorabi F, J Jänis, J Valjakka, S Isoniemi, P Vainiotalo, D Vullo, CT Supuran, et al. 2008. "Modification of Carbonic Anhydrase II with Acetaldehyde, the First Metabolite of Ethanol, Leads to Decreased Enzyme Activity." BMC Biochemistry 9: 32.

Brecher AS, K Hellman, and M H Basista. 1997. "A Perspective on Acetaldehyde Concentrations and Toxicity in Man and Animals." Alcohol (Fayetteville, N.Y.) 14 (5) (October): 493-496.

Briske-Anderson MJ, JW Finley, and SM Newman. 1997. "The Influence of Culture Time and Passage Number on the Morphological and Physiological Development of Caco-2 Cells." Proceedings of the Society for Experimental Biology and Medicine. Society for Experimental Biology and Medicine (New York, N.Y.) 214 (3) (March): 248257.

Bryant JC, RS Westphal, and BE Wadzinski. 1999. "Methylated C-terminal Leucine Residue of PP2A Catalytic Subunit Is Important for Binding of Regulatory Balpha Subunit." The Biochemical Journal 339 ( Pt 2) (April 15): 241-246.

Caldwell GM, CE Jones, Y Soon, R Warrack, DG Morton, and GM Matthews. 2008. "Reorganisation of Wnt-response Pathways in Colorectal Tumorigenesis." British Journal of Cancer 98 (8) (April 22): 1437-1442. 
Chen, Y, C Merzdorf, D L Paul, and D A Goodenough. 1997. "COOH Terminus of Occludin Is Required for Tight Junction Barrier Function in Early Xenopus Embryos." The Journal of Cell Biology 138 (4) (August 25): 891-899.

Chiang CP, SW Jao, SP Lee, PC Chen, CC Chung, SL Lee, S Nieh, and SJ Yin. 2012. "Expression Pattern, Ethanol-metabolizing Activities, and Cellular Localization of Alcohol and Aldehyde Dehydrogenases in Human Large Bowel: Association of the Functional Polymorphisms of ADH and ALDH Genes with Hemorrhoids and Colorectal Cancer." Alcohol (Fayetteville, N.Y.) 46(1) (February): 37-49.

Cho CH, and V Purohit. 2006. Alcohol, Tobacco, and Cancer. 1st ed. S. Karger AG (Switzerland).

Cho US, and W Xu. 2007. "Crystal Structure of a Protein Phosphatase 2A Heterotrimeric Holoenzyme.” Nature 445 (7123) (January 4): 53-57.

Claude P. 1978. "Morphological Factors Influencing Transepithelial Permeability: a Model for the Resistance of the Zonula Occludens." The Journal of Membrane Biology 39 (2-3) (March 10): 219-232.

Colegio OR, CM Van Itallie, HJ McCrea, C Rahner, and JM Anderson. 2002. "Claudins Create Charge-selective Channels in the Paracellular Pathway Between Epithelial Cells." American Journal of Physiology. Cell Physiology 283 (1) (July): C142-C147.

Comporti M, C Signorini, S Leoncini, C Gardi, L Ciccoli, A Giardini, D Vecchio, and B Arezzini. 2010. "Ethanol-induced Oxidative Stress: Basic Knowledge." Genes \& Nutrition 5 (2) (June): 101-109.

Debnath J, and JS Brugge. 2005. "Modelling Glandular Epithelial Cancers in Threedimensional Cultures." Nature Reviews. Cancer 5 (9) (September): 675-688.

Debnath J, SK Muthuswamy, and JS Brugge. 2003. "Morphogenesis and Oncogenesis of MCF-10A Mammary Epithelial Acini Grown in Three-dimensional Basement Membrane Cultures." Methods (San Diego, Calif.) 30 (3) (July): 256-268.

Decaestecker C, O Debeir, P Van Ham, and R Kiss. 2007. "Can Anti-migratory Drugs Be Screened in Vitro? A Review of 2D and 3D Assays for the Quantitative Analysis of Cell Migration." Medicinal Research Reviews 27 (2) (March 1): 149-176.

Deshmukh PA, BC Blunt, and PA Hofmann. 2007. "Acute Modulation of PP2A and Troponin I Phosphorylation in Ventricular Myocytes: Studies with a Novel PP2A Peptide Inhibitor." American Journal of Physiology. Heart and Circulatory Physiology 292 (2) (February): H792-799. 
van den Donk M, M van Engeland, L Pellis, BJM Witteman, FJ Kok, J Keijer, and E Kampman. 2007. "Dietary Folate Intake in Combination with MTHFR C677T Genotype and Promoter Methylation of Tumor Suppressor and DNA Repair Genes in Sporadic Colorectal Adenomas." Cancer Epidemiology, Biomarkers \& Prevention: A Publication of the American Association for Cancer Research, Cosponsored by the American Society of Preventive Oncology 16 (2) (February): 327-333.

Edenberg HJ. 2007. "The Genetics of Alcohol Metabolism: Role of Alcohol Dehydrogenase and Aldehyde Dehydrogenase Variants." Alcohol Research \& Health: The Journal of the National Institute on Alcohol Abuse and Alcoholism 30 (1): 5-13.

Eng MY, SE Luczak, and TL Wall. 2007. "ALDH2, ADH1B, and ADH1C Genotypes in Asians: a Literature Review." Alcohol Research \& Health: The Journal of the National Institute on Alcohol Abuse and Alcoholism 30 (1): 22-27.

Entschladen F, TL Drell IV, K Lang, K Masur, D Palm, P Bastian, B Niggemann, and KS Zaenker. 2005. "Analysis Methods of Human Cell Migration." Experimental Cell Research 307 (2) (July 15): 418-426.

Fanning AS, BJ Jameson, LA Jesaitis, and JM Anderson. 1998. "The Tight Junction Protein ZO-1 Establishes a Link Between the Transmembrane Protein Occludin and the Actin Cytoskeleton." The Journal of Biological Chemistry 273 (45) (November 6): 29745-29753.

Farooqui R, and G Fenteany. 2005. "Multiple Rows of Cells Behind an Epithelial Wound Edge Extend Cryptic Lamellipodia to Collectively Drive Cell-sheet Movement." The Journal of Cell Science 118 (1) (January 1): 51-63.

Farquhar MG, and GE Palade. 1963. "Junctional Complexes in Various Epithelia." The Journal of Cell Biology 17 (2) (May 1): 375 -412.

Farshori P, and B Kachar. 1999. "Redistribution and Phosphorylation of Occludin During Opening and Resealing of Tight Junctions in Cultured Epithelial Cells." The Journal of Membrane Biology 170 (2) (July 15): 147-156.

Fathi AR, A Krautheim, S Lucke, K Becker, and HJ Steinfelder. 2002. "Nonradioactive Technique to Measure Protein Phosphatase 2A-like Activity and Its Inhibition by Drugs in Cell Extracts." Analytical Biochemistry 310 (2) (November 15): 208-214.

Feldman GJ, JM Mullin, and MP Ryan. 2005. "Occludin: Structure, Function and Regulation.” Advanced Drug Delivery Reviews 57 (6) (April 25): 883-917.

Fewell GD, and K Schmitt. 2006. "Vector-based RNAi Approaches for Stable, Inducible and Genome-wide Screens.” Drug Discovery Today 11 (21-22) (November): 975-982. 
Fisher SJ, PW Swaan, and ND Eddington. 2010. "The Ethanol Metabolite Acetaldehyde Increases Paracellular Drug Permeability In Vitro and Oral Bioavailability In Vivo." Journal of Pharmacology and Experimental Therapeutics 332 (1) (January 1): 326 -333.

Fodde R, and T Brabletz. 2007. "Wnt/[beta]-catenin Signaling in Cancer Stemness and Malignant Behavior." Current Opinion in Cell Biology 19 (2) (April): 150-158.

Fogh J. 1975. Human Tumor Cells in Vitro / Edited by Jorgen Fogh. New York :: Plenum Press.

Frohlich JJ. 1996. "Effects of Alcohol on Plasma Lipoprotein Metabolism." Clinica Chimica Acta; International Journal of Clinical Chemistry 246 (1-2) (March 15): 39-49.

Furuse M, K Fujita, T Hiiragi, K Fujimoto, and S Tsukita. 1998. "Claudin-1 and -2: Novel Integral Membrane Proteins Localizing at Tight Junctions with No Sequence Similarity to Occludin." The Journal of Cell Biology 141 (7) (June 29): 1539-1550.

Furuse, M, T Hirase, M Itoh, A Nagafuchi, S Yonemura, S Tsukita, and S Tsukita. 1993. "Occludin: a Novel Integral Membrane Protein Localizing at Tight Junctions." The Journal of Cell Biology 123 (6 Pt 2) (December): 1777-1788.

Furuse, M, M Itoh, T Hirase, A Nagafuchi, S Yonemura, S Tsukita, and S Tsukita. 1994. "Direct Association of Occludin with ZO-1 and Its Possible Involvement in the Localization of Occludin at Tight Junctions.” The Journal of Cell Biology 127 (6 Pt 1) (December): 1617-1626.

Gao CM, T Takezaki, JZ Wu, XM Zhang, HX Cao, JH Ding, YT Liu, et al. 2008. "Polymorphisms of Alcohol Dehydrogenase 2 and Aldehyde Dehydrogenase 2 and Colorectal Cancer Risk in Chinese Males." World Journal of Gastroenterology: WJG 14 (32) (August 28): 5078-5083.

Gentry MS, Y Li, H Wei, FF Syed, SH Patel, RL Hallberg, and DC Pallas. 2005. “A Novel Assay for Protein Phosphatase 2A (PP2A) Complexes in Vivo Reveals Differential Effects of Covalent Modifications on Different Saccharomyces Cerevisiae PP2A Heterotrimers." Eukaryotic Cell 4 (6) (June): 1029-1040.

Ghandehari H, PL Smith, H Ellens, PY Yeh, and J Kopecek. 1997. "Size-dependent Permeability of Hydrophilic Probes Across Rabbit Colonic Epithelium." The Journal of Pharmacology and Experimental Therapeutics 280 (2) (February): 747-753.

Gonzalez FJ. 2005. "Role of Cytochromes P450 in Chemical Toxicity and Oxidative Stress: Studies with CYP2E1." Mutation Research/Fundamental and Molecular Mechanisms of Mutagenesis 569 (1-2) (January 6): 101-110. 
González-Mariscal L, E Garay, and M Quirós. 2010. "Chapter 6 - Regulation of Claudins by Posttranslational Modifications and Cell-Signaling Cascades." In Current Topics in Membranes, Volume 65:113-150. Academic Press.

González-Mariscal L, R Tapia, and D Chamorro. 2008. “Crosstalk of Tight Junction Components with Signaling Pathways." Biochimica Et Biophysica Acta 1778 (3) (March): 729-756.

Götz J, A Probst, E Ehler, B Hemmings, and W Kues. 1998. "Delayed Embryonic Lethality in Mice Lacking Protein Phosphatase 2A Catalytic Subunit Ca." Proceedings of the National Academy of Sciences 95 (21) (October 13): 12370 -12375.

Grafström RC, JM Dypbukt, K Sundqvist, L Atzori, I Nielsen, RD Curren, and C C Harris. 1994. "Pathobiological Effects of Acetaldehyde in Cultured Human Epithelial Cells and Fibroblasts." Carcinogenesis 15 (5) (May 1): 985 -990.

Grazi E, H Meloche, G Martinez, WA Wood, and BL Horecker. 1963. "Evidence for Schiff Base Formation in Enzymatic Aldol Condensations." Biochemical and Biophysical Research Communications 10 (1) (January 18): 4-10.

Gros E, S Deshayes, MC Morris, G Aldrian-Herrada, J Depollier, F Heitz, and G Divita. 2006. "A Non-covalent Peptide-based Strategy for Protein and Peptide Nucleic Acid Transduction.” Biochimica Et Biophysica Acta 1758 (3) (March): 384-393.

Gudjonsson T, L Rønnov-Jessen, R Villadsen, MJ Bissell, and OW Petersen. 2003. "To Create the Correct Microenvironment: Three-dimensional Heterotypic Collagen Assays for Human Breast Epithelial Morphogenesis and Neoplasia." Methods (San Diego, California) 30 (3) (July): 247-255.

Haorah J, SH Ramirez, N Floreani, S Gorantla, B Morsey, and Y Persidsky. 2008. "Mechanism of Alcohol-induced Oxidative Stress and Neuronal Injury." Free Radical Biology \& Medicine 45 (11) (December 1): 1542-1550.

Hartsock A, and WJ Nelson. 2008. "Adherens and Tight Junctions: Structure, Function and Connections to the Actin Cytoskeleton." Biochimica Et Biophysica Acta 1778 (3) (March): 660-669.

Herter P, C Kuhnen, KM Müller, A Wittinghofer, and O Müller. 1999. "Intracellular Distribution of Beta-catenin in Colorectal Adenomas, Carcinomas and Peutz-Jeghers Polyps." Journal of Cancer Research and Clinical Oncology 125 (5): 297-304.

Hidalgo IJ, TJ Raub, and RT Borchardt. 1989. "Characterization of the Human Colon Carcinoma Cell Line (Caco-2) as a Model System for Intestinal Epithelial Permeability." Gastroenterology 96 (3) (March): 736-749. 
Hirose M, S Kono, S Tabata, S Ogawa, K Yamaguchi, M Mineshita, T Hagiwara, et al. 2005. "Genetic Polymorphisms of Methylenetetrahydrofolate Reductase and Aldehyde Dehydrogenase 2, Alcohol Use and Risk of Colorectal Adenomas: Self-Defense Forces Health Study." Cancer Science 96 (8) (August): 513-8.

Homann N, J Tillonen, JH Meurman, H Rintamäki, C Lindqvist, M Rautio, H JousimiesSomer, and M Salaspuro. 2000. "Increased Salivary Acetaldehyde Levels in Heavy Drinkers and Smokers: a Microbiological Approach to Oral Cavity Cancer." Carcinogenesis 21 (4) (April): 663-668.

Hooper SJ, MJ Wilson, and SJ Crean. 2009. "Exploring the Link Between Microorganisms and Oral Cancer: A Systematic Review of the Literature." Head \& Neck 31 (9): 1228-1239.

Huo Q, T Kinugasa, L Wang, J Huang, J Zhao, H Shibaguchi, M Kuroki, et al. 2009. "Claudin-1 Protein Is a Major Factor Involved in the Tumorigenesis of Colorectal Cancer." Anticancer Research 29 (3) (March): 851-857.

IARC. 2010. Alcohol Consumption and Ethyl Carbamate. Vol. 96. Monographs on the Evaluation of Carcinogenic Risk to Humans. Lyon, France: International Agency for Research on Cancer.

Ikehara T, S Ikehara, S Imamura, F Shinjo, and T Yasumoto. 2007. "Methylation of the C-terminal Leucine Residue of the PP2A Catalytic Subunit Is Unnecessary for the Catalytic Activity and the Binding of Regulatory Subunit (PR55/B)." Biochemical and Biophysical Research Communications 354 (4) (March 23): 1052-1057.

Isse Toyohi, K Matsuno, T Oyama, K Kitagawa, and T Kawamoto. 2005. “Aldehyde Dehydrogenase 2 Gene Targeting Mouse Lacking Enzyme Activity Shows High Acetaldehyde Level in Blood, Brain, and Liver After Ethanol Gavages." Alcoholism, Clinical and Experimental Research 29 (11) (November): 1959-1964.

Van Itallie CM, and JM Anderson. 2006. "Claudins and Epithelial Paracellular Transport." Annual Review of Physiology 68: 403-429.

Van Itallie CM, S Rogan, A Yu, LS Vidal, J Holmes, and JM Anderson. 2006. "Two Splice Variants of Claudin-10 in the Kidney Create Paracellular Pores with Different Ion Selectivities." American Journal of Physiology. Renal Physiology 291 (6) (December): F1288-F1299.

Jain S, T Suzuki, A Seth, G Samak, and RK Rao. 2011. "Protein Kinase Cל Phosphorylates Occludin and Promotes Assembly of Epithelial Tight Junctions." The Biochemical Journal 437 (2) (July 15): 289-299. 
Janssens V, and J Goris. 2001. "Protein Phosphatase 2A: a Highly Regulated Family of Serine/threonine Phosphatases Implicated in Cell Growth and Signalling." The Biochemical Journal 353 (Pt 3) (February 1): 417-439.

Janssens V, S Longin, and J Goris. 2008. "PP2A Holoenzyme Assembly: In Cauda Venenum (the Sting Is in the Tail)." Trends in Biochemical Sciences 33 (3) (March): 113-121.

Jelski W, and M Szmitkowski. 2008. "Alcohol Dehydrogenase (ADH) and Aldehyde Dehydrogenase (ALDH) in the Cancer Diseases." Clinica Chimica Acta; International Journal of Clinical Chemistry 395 (1-2) (September): 1-5.

Ji C. 2012. "Mechanisms of Alcohol-induced Endoplasmic Reticulum Stress and Organ Injuries.” Biochemistry Research International 2012: 216450.

Keilin D, and E Hartree. 1945. "Properties of Catalase. Catalysis of Coupled Oxidation of Alcohols.” Biochemical Journal 39 (4): 293-301.

Kinugasa T, Y Akagi, T Yoshida, Y Ryu, I Shiratuchi, N Ishibashi, and K Shirouzu. 2010. "Increased Claudin-1 Protein Expression Contributes to Tumorigenesis in Ulcerative Colitis-associated Colorectal Cancer." Anticancer Research 30 (8) (August): 3181-3186.

Klaus A, and W Birchmeier. 2008. "Wnt Signalling and Its Impact on Development and Cancer." Nature Reviews. Cancer 8 (5) (May): 387-398.

Koivisto T, and M Salaspuro. 1998. "Acetaldehyde Alters Proliferation, Differentiation and Adhesion Properties of Human Colon Adenocarcinoma Cell Line Caco-2." Carcinogenesis 19 (11) (November): 2031-2036.

Kren L, M Hermanová, VN Goncharuk, P Kaur, JS Ross, Z Pavlovský, and K Dvorák. 2003. "Downregulation of Plasma Membrane Expression/cytoplasmic Accumulation of Beta-catenin Predicts Shortened Survival in Non-small Cell Lung Cancer. A Clinicopathologic Study of 100 Cases." Ceskoslovenská Patologie 39 (1) (January): 1720.

Krol J, I Loedige, and W Filipowicz. 2010. "The Widespread Regulation of microRNA Biogenesis, Function and Decay." Nature Reviews Genetics 11 (9): 597-610.

Kunugita N, T Isse, T Oyama, K Kitagawa, M Ogawa, T Yamaguchi, T Kinaga, and T Kawamoto. 2008. "Increased Frequencies of Micronucleated Reticulocytes and T-cell Receptor Mutation in Aldh2 Knockout Mice Exposed to Acetaldehyde." The Journal of Toxicological Sciences 33 (1) (February): 31-36. 
Lange LG, and BE Sobel. 1983. "Mitochondrial Dysfunction Induced by Fatty Acid Ethyl Esters, Myocardial Metabolites of Ethanol." Journal of Clinical Investigation 72 (2) (August): 724-731.

Laurent-Puig P, H Blons, and PH Cugnenc. 1999. "Sequence of Molecular Genetic Events in Colorectal Tumorigenesis." European Journal of Cancer Prevention: The Official Journal of the European Cancer Prevention Organisation (ECP) 8 Suppl 1 (December): S39-S47.

Lees GJ, and GR Jago. 1978. "Role of Acetaldehyde in Metabolism: A Review 1. Enzymes Catalyzing Reactions Involving Acetaldehyde.” Journal of Dairy Science 61 (9) (September 1): 1205-1215.

Legrand C, JM Bour, C Jacob, J Capiaumont, A Martial, A Marc, M Wudtke, et al. 1992. "Lactate Dehydrogenase (LDH) Activity of the Number of Dead Cells in the Medium of Cultured Eukaryotic Cells as Marker." Journal of Biotechnology 25 (3) (September): 231-243.

Li SY, SAB Gilbert, Q Li, and J Ren. 2009. “Aldehyde Dehydrogenase-2 (ALDH2) Ameliorates Chronic Alcohol Ingestion-induced Myocardial Insulin Resistance and Endoplasmic Reticulum Stress." Journal of Molecular and Cellular Cardiology 47 (2) (August): 247-255.

Li SY, and J Ren. 2008. "Cardiac Overexpression of Alcohol Dehydrogenase Exacerbates Chronic Ethanol Ingestion-induced Myocardial Dysfunction and Hypertrophy: Role of Insulin Signaling and ER Stress." Journal of Molecular and Cellular Cardiology 44 (6) (June): 992-1001.

Lieber CS. 2005. "Metabolism of Alcohol." Clinics in Liver Disease 9 (1) (February): 135 .

Lightfoot TJ, JH Barrett, T Bishop, EL Northwood, G Smith, MJV Wilkie, RJC Steele, et al. 2008. "Methylene Tetrahydrofolate Reductase Genotype Modifies the Chemopreventive Effect of Folate in Colorectal Adenoma, but Not Colorectal Cancer." Cancer Epidemiology, Biomarkers \& Prevention: A Publication of the American Association for Cancer Research, Cosponsored by the American Society of Preventive Oncology 17 (9) (August 14): 2421-2430.

Liscovitch M, M Czarny, G Fiucci, and X Tang. 2000. "Phospholipase D: Molecular and Cell Biology of a Novel Gene Family.” Biochemical Journal 345: 401-415.

Longin S, K Zwaenepoel, JV Louis, S Dilworth, J Goris, and V Janssens. 2007. "Selection of Protein Phosphatase 2A Regulatory Subunits Is Mediated by the C Terminus of the Catalytic Subunit." The Journal of Biological Chemistry 282 (37) (September 14): 26971-26980. 
Lorenti Garcia C, M Mechilli, LP De Santis, A Schinoppi, K Kobos, and F Palitti. 2009. "Relationship Between DNA Lesions, DNA Repair and Chromosomal Damage Induced by Acetaldehyde." Mutation Research 662 (1-2) (March 9): 3-9.

Lotz M, I Rabinovitz, and A Mercurio. 2000. "Intestinal Restitution: Progression of Actin Cytoskeleton Rearrangements and Integrin Function in a Model of Epithelial Wound Healing." The American Journal of Pathology 156 (3) (March): 985-996.

Luque-García JL, JL Martínez-Torrecuadrada, C Epifano, M Cañamero, I Babel, and JI Casal. 2010. "Differential Protein Expression on the Cell Surface of Colorectal Cancer Cells Associated to Tumor Metastasis." Proteomics 10 (5) (March): 940-952.

Matsuda T, A Matsumoto, M Uchida, RA Kanaly, K Misaki, S Shibutani, T Kawamoto, et al. 2007. "Increased Formation of Hepatic N2-ethylidene-2'-deoxyguanosine DNA Adducts in Aldehyde Dehydrogenase 2-knockout Mice Treated with Ethanol." Carcinogenesis 28 (11) (November): 2363-2366.

Matsuda T, H Yabushita, RA Kanaly, S Shibutani, and A Yokoyama. 2006. "Increased DNA Damage in ALDH2-deficient Alcoholics." Chemical Research in Toxicology 19 (10) (October): 1374-1378.

Matsuo K, K Wakai, K Hirose, H Ito, T Saito, T Suzuki, T Kato, et al. 2006. "A Genegene Interaction Between ALDH2 Glu487Lys and ADH2 His47Arg Polymorphisms Regarding the Risk of Colorectal Cancer in Japan." Carcinogenesis 27 (5) (May): 10181023.

Matter K, S Aijaz, A Tsapara, and MS Balda. 2005. "Mammalian Tight Junctions in the Regulation of Epithelial Differentiation and Proliferation." Current Opinion in Cell Biology 17 (5) (October): 453-458.

Mauch TJ, TM Donohue, RK Zetterman, MF Sorrell, and DJ Tuma. 1986. "Covalent Binding of Acetaldehyde Selectively Inhibits the Catalytic Activity of Lysine-dependent Enzymes." Hepatology (Baltimore, Md.) 6 (2) (April): 263-269.

Middaugh LD, BM Kelley, AE Bandy, and KK McGroarty. 1999. "Ethanol Consumption by C57BL/6 Mice: Influence of Gender and Procedural Variables." Alcohol 17 (3) (April): 175-183.

Morris MC, J Depollier, J Mery, F Heitz, and G Divita. 2001. "A Peptide Carrier for the Delivery of Biologically Active Proteins into Mammalian Cells." Nature Biotechnology 19 (12) (December): 1173-1176.

Moyes SM, JF Morris, and KE Carr. 2010. "Culture Conditions and Treatments Affect Caco-2 Characteristics and Particle Uptake." International Journal of Pharmaceutics 387 (1-2) (March 15): 7-18. 
Munck BG, and SN Rasmussen. 1977. "Paracellular Permeability of Extracellular Space Markers Across Rat Jejunum in Vitro. Indication of a Transepithelial Fluid Circuit." The Journal of Physiology 271 (2) (October): 473-488.

Niessen CM. 2007. "Tight Junctions/Adherens Junctions: Basic Structure and Function." Journal of Investigative Dermatology 127 (11) (November 1): 2525-2532.

Nita-Lazar M, I Rebustini, J Walker, and MA Kukuruzinska. 2010. "Hypoglycosylated E-cadherin Promotes the Assembly of Tight Junctions Through the Recruitment of PP2A to Adherens Junctions.” Experimental Cell Research 316 (11) (July 1): 1871-1884.

Nunbhakdi-Craig V, L Craig, T Machleidt, and E Sontag. 2003. "Simian Virus 40 Small Tumor Antigen Induces Deregulation of the Actin Cytoskeleton and Tight Junctions in Kidney Epithelial Cells.” Journal of Virology 77 (5) (March): 2807-2818.

Nunbhakdi-Craig, V, T Machleidt, E Ogris, D Bellotto, CL White, and ESontag. 2002. "Protein Phosphatase 2A Associates with and Regulates Atypical PKC and the Epithelial Tight Junction Complex." The Journal of Cell Biology 158 (5) (September 2): 967-978.

Ogris E, DM Gibson, and DC Pallas. 1997. "Protein Phosphatase 2A Subunit Assembly: The Catalytic Subunit Carboxy Terminus Is Important for Binding Cellular B Subunit but Not Polyomavirus Middle Tumor Antigen.” Oncogene 15 (December 18): 911-917.

Orellana M, E Valdés, J Fernández, and R Rodrigo. 1998. “Effects of Chronic Ethanol Consumption on Extramitochondrial Fatty Acid Oxidation and Ethanol Metabolism by Rat Kidney." General Pharmacology: The Vascular System 30 (5) (May): 719-723.

Osanai M, M Murata, N Nishikiori, H Chiba, T Kojima, and N Sawada. 2007. "Occludinmediated Premature Senescence Is a Fail-safe Mechanism Against Tumorigenesis in Breast Carcinoma Cells." Cancer Science 98 (7) (July): 1027-1034.

Paddison PJ., AA Caudy, E Bernstein, GJ Hannon, and DS Conklin. 2002. "Short Hairpin RNAs (shRNAs) Induce Sequence-specific Silencing in Mammalian Cells." Genes \& Development 16 (8) (April 15): 948-958.

Pannequin J, N Delaunay, C Darido, T Maurice, P Crespy, MA Frohman, MS. Balda, et al. 2007. "Phosphatidylethanol Accumulation Promotes Intestinal Hyperplasia by Inducing ZONAB-Mediated Cell Density Increase in Response to Chronic Ethanol Exposure.” Molecular Cancer Research 5 (11) (November 1): 1147-1157.

Paradis V, JY Scoazec, M Kollinger, A Holstege, A Moreau, G Feldmann, and P Bedossa. 1996. "Cellular and Subcellular Localization of Acetaldehyde-protein Adducts in Liver Biopsies from Alcoholic Patients.” J Histochem Cytochem 44 (9) (September 1): 1051-1057. 
Pastor R, C Sanchis-Segura, and C Aragon. 2002. "Ethanol-stimulated Behaviour in Mice Is Modulated by Brain Catalase Activity and H 2 O 2 Rate of Production."

Psychopharmacology 165 (1) (December 1): 51-59. doi:10.1007/s00213-002-1241-9.

Pednekar MS, G Sansone, and PC Gupta. 2012. "Association of Alcohol, Alcohol and Tobacco with Mortality: Findings from a Prospective Cohort Study in Mumbai (Bombay), India.” Alcohol (Fayetteville, N.Y.) 46 (2) (March): 139-146.

Petersen OH, AV Tepikin, JV Gerasimenko, OV Gerasimenko, R Sutton, and DN Criddle. 2009. "Fatty Acids, Alcohol and Fatty Acid Ethyl Esters: Toxic Ca2+ Signal Generation and Pancreatitis." Cell Calcium 45 (6) (June): 634-642.

Piedra J, D Martinez, J Castano, S Miravet, M Dunach, and AG de Herreros. 2001. "Regulation of Beta-catenin Structure and Activity by Tyrosine Phosphorylation." The Journal of Biological Chemistry 276 (23) (June 8): 20436-20443. doi:10.1074/jbc.M100194200.

Polette M, M Mestdagt, S Bindels, B Nawrocki-Raby, W Hunziker, JM Foidart, P Birembaut, and C Gilles. 2007. "Beta-catenin and ZO-1: Shuttle Molecules Involved in Tumor Invasion-associated Epithelial-mesenchymal Transition Processes." Cells, Tissues, Organs 185 (1-3): 61-65.

Pollack AL, RB Runyan, and KE Mostov. 1998. "Morphogenetic Mechanisms of Epithelial Tubulogenesis: MDCK Cell Polarity Is Transiently Rearranged Without Loss of Cell-cell Contact During Scatter Factor/Hepatocyte Growth Factor-induced Tubulogenesis.” Developmental Biology 204 (1) (December 1): 64-79.

Pragst F, V Auwaerter, F Sporkert, and K Spiegel. 2001. "Analysis of Fatty Acid Ethyl Esters in Hair as Possible Markers of Chronically Elevated Alcohol Consumption by Headspace Solid-phase Microextraction (HS-SPME) and Gas Chromatography-mass Spectrometry (GC-MS).” Forensic Science International 121 (1-2) (September 15): 7688.

Pronko P, L Bardina, V Satanovskaya, A Kuzmich, and S Zimatkin. 2002. "Effect of Chronic Alcohol Consumption on the Ethanol- and Acetaldehyde-metabolizing Systems in the Rat Gastrointestinal Tract." Alcohol and Alcoholism (Oxford, Oxfordshire) 37 (3): 229-235.

Querol A, MT Fernandez-Espinar, M del Olmo, and E Barrio. 2003. "Adaptive Evolution of Wine Yeast." International Journal of Food Microbiology 86 (1-2) (September 1): 310 .

Rafelski, SM, and JA. Theriot. 2004. "Crawling Toward a Unified Model of Cell Motility: Spatial and Temporal Regulation of Actin Dynamics." Annual Review of Biochemistry 73 (1): 209-239. 
Ranaldi G, R Consalvo, Y Sambuy, and ML Scarino. 2003. "Permeability Characteristics of Parental and Clonal Human Intestinal Caco-2 Cell Lines Differentiated in Serumsupplemented and Serum-free Media." Toxicology in Vitro 17 (5-6): 761-767.

Rao RK. 1998. "Acetaldehyde-induced Increase in Paracellular Permeability in Caco-2 Cell Monolayer." Alcoholism, Clinical and Experimental Research 22 (8) (November): 1724-1730.

Rao RK. 2008. “Acetaldehyde-induced Barrier Disruption and Paracellular Permeability in Caco-2 Cell Monolayer." Methods in Molecular Biology (Clifton, N.J.) 447: 171-183.

Rao RK, A Seth, and P Sheth. 2004. "Recent Advances in Alcoholic Liver Disease I. Role of Intestinal Permeability and Endotoxemia in Alcoholic Liver Disease." American Journal of Physiology. Gastrointestinal and Liver Physiology 286 (6) (June): G881G884.

Regodon Mateos JA, F Perez-Nevado, and M Ramirez Fernandez. 2006. "Influence of Saccharomyces Cerevisiae Yeast Strain on the Major Volatile Compounds of Wine." Enzyme and Microbial Technology 40 (1) (December 6): 151-157.

Rescigno M, M Urbano, B Valzasina, M Francolini, G Rotta, R Bonasio, F Granucci, JP Kraehenbuhl, P Ricciardi-Castagnoli, et al. 2001. "Dendritic Cells Express Tight Junction Proteins and Penetrate Gut Epithelial Monolayers to Sample Bacteria." Nature Immunology 2 (4): 361-367.

Roustan JL, and JM Sablayrolles. 2002. "Modification of the Acetaldehyde Concentration During Alcoholic Fermentation and Effects on Fermentation Kinetics." Journal of Bioscience and Bioengineering 93 (4): 367-375.

Rydzewska G, G Jurkowska, and A Gabryelewicz. 1996. "The Influence of Acute Ethanol Ingestion on Phospholipase D Activity in Rat Pancreas." International Journal of Gastrointestinal Cancer 20 (1): 59-68.

Sablina AA, M Hector, N Colpaert, and WC Hahn. 2010. "Identification of PP2A Complexes and Pathways Involved in Cell Transformation." Cancer Research 70 (24) (December 15): 10474-10484.

Saieva C, G Bardazzi, G Masala, A Quartini, M Ceroti, A Iozzi, E Gelain, A Querci, A Allamani, and D Palli. 2012. "General and Cancer Mortality in a Large Cohort of Italian Alcoholics." Alcoholism: Clinical and Experimental Research 36 (2) (February 1): 342350 .

Saitou, M, M Furuse, H Sasaki, J D Schulzke, M Fromm, H Takano, T Noda, and S Tsukita. 2000. "Complex Phenotype of Mice Lacking Occludin, a Component of Tight Junction Strands." Molecular Biology of the Cell 11 (12) (December): 4131-4142. 
Sakakibara A, M Furuse, M Saitou, Y Ando-Akatsuka, and S Tsukita. 1997. "Possible Involvement of Phosphorylation of Occludin in Tight Junction Formation." The Journal of Cell Biology 137 (6) (June 16): 1393-1401.

Salaspuro, M. 1996. "Bacteriocolonic Pathway for Ethanol Oxidation: Characteristics and Implications." Annals of Medicine 28 (3) (June): 195-200.

Salaspuro, M. 2003. "Acetaldehyde, Microbes, and Cancer of the Digestive Tract." Critical Reviews in Clinical Laboratory Sciences 40 (2) (April): 183-208.

Salaspuro, M. 2009. "Acetaldehyde as a Common Denominator and Cumulative Carcinogen in Digestive Tract Cancers." Scandinavian Journal of Gastroenterology (April 24): 1-15.

Samak, G, S Aggarwal, and RK Rao. 2011. "ERK Is Involved in EGF-mediated Protection of Tight Junctions, but Not Adherens Junctions, in Acetaldehyde-treated Caco2 Cell Monolayers." American Journal of Physiology. Gastrointestinal and Liver Physiology 301 (1) (July): G50-G59.

Schneeberger, Eveline E, and Robert D Lynch. 2004. "The Tight Junction: a Multifunctional Complex." American Journal of Physiology. Cell Physiology 286 (6) (June): C1213-C1228.

Seitz, HK, and P Becker. 2007. "Alcohol Metabolism and Cancer Risk.” Alcohol Research \& Health: the Journal of the National Institute on Alcohol Abuse and Alcoholism 30 (1): 38-41, 44-7.

Seitz HK, B Maurer, and F Stickel. 2005. "Alcohol Consumption and Cancer of the Gastrointestinal Tract." Digestive Diseases (Basel, Switzerland) 23 (3-4): 297-303.

Seitz HK, and P Meier. 2007. "The Role of Acetaldehyde in Upper Digestive Tract Cancer in Alcoholics." Translational Research : the Journal of Laboratory and Clinical Medicine 149 (6) (June): 293-297.

Seitz HK, and F Stickel. 2007. "Molecular Mechanisms of Alcohol-mediated Carcinogenesis." Nature Reviews. Cancer 7 (8) (August): 599-612.

Seth A, P Sheth, B C Elias, and RK Rao. 2007. "Protein Phosphatases 2A and 1 Interact with Occludin and Negatively Regulate the Assembly of Tight Junctions in the Caco-2 Cell Monolayer." The Journal of Biological Chemistry 282 (15) (April 13): 1148711498.

Shaw KRM, CN Wrobel, and JS Brugge. 2004. "Use of Three-dimensional Basement Membrane Cultures to Model Oncogene-induced Changes in Mammary Epithelial Morphogenesis." Journal of Mammary Gland Biology and Neoplasia 9 (4) (October): 297-310. 
Shaw S, E Jayatilleke, V Herbert, and N Colman. 1989. "Cleavage of Folates During Ethanol Metabolism. Role of Acetaldehyde/xanthine Oxidase-generated Superoxide." The Biochemical Journal 257 (1) (January 1): 277-280.

Shen L, CR Weber, and JR Turner. 2008. "The Tight Junction Protein Complex Undergoes Rapid and Continuous Molecular Remodeling at Steady State." The Journal of Cell Biology 181 (4) (May 19): 683-695.

Sheth P, G Samak, JA Shull, A Seth, and RK Rao. 2009. "Protein Phosphatase 2A Plays a Role in Hydrogen Peroxide-induced Disruption of Tight Junctions in Caco-2 Cell Monolayers." The Biochemical Journal 421 (1) (July 1): 59-70.

Sheth P, A Seth, KJ Atkinson, T Gheyi, G Kale, F Giorgianni, DM Desiderio, C Li, AP Naren, and RK Rao. 2007. "Acetaldehyde Dissociates the PTP1B-E-cadherin-betacatenin Complex in Caco-2 Cell Monolayers by a Phosphorylation-dependent Mechanism.” The Biochemical Journal 402 (2) (March 1): 291-300.

Shi Y. 2009. "Serine/Threonine Phosphatases: Mechanism Through Structure." Cell 139 (3) (October 30): 468-484.

Shimoda T, S Kohno, A Takao, C Fujiwara, H Matsuse, H Sakai, T Watanabe, K Hara, and S Asai. 1996. "Investigation of the Mechanism of Alcohol-induced Bronchial Asthma." The Journal of Allergy and Clinical Immunology 97 (1 Pt 1) (January): 74-84.

Shin K, VC Fogg, and B Margolis. 2006. "Tight Junctions and Cell Polarity." Annual Review of Cell and Developmental Biology 22: 207-235.

Sisson JH, and D. J Tuma. 1994. "Vapor Phase Exposure to Acetaldehyde Generated from Ethanol Inhibits Bovine Bronchial Epithelial Cell Ciliary Motility." Alcoholism: Clinical and Experimental Research 18 (5) (October 1): 1252-1255.

Stampwala SS, RH Bunge, TR Hurley, NE Willmer, AJ Brankiewicz, CE Steinman, TA Smitka, and JC French. 1983. "Novel Antitumor Agents CI-920. PD 113.270 AND PD 113, 271." The Journal of Antibiotics 36 (12): 1601-1605.

Stanevich V, L Jiang, KA. Satyshur, Y Li, PD Jeffrey, Z Li, P Menden, MF Semmelhack, and Y Xing. 2011. "The Structural Basis for Tight Control of PP2A Methylation and Function by LCMT-1.” Molecular Cell 41 (3) (February 4): 331-342.

Stein, Scott, Yanbin Lao, In-Young Yang, Stephen S Hecht, and Masaaki Moriya. 2006. "Genotoxicity of Acetaldehyde- and Crotonaldehyde-induced 1,N2propanodeoxyguanosine DNA Adducts in Human Cells." Mutation Research 608 (1) (September 19): 1-7. 
Stevenson, BR, JD Siliciano, MS Mooseker, and DA Goodenough. 1986. "Identification of ZO-1: a High Molecular Weight Polypeptide Associated with the Tight Junction (zonula Occludens) in a Variety of Epithelia." The Journal of Cell Biology 103 (3) (September): 755-766.

Strack S, J T Cribbs, and L Gomez. 2004. "Critical Role for Protein Phosphatase 2A Heterotrimers in Mammalian Cell Survival.” The Journal of Biological Chemistry 279 (46) (November 12): 47732-47739.

Suzuki T, BC Elias, A Seth, L Shen, JR Turner, F Giorgianni, D Desiderio, R Guntaka, and RKRao. 2009. "PKC Eta Regulates Occludin Phosphorylation and Epithelial Tight Junction Integrity." Proceedings of the National Academy of Sciences of the United States of America 106 (1) (January 6): 61-66.

Swingle, MS, L Amable, BG Lawhorn, SB Buck, CP Burke, P Ratti, KL Fischer, DL Boger, and RE Honkanen. 2009. "Structure-Activity Relationship Studies of Fostriecin, Cytostatin and Key Analogues, with PP1, PP2A, PP5, and (\{beta\}12-\{beta 13 )-chimeras (PP1/PP2A and PP5/PP2A) Provide Further Insight Into Inhibitory Actions of Fostriecin Family Inhibitors." The Journal of Pharmacology and Experimental Therapeutics 331 (1) (July 10): 45-53.

Swingle MS, L Ni, and RE Honkanen. 2007. "Small-molecule Inhibitors of Ser/thr Protein Phosphatases: Specificity, Use and Common Forms of Abuse." Methods in Molecular Biology (Clifton, N.J.) 365: 23-38.

Takeuchi T, N Takahashi, K Ishi, T Kusayanagi, K Kuramochi, and F Sugawara. 2009. "Antitumor Antibiotic Fostriecin Covalently Binds to Cysteine-269 Residue of Protein Phosphatase 2A Catalytic Subunit in Mammalian Cells.” Bioorganic \& Medicinal Chemistry 17 (23) (December 1): 8113-8122.

Tamura A, Y Kitano, M Hata, T Katsuno, K Moriwaki, H Sasaki, H Hayashi, et al. 2008. "Megaintestine in Claudin-15-Deficient Mice." Gastroenterology 134 (2) (February): 523-534.e3.

Tétreault MP, P Chailler, JF Beaulieu, N Rivard, and D Ménard. 2008. "Specific Signaling Cascades Involved in Cell Spreading During Healing of Micro-wounded Gastric Epithelial Monolayers." Journal of Cellular Biochemistry 105 (5) (December 1): 1240-1249.

Tønnesen, H. 1999. "The Alcohol Patient and Surgery." Alcohol and Alcoholism (Oxford, Oxfordshire) 34 (2) (April): 148-152.

Tuma, DJ, RB Jennett, and MF Sorrell. 1987. "The Interaction of Acetaldehyde with Tubulin.” Annals of the New York Academy of Sciences 492: 277-286. 
Tuma, DJ, ML Kearley, GM Thiele, S Worrall, A Haver, LW Klassen, and MF Sorrell. 2001. "Elucidation of Reaction Scheme Describing Malondialdehyde-acetaldehydeprotein Adduct Formation." Chemical Research in Toxicology 14 (7) (July): 822-832.

Tunac, JB, BD Graham, and WE Dobson. 1983. "Novel Antitumor Agents CI-920, PD 113, 270 and PD 113.271." The Journal of Antibiotics 36 (12): 1595-1600.

Ulrich, CM. 2007. "Folate and Cancer Prevention: a Closer Look at a Complex Picture." Am J Clin Nutr 86 (2) (August 1): 271-273.

Vincon P, J Wunderer, UA Simanowski, M Koll, VR Preedy, TJ Peters, J Werner, R Waldherr, and HK Seitz. 2003. "Inhibition of Alcohol-associated Colonic Hyperregeneration by Alpha-tocopherol in the Rat." Alcoholism, Clinical and Experimental Research 27 (1) (January): 100-106.

Walsh AH, A Cheng, and RE Honkanen. 1997. "Fostriecin, an Antitumor Antibiotic with Inhibitory Activity Against Serine/threonine Protein Phosphatases Types 1 (PP1) and 2A (PP2A), Is Highly Selective for PP2A." FEBS Letters 416 (3) (October 27): 230-234.

Weide MR, and JF Ernst. 1999. "Caco-2 Monolayer as a Model for Transepithelial Migration of the Fungal Pathogen Candida Albicans.” Mycoses 42 Suppl 2: 61-67.

Wera S, A Fernandez, NJC Lamb, P Turowski, M Hemmings-Mieszczak, RE MayerJaekel, and BA Hemmings. 1995. "Deregulation of Translational Control of the 65-kDa Regulatory Subunit (PR65) of Protein Phosphatase 2A Leads to Multinucleated Cells." Journal of Biological Chemistry 270 (36): 21374 -21381.

Westerlund M, D Galter, A Carmine, and L Olson. 2005. "Tissue- and Species-specific Expression Patterns of Class I, III, and IV Adh and Aldh 1 mRNAs in Rodent Embryos." Cell and Tissue Research 322 (2) (November): 227-236.

Wills NK, L Reuss, and SA Lewis. 1996. Epithelial Transport: a Guide to Methods and Experimental Analysis. Springer.

Wong V. 1997. "Phosphorylation of Occludin Correlates with Occludin Localization and Function at the Tight Junction." The American Journal of Physiology 273 (6 Pt 1) (December): C1859-C1867.

Xiang B, and SK Muthuswamy. 2006. "Using Three-dimensional Acinar Structures for Molecular and Cell Biological Assays.” Methods in Enzymology 406: 692-701.

Xing Y, Z Li, Y Chen, J B Stock, PD Jeffrey, and Y Shi. 2008. "Structural Mechanism of Demethylation and Inactivation of Protein Phosphatase 2A." Cell 133 (1) (April 4): 154163. 
Xu DS, RB Jennett, SL Smith, MF Sorrell, and DJ Tuma. 1989. "Covalent Interactions of Acetaldehyde with the Actin/microfilament System." Alcohol and Alcoholism (Oxford, Oxfordshire) 24 (4): 281-289.

Yamashita S, T Furubayashi, M Kataoka, T Sakane, H Sezaki, and H Tokuda. 2000. "Optimized Conditions for Prediction of Intestinal Drug Permeability Using Caco-2 Cells." European Journal of Pharmaceutical Sciences 10 (3) (May): 195-204.

Yamashita S, K Konishi, Y Yamazaki, Y Taki, T Sakane, H Sezaki, and Y Furuyama. 2002. "New and Better Protocols for a Short-term Caco-2 Cell Culture System." Journal of Pharmaceutical Sciences 91 (3) (March): 669-679.

Yin G, S Kono, K Toyomura, MA Moore, J Nagano, T Mizoue, R Mibu, et al. 2007. "Alcohol Dehydrogenase and Aldehyde Dehydrogenase Polymorphisms and Colorectal Cancer: The Fukuoka Colorectal Cancer Study." Cancer Science 98 (8) (August): 124853.

Yokoyama A, E Tsutsumi, H Imazeki, Y Suwa, C Nakamura, T Mizukami, and T Yokoyama. 2008. "Salivary Acetaldehyde Concentration According to Alcoholic Beverage Consumed and Aldehyde Dehydrogenase-2 Genotype." Alcoholism, Clinical and Experimental Research 32(9) (September): 1607-1614.

Yokoyama T, K Saito, H Lwin, N Yoshiike, A Yamamoto, Y Matsushita, C Date, and Ho Tanaka. 2005. "Epidemiological Evidence That Acetaldehyde Plays a Significant Role in the Development of Decreased Serum Folate Concentration and Elevated Mean Corpuscular Volume in Alcohol Drinkers." Alcoholism, Clinical and Experimental Research 29 (4) (April): 622-630.

Zhang X, JW Cromwell, BD Kunjummen, D Yee, and J Garcia-Aguilar. 2003. "The Alpha2 and Alpha3 Integrins Are Required for Morphologic Differentiation of an Intestinal Epithelial Cell Line.” Surgery 133 (4) (April): 429-437.

Zimatkin SM, and AL Buben. 2007. "Ethanol Oxidation in the Living Brain." Alcohol and Alcoholism (Oxford, Oxfordshire) 42 (6) (December): 529-532. 


\section{VITA}

Mitzi was born in 1971 to a maintenance electrician and a housewife living in an old house on her grandparents' farm outside Franklin, Tennessee. Despite her family's low socioeconomic status, her parents always encouraged academic excellence. She was the valedictorian of a highly competitive high school class and went to Cumberland University in Lebanon, Tennessee, with the help of merit-based scholarships. She was a Tennessee Scholar and a National Merit Scholarship finalist.

She graduated with a double major math/science and elementary education Bachelor of Science degree in 1993. She was co-valedictorian of her college class with a 4.0 GPA. She accepted a middle-school teaching position in Sumner County, Tennessee and remained there through May of 2003. She was voted Teacher of the Year for her school in 1999, her first year of eligibility.

While she was teaching, an assistant principal suggested that she enter an NSFsponsored summer Master's program for teachers at Vanderbilt. Tuition was covered and a small stipend would be paid. She earned her Master's Degree in Biological Sciences from Vanderbilt in 2002, with research in the x-ray fiber diffraction studies of filamentous plant viruses. This program whetted her interest in research.

By the end of 2003, she was ready for a career change.. She attended Austin Peay State University and the University of Memphis as a part of the effort to return to graduate school. At the University of Memphis, she participated in research on the properties of irradiated ultra-high molecular weight polyethylene and presented her first poster at a meeting of the Society for Biomaterials in Pittsburgh, Pennsylvania.

She entered the Integrated Program in Biomedical Sciences at the University of Tennessee Health Science Center in the fall of 2006. She joined the lab of Radhakrishna Rao. He helped her to earn a pre-doctoral Kirschstein fellowship from NIH. He also enabled her to present her data at three international conferences, thus furthering her professional development and helping her build a professional reputation. She will be leaving UTHSC with a Doctor of Philosophy degree in Biomedical Sciences, concentration in cell biology and biochemistry. This degree has enabled her to accept an assistant professorship at a small college in northeastern Mississippi. 